Universidad de Lima

Escuela de Posgrado

Maestría en Administración y Dirección de Negocios

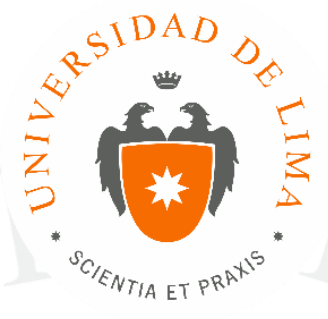

\title{
OPORTUNIDAD DE NEGOCIO EN LA \\ PRODUCCIÓN DE TÉ FILTRANTE A BASE DE FRUTA DESHIDRATADA
}

Trabajo de investigación para optar el Grado Académico de Maestro en Administración y Dirección de Negocios

JANNINA CAROLINA TORRES BUENDIA Código 19863053

DENISSE STHEFANY VELASQUEZ MORANTE

Código 20160006

Asesor: Edmundo Casavilca Maldonado

\author{
Lima - Perú
}

Diciembre de 2017 
(Hoja en blanco) 


\section{RESUMEN EJECUTIVO}

El mundo está destacando la importancia de la vida sana, despertando la conciencia de buscar lo mejor para nuestro cuerpo, mente y alma. Es así que observamos el gran potencial que existe en el mercado de consumo de bebidas no carbonatadas, validado por el crecimiento en Lima y en el mundo del consumo de agua embotellada, hablamos de un incremento promedio de $10 \%$ anual en los últimos cinco años (Instituto de Estudios Economicos y Sociales, 2017) y si a esto le sumamos el gran éxito obtenido en las ferias internacionales por el consumo de bebidas hechas a base de productos naturales basándose en formulaciones nuevas, mezcla de sabores y en el uso de empaques novedosos, nace la motivación de presentar la siguiente propuesta de innovación ofreciendo una solución a una necesidad latente del consumidor actual.

La industria de bebidas no carbonatadas está en el corazón de la mega tendencia que tiende a la búsqueda de lo natural en el consumo de bienes; la población hoy en día, busca salud y la economía mundial también porque está altamente influenciada por las tecnologías renovables y la innovación en los modelos de negocio. El reto consiste en calar en la mente del consumidor a través del uso de un proceso ancestral como el deshidratado para ofrecer una bebida alternativa de calidad, que tiene un efecto en la salud a través de combinaciones energéticas, antioxidantes, a un precio accesible.

El alcance de este proyecto implica hacernos la pregunta de ¿Cuándo asumir una mega tendencia?

La propuesta de "Al Sol S.A.C.” a través de su producto K'isa Té, radica en ofrecer un té filtrante hecho a base de frutas deshidratadas, en un primer momento hecho de frutas cítricas ya que se obtiene un mayor rendimiento en el proceso y por las características antioxidantes de la vitamina $\mathrm{C}$ que se encuentra en los llamados berries peruanos $^{1}$, los cuales serán formulados con otros insumos totalmente naturales como el té verde o negro siendo el gran diferenciador en nuestro producto el uso de hojas de estevia, hecho que lo hace "único" respecto a los demás productos de su categoría que existen hoy en el mercado, sumándose el hecho de que nuestra formulación se podrá activar en agua fría, facilitando su consumo en toda ocasión; la presentación para venta en un primer momento se hará en cajas de 25 sobres. La idea es que luego podamos ofrecer combos en función a los beneficios otorgados para la salud. Su comercialización

\footnotetext{
${ }^{1}$ Arándanos, moras, frambuesas y fresas
} 
se hará a través del canal moderno en un $80 \%$ dejando un $20 \%$ para su colocación en canal digital y en tiendas especializadas. En nuestra opinión personal no hay en el mercado limeño un producto con las características del que estamos presentando.

Para que una innovación sea exitosa debe cumplir ciertos requisitos entre ellos: ser sostenible y rentable.

Sostenibilidad es lo que da vida al negocio a largo plazo y bajo este concepto creemos que tenemos muchas oportunidades para ofrecer a nuestros clientes después de haber posicionado nuestro té filtrante siempre relacionadas con el giro principal del negocio, como la producción de bocaditos de fruta deshidratada para humanos y/o mascotas.

"Hay una tendencia mundial de los consumidores hacia los productos saludables y naturales, bajos en calorías y ricos en antioxidantes; el Perú no es ajeno a esta tendencia, y la categoría de té bebibles cumple con lo que demandan los consumidores; de ahí su potencial de crecimiento en penetración" (Gestión, 2015).

Finalmente, la inversión inicial de "Al Sol S.A.C.” asciende a S/ 220,391.00, y se recuperará antes de cumplir los dos primeros años de operaciones. A un horizonte de cinco años, el proyecto cuenta con un VAN de S/ 748,227 y una TIR de 132\%. A partir de lo expuesto, se puede concluir que el proyecto es viable y contribuirá con el mercado objetivo y a maximizar los resultados de los accionistas. Se debe recalcar, que de acuerdo a la investigación de mercado se ha identificado una demanda potencial en otros sectores, lo que muestra la escalabilidad del negocio. 


\section{TABLA DE CONTENIDO}

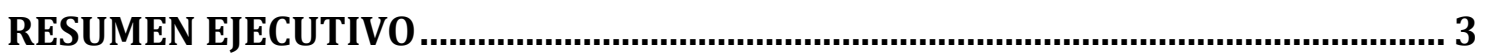

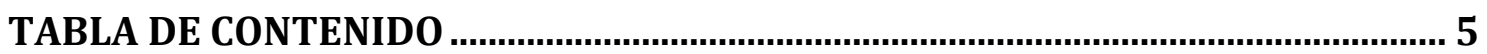

ÍNDICE DE TABLAS ................................................................................................ 7

ÍNDICE DE GRÁFICOS ............................................................................................. 8

CAPÍTULO I: ASPECTOS GENERALES DEL NEGOCIO_........................................... 9

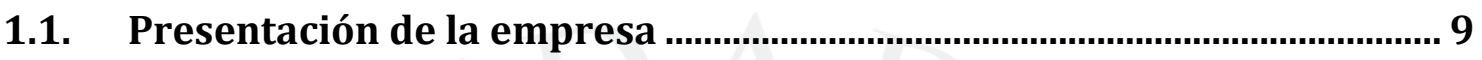

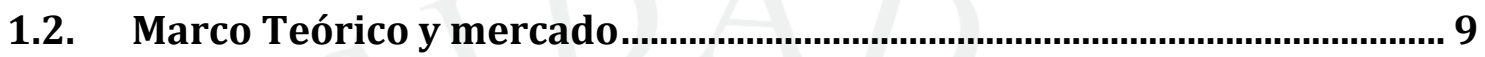

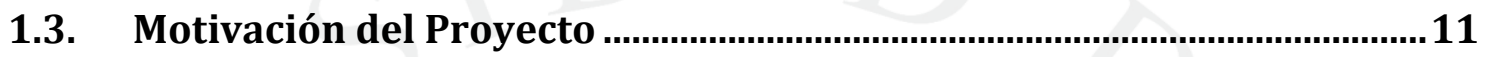

1.4. Percepción de la necesidad: Análisis Problema - Solución.....................11

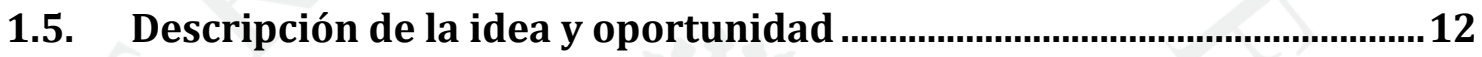

1.6. Justificación del atractivo de la propuesta ................................................. 12

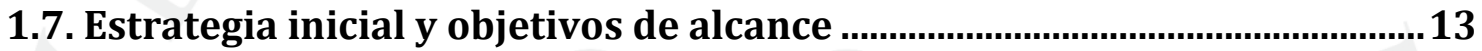

1.8. Impacto comercial y responsabilidad social ....................................................14

CAPÍTULO II: IDEA, INVESTIGACIÓN Y VALIDACIÓN DE SOLUCIÓN................... 15

2.1. Diseño y Metodología de la investigación ......................................................... 15

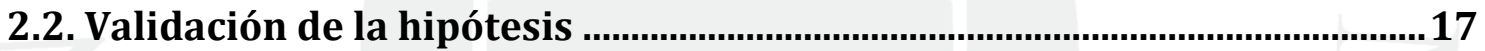

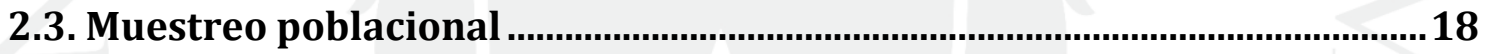

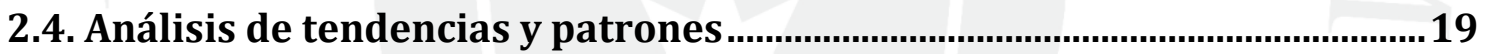

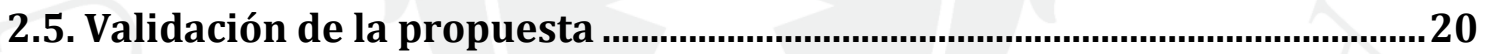

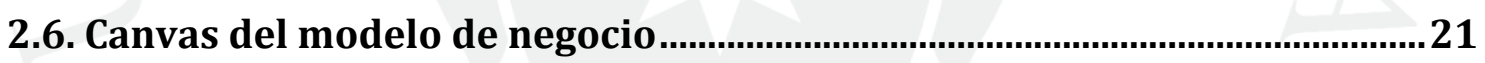

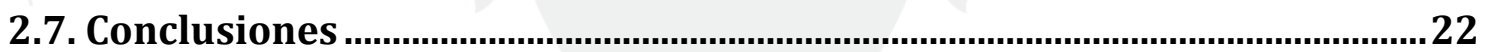

CAPÍTULO III: PLANEAMIENTO ESTRATÉGICO ...................................................... 23

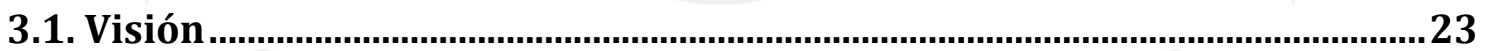

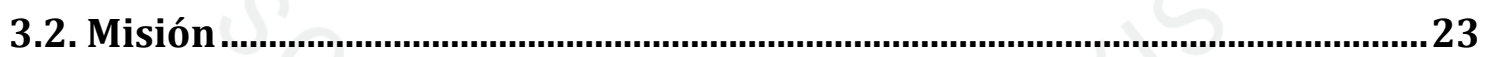

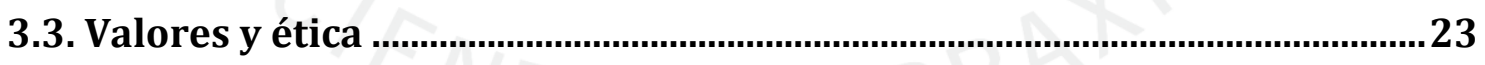

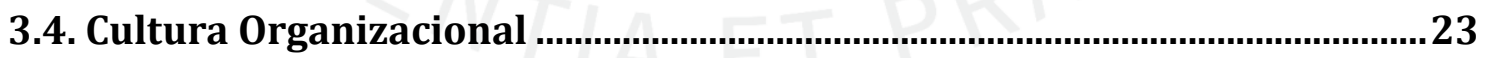

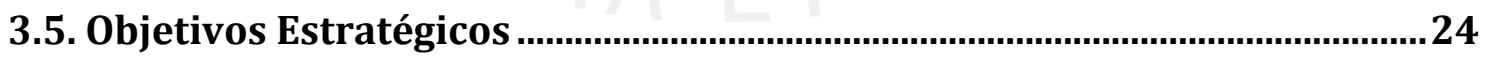

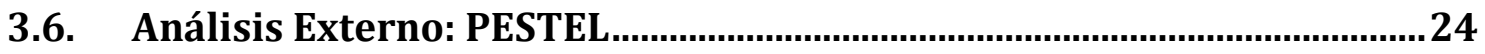

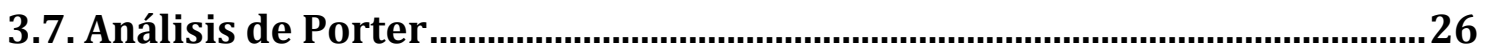

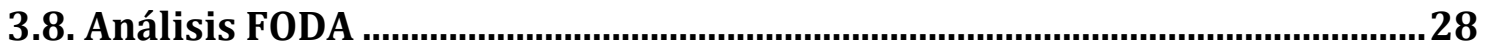

CAPÍTULO IV: PLAN DE MARKETING ...............................................................29

4.1. Planeamiento de objetivos generales de marketing .....................................29

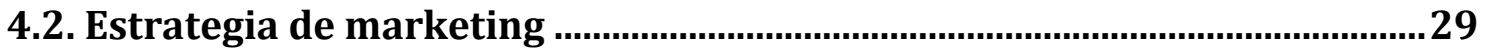




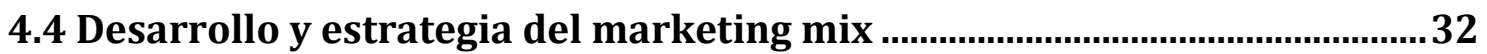

4.5. Plan de ventas y Proyección de la Demanda .................................................. 33

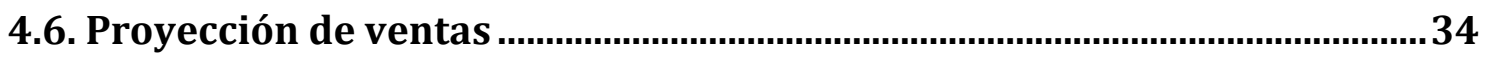

CAPÍTULO V: PLAN DE OPERACIONES ................................................................35

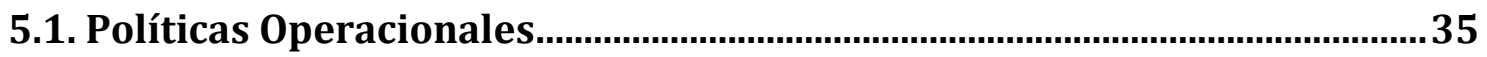

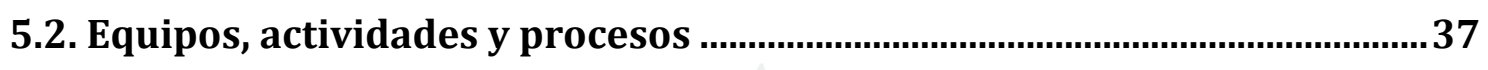

CAPÍTULO VI: ESTRUCTURA ORGANIZACIONAL Y RECURSOS HUMANOS .......44

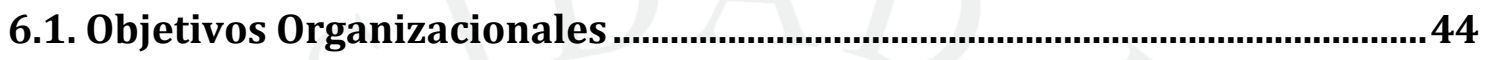

6.2. Diseño de Puestos y Responsabilidades .........................................................45

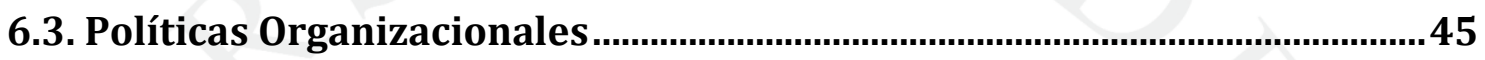

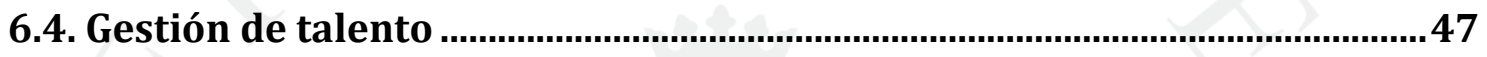

6.5. Estructura de gastos de Recursos Humanos..............................................48

CAPÍTULO VII: PLAN ECONÓMICO - FINANCIERO ...............................................49

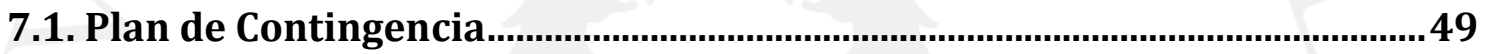

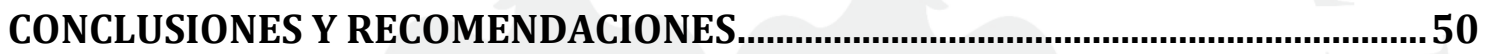

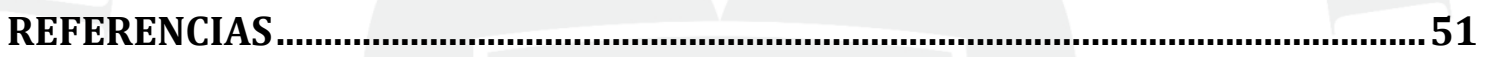

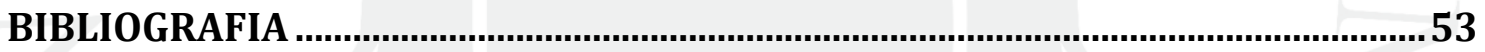

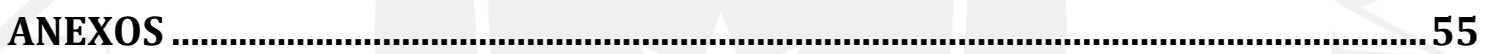

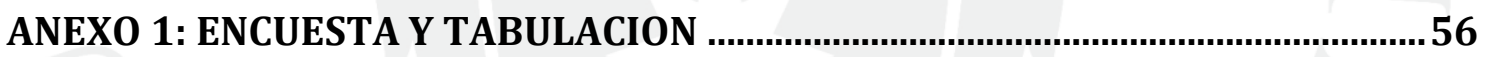

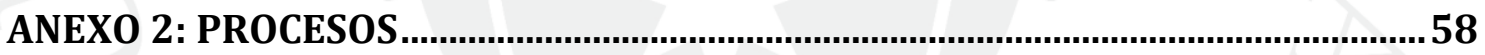

ANEXO 3: DISEÑO Y CAPACIDAD DE INSTALACIONES ...................................59

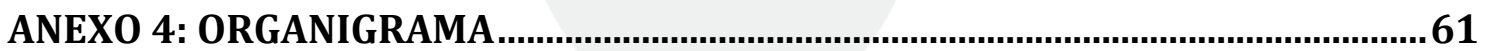

ANEXO 5: DISEÑO DE PUESTOS Y RESPONSABILIDADES..................................62

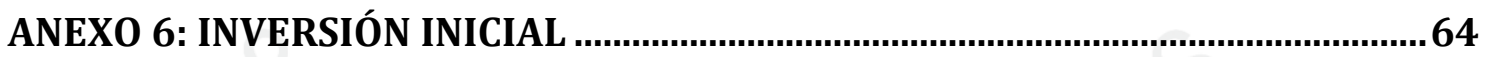

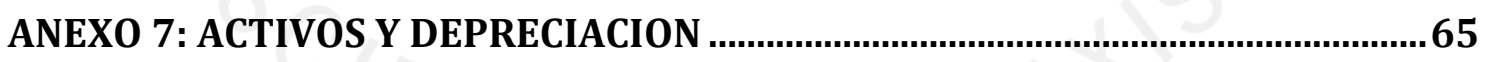

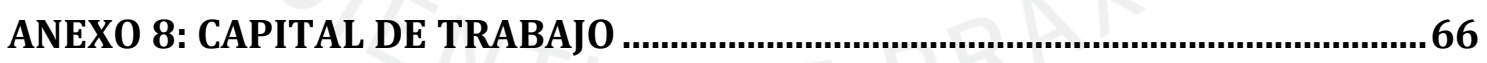

ANEXO 9: ESTRUCTURA DE DEUDA Y APALANCAMIENTO_.................................67

ANEXO 10: ESTADO DE GANANCIAS Y PERDIDAS........................................... 71

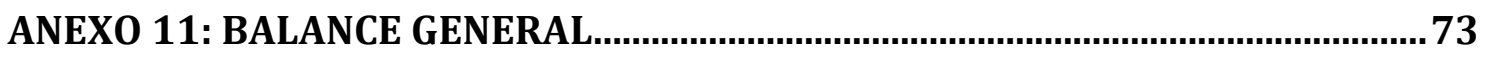

ANEXO 12: FLUJO DE CAJA E INDICADORES ECONOMICOS ...............................74

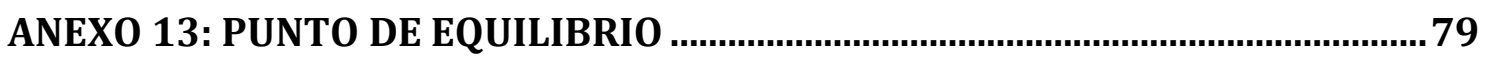

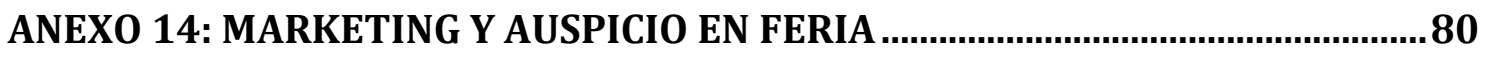

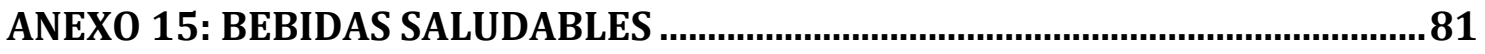

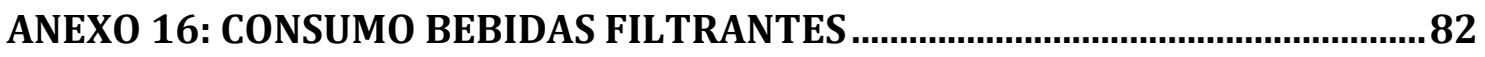




\section{ÍNDICE DE TABLAS}

Tabla $\mathrm{N}^{\circ} 1$ : Objetivos generales y específicos de la investigación

Tabla $\mathrm{N}^{\circ} 2$ : Ficha técnica del grupo de enfoque.

Tabla N³: Ficha técnica de la encuesta

Tabla $N^{\circ} 4$ : Modelo CANVAS

Tabla N5: Objetivos Estratégicos

Tabla N${ }^{\circ}$ : Ranking Doing Business de Latinoamerica

Tabla $N^{\circ} 7$ : Lista de competidores

Tabla N8: Análisis FODA

Tabla $\mathrm{N}^{\circ}$ 9: Objetivos de Marketing

Tabla N¹0: Estimación de la Demanda

Tabla N¹1: Proyección de la Demanda Anual - Escenario Base

Tabla $\mathrm{N}^{\circ} 12$ : Proyección de Ventas

Tabla Nº13: Objetivos de Operaciones

Tabla N ${ }^{\circ} 14$ : Requerimiento de Maquinaria

Tabla N¹5: Requerimiento de Compras

Tabla N¹6: Objetivos de Recursos Humanos

Tabla Nº17: Planilla Mensual

Tabla $N^{\circ} 18$ : Presupuesto de Recursos Humanos

Tabla Nº19: Objetivos Financieros

Tabla N²0: Resultados Económicos

Tabla No21: Plan de Contingencia 


\section{ÍNDICE DE GRÁFICOS}

Gráfico $\mathrm{N}^{\circ} 1$ : Fases del Proyecto

Gráfico $\mathrm{N}^{\circ} 2$ : Ingresos y Gastos NSE A\&B

Gráfico N³: Producción Nacional de Agua Embotellada de mesa, principales empresas 2012 - 2017 (Millones de Litros)

Gráfico N4: Hábitos de Salud entre Peruanos

Gráfico N5: Flujo de Procesos

Gráfico $\mathrm{N}^{\circ}$ 6: Diseño de las áreas de la empresa

Gráfico N7: Equipos de trabajo y apoyo

Gráfico No8: Áreas de trabajo

Gráfico $\mathrm{N}^{\circ}$ 9: Cadena de Valor

Gráfico $\mathrm{N}^{\circ} 10$ : DAP

Gráfico $N^{\circ} 11$ : Proceso de Venta

Gráfico $\mathrm{N}^{\circ} 12$ : Flujograma de la actividad

Gráfico $N^{\circ} 13$ : Diagrama de PERT

Gráfico $\mathrm{N}^{\circ} 14$ : Cuadro de tiempo

Gráfico $\mathrm{N}^{\circ} 15$ : Balance Scorecard 


\section{CAPÍTULO I: ASPECTOS GENERALES DEL NEGOCIO}

\subsection{Presentación de la empresa}

“Al Sol” es una empresa que iniciará operaciones en Lima Metropolitana dentro del CIIU 1549 - Elaboración de otros productos alimenticios n.c.p. para la elaboración de un té filtrante natural. Es así que su producto " $\mathrm{K}$ 'isa Té” nace con la intención de ser la primera línea de filtrantes hechos a base de fruta deshidratada $100 \%$ peruana. Con su slogan “Te nutre, Te envuelve” busca promover la nutrición e importancia de una vida saludable a través de un producto innovador y orgánico.

\subsection{Marco Teórico y mercado}

El alto índice de enfermedades crónicas ${ }^{2}$ en el mundo ha despertado la conciencia de las personas a mejorar su calidad de vida buscando conseguir un equilibrio entre cuerpo y alma, siendo la prevención y el cuidado personal el mejor aliado de los alimentos y bebidas saludables.

Una alimentación saludable consiste en ingerir una variedad de alimentos que te brinden los nutrientes que necesitas para mantenerte sana, sentirte bien y tener energía. Estos nutrientes incluyen las proteínas, los carbohidratos, las grasas, el agua, las vitaminas y los minerales (Breast Cancer Organization, 2013).

La alimentación es la mejor herramienta para conseguir una vida más larga y de calidad sin embargo para considerar que sea la adecuada debemos prestar atención no solo a los alimentos sólidos sino de manera especial a la ingesta líquida.

En mayo de 2004 la Organización Mundial de la Salud, aprobó la Estrategia Mundial de la Salud en la que se contempla la colaboración de las empresas de alimentación y bebidas como elemento crítico para lograr el objetivo de mejorar la salud pública, mejorando el campo de la dieta y la prevención de enfermedades crónicas. Se debe buscar mantener informado al consumidor, a través del etiquetado de manera que la elección sana sea la fácil (OMS, 2017).

Ipsos Global Trends (IGT) a través de su último estudio Las Mega tendencias que definirán el nuevo mundo, identifica ocho tendencias (Lampadia, 2017) de las cuales nos centraremos en tres para validar el presente plan de negocio:

\footnotetext{
${ }^{2}$ Entiéndase como enfermedades crónicas para este estudio, diabetes, obesidad, cáncer, enfermedades cardiovasculares y lipídicas.
} 
- Atención a los medios de comunicación. Seis de cada diez personas aseguran estar constantemente mirando una pantalla, cifra incluso mayor en jóvenes de 16 a 24 años en hogares de altos ingresos.

- Búsqueda de simplicidad y control. Percepción de que el mundo se mueve más rápido y es difícil saber en quién confiar.

- Mundo más saludable. Las personas quieren empoderarse para tomar control sobre sus hábitos alimenticios y físicos en busca de mejorar su calidad de vida.

En el Perú, los hábitos tradicionales de consumo han notado un cambio en alimentos y bebidas, el consumidor se ha vuelto más exigente al decidir qué comer así vemos su preferencia en alimentos bajos en grasa, alimentos sanos para niños y preferencia a las bebidas que son libres de azúcar.

Dentro de las opciones para una hidratación saludable, encontramos los tés filtrantes que dan sabor al agua de manera natural. Actualmente podemos identificar a las siguientes marcas en el mercado:

- $\quad$ Lipton es una marca de Pepsico presente en más de 150 países, se da a conocer como una bebida para hidratarse y $100 \%$ natural, entres sus sabores más comercializados en nuestro medio el limón, melocotón y té verde. $\mathrm{Su}$ presentación es té filtrante y en botella.

- $\quad$ Nature's Heart es una marca de productos saludables de la línea de Terrafertil, presentando línea de té filtrantes, de frutas deshidratadas y bebidas instantáneas, también cuentan con snacks y jugos.

- La Fidelia nace con idea de ser una línea de filtrantes artesanales hecha a base de hierbas, flores y frutos $100 \%$ peruanos.

- Bigelow es una empresa americana socialmente responsable, presenta más de 120 sabores de té especiales resaltando su fabricación ecológica y empaque reciclable.

Cada día hay más consumidores que consideran el impacto en la sociedad y el medio ambiente de una empresa para convertirse en clientes (Austria, 2015).

Entre las mejores prácticas empresariales encontramos que Terrafertil es el más grande procesador de aguaymanto del mundo y trabaja con pequeños agricultores teniendo un impacto social medible, en esa línea encontramos que Lipton realiza el cultivo de té con prácticas de agricultura sostenible y participa del programa “Trees 2000" 
en el cual plantan cuarenta mil árboles cada año contribuyendo a frenar la deforestación global.

Por su parte Bigelow es reconocido por contar con 880 paneles solares desde 2007 ahorrando 6`429,534 Kw., también tienen la distinción de ser una compañía de "Basura cero a vertederos".

En el caso de La Fidelia no hemos encontrado información del impacto social ya que no cuenta con página web.

\subsection{Motivación del Proyecto}

La presente propuesta de negocio nace de la experiencia de las socias de este proyecto, dado que somos conscientes de la importancia del equilibrio mente y cuerpo para el bienestar de una persona, el haber dejado de gozar de salud por el diagnóstico de una enfermedad nos hizo replantear los objetivos de vida, en donde la práctica de un deporte y el consumo de productos saludables son los pilares, como bien se dice "somos el reflejo de lo que comemos". Una de las participantes, tomo conocimiento del proceso de deshidratar fruta de manera doméstica obteniendo la misma fruta bajo otra presentación, sin agua pero siempre manteniendo su poder nutricional. De aquí surge la idea de ir probando con diferentes frutas ofreciéndola a familiares, en todo momento la respuesta fue positiva. La iniciativa de hacerlo a mayor escala nos llevó a investigar más sobre el proceso de deshidratación, la merma en el mismo, el costo del producto y a presentarlo como proyecto final de maestría, a solicitud de nuestros asesores, buscamos ofrecer un formato más innovador planteando un té filtrante atendiendo a un requerimiento del consumidor actual y estamos convencidas de que la idea será sostenible en el tiempo, brindándonos un retorno económico.

\subsection{Percepción de la necesidad: Análisis Problema - Solución}

El consumidor peruano al igual que el consumidor mundial está buscando mantener un estilo de vida saludable, fundamentalmente debido a los índices cada vez más altos de enfermedades como la diabetes, hipertensión así como el estrés, todo esto producto de un ritmo de vida más acelerado en la cual no contamos con el tiempo suficiente para alimentarnos correctamente, teniendo que optar por lo que tenemos a la mano como comida chatarra y bebidas carbonatadas o gaseosas.

El problema que percibimos es el siguiente: Más del 20\% de las calorías que consumimos provienen de las bebidas. Las "calorías líquidas" provocan menos saciedad que los alimentos sólidos, por lo que son un factor de riesgo para la salud humana. El consumo excesivo de bebidas azucaradas (refrescos, aguas frescas, jugos, café y té con 
azúcar adicionada, bebidas deportivas, jugos de fruta naturales- con y sin azúcar adicionada) conlleva a una ingestión elevada de calorías (energía), resultando en sobrepeso y obesidad, aumentando el riesgo de desarrollar diabetes y enfermedades cardiovasculares (Dommarco, 2014). Sin embargo ingerir alguna bebida saludable del mercado implica pagar un precio elevado.

La necesidad se observa de la siguiente manera: Al existir una tendencia saludable, las personas necesitan opciones de bebidas saludables a bajo costo.

La solución que proponemos es $\mathrm{K}$ 'isa Té (té filtrante natural a base de frutas deshidratas endulzado con estevia). Un producto que cumple con las características que requiere el consumidor que sea natural, a un costo accesible, que pueda encontrarlo en diferentes puntos de venta y que sea muy práctico en su uso.

\subsection{Descripción de la idea y oportunidad}

Desarrollar un modelo de negocio en base a un proceso ancestral, el deshidratado de frutas para ofrecer un producto llamado " $K$ 'isa Té" que es un filtrante de frutas, clasificando las mismas en función al beneficio que ofrecen a nuestro organismo y pueden ser antioxidantes o energizantes. El concepto que buscamos posicionar en la mente del consumidor es, que puede encontrar a su alcance un producto saludable orgánico y natural, que a la vez que te hidrata y nutre tiene un buen sabor a un precio competitivo y que es un aliado en el logro del objetivo de mejorar tu estilo de vida.

\subsection{Justificación del atractivo de la propuesta}

La justificación de la propuesta de negocio la encontramos en el crecimiento de la categoría de refrescos llamada bebidas "saludables", creemos que nuestra propuesta de valor basada en el uso de frutas deshidratadas, elemento totalmente innovador, ofrece un beneficio a nuestro cliente. Las frutas no contienen azúcar refinada, tienen propiedades medicinales y antioxidantes. En el marco del foro Fuerza del Milenio llevado a cabo en Lima en el 2016, se comentó lo ya expresado en las cifras del Ministerio de la Producción, la agroindustria representa el 35\% de la innovación en el país siendo el principal sector de los programas de fomento a la innovación según Innóvate Perú (CNN Español, 2016), es así que la alta biodiversidad que encontramos en nuestro país nos permitirá innovar en la combinación de ingredientes naturales y sabores para mantener encantado a nuestro público objetivo.

La hora del té, después del agua, los tés embotellados son probablemente la alternativa percibida como la más saludable. Y, dada su baja penetración, su crecimiento en ventas alcanza hasta los tres dígitos en provincias. Según Kantar Worldpanel, en los 
dos primeros meses del año, los hogares peruanos gastaron 53,8\% más en esta categoría. Y Euromonitor prevé que este mercado crecerá alrededor de 87\% hasta el 2020 (Gestion, 2016).

Finalmente, el existente creciente deseo de las personas por mantener un estilo de vida saludable, el incremental poder de decisión de los Millennials ${ }^{3}$, la identificación con productos eco-amigables y la creación de empatía con empresas que mantienen un proceso de producción amigable con el planeta; son todas razones que aseguran un potencial cliente en el futuro y la sostenibilidad del negocio en el tiempo.

\subsection{Estrategia inicial y objetivos de alcance}

El éxito de nuestro proyecto radica en la presentación de un producto innovador ya que combina la tendencia de mercado de hoy, que es consumir productos naturales con la oferta de la biodiversidad de frutas y verduras de nuestro país; tecnología, el proceso productivo que planteamos conserva todos los nutrientes del insumo base; diseño de empaque practico tanto en los productos por unidad, así como en las cajas, funcionalidad acorde para su consumo, en esta vida moderna. La estrategia empresarial se centrará en ofrecer una bebida alternativa de alta calidad a un menor costo, basado en el proceso productivo que tendremos, así como en el costo de la materia prima a emplear debido a la oferta que se tiene y al volumen de compra. La estrategia inicial será:

- Penetración del mercado

- Educación sobre los beneficios de la fruta deshidratada

- Escalable a una línea de productos saludables como bocaditos y barras de fruta deshidratada.

En general las fases del proyecto serán

\section{Gráfico $N^{\circ}$ 1: Fases del Proyecto}

\section{Prototipeo y Costeo:} - Encuestas y/o Focus group, entrevista con nutricionistas. - Equipamiento de planta. Prototipeo de productos y diseño de empaque. - Costo y rentabilidad

\section{Productos y negociación:}

- Registro de Marca

- Obtención registros sanitarios y

licencia funcionamiento de planta

- Ccomercialización
3. Promoción y mercadeo

- Degustaciones en ferias fitness y eventos. Página web,redes

Fuente: Elaboración propia

\footnotetext{
${ }^{3}$ Millennial se entiende por este concepto a las personas consideradas como la generación Y nacidos en los 80. De mente abierta, tienen poder de compra, trabajan, consumen y se mueven en canales digitales.
} 


\subsection{Impacto comercial y responsabilidad social}

Una de las variables consideradas para el desarrollo del proyecto es el impacto económico observado en el mercado objetivo al cual apuntamos, es así que de acuerdo a la información de ingresos y gastos en el nivel socioeconómico A y B de los años 2015, 2016 y agosto de 2017, se registra un incremento en el promedio general del ingreso y gasto familiar mensual en alimentación y conservación de la salud.

Gráfico N²: Ingresos y Gastos NSE A\&B

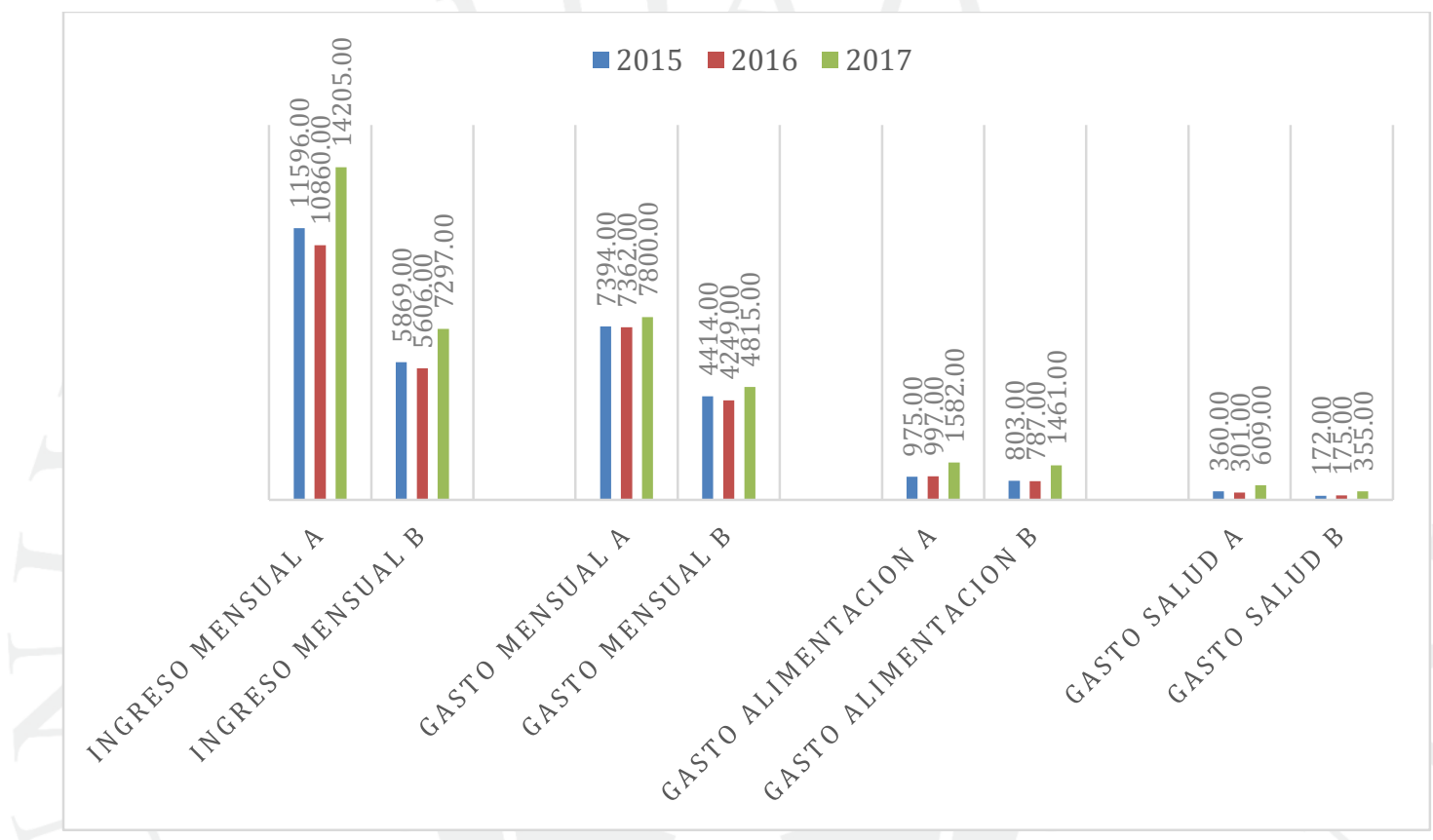

Fuente: APEIM 2015, 2016, agosto 2017

Elaboración propia

A su vez "Al Sol S.A.C." cumpliendo con una de las políticas de responsabilidad social de la empresa, contribuirá con la comunidad y la preservación del planeta en la generación de menor desecho de bebidas de té envasadas en PET, esto se valida con la información.

En Lima y Callao se desechan 430 toneladas de botellas de bebidas de plástico (Gestión, 2016). 


\section{CAPÍTULO II: IDEA, INVESTIGACIÓN Y VALIDACIÓN DE SOLUCIÓN}

\subsection{Diseño y Metodología de la investigación}

El plan de investigación tiene por finalidad determinar el perfil, la percepción y reacción del consumidor de bebidas comerciales frente a una alternativa saludable ofrecida, así como validar que los consumidores estén dispuestos a adquirir nuestra bebida alternativa en beneficio de su calidad de vida. Por tal motivo se han planteado los siguientes objetivos y herramientas de la investigación.

Tabla $N^{\circ}$ 1: Objetivos Generales y Específicos de Investigación

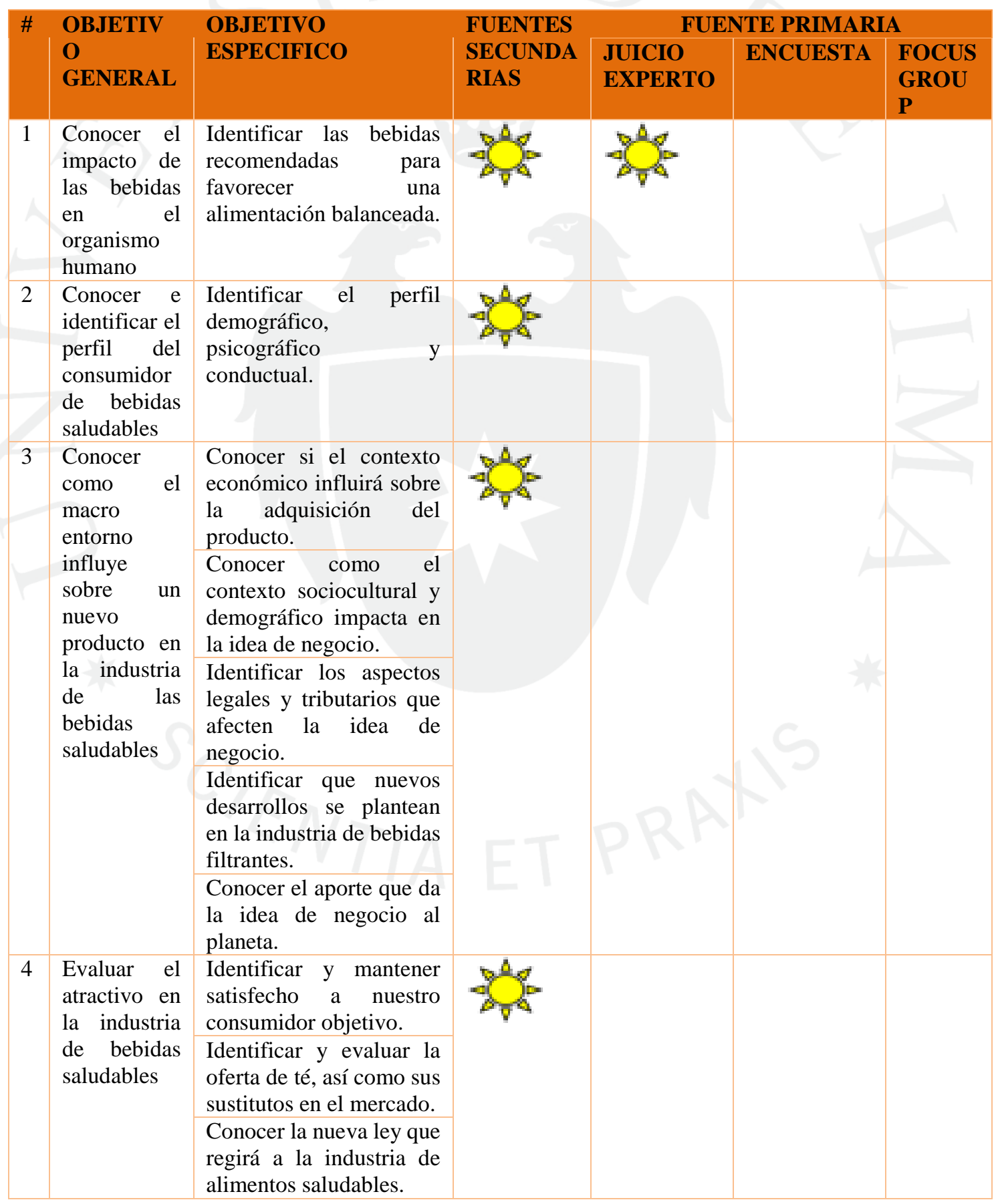




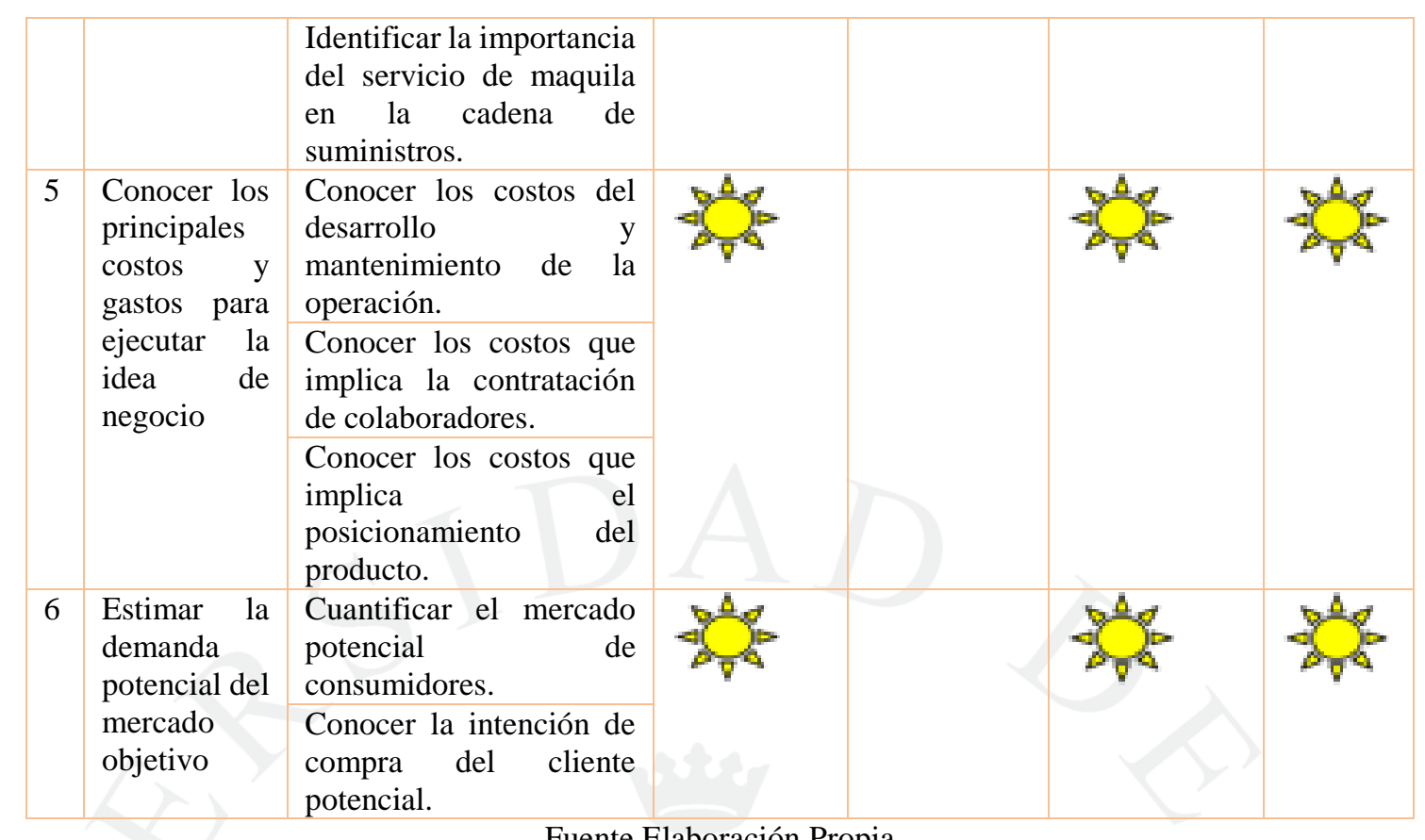

Fuente Elaboración Propia

Para alcanzar los objetivos planteados se realizó un sondeo de mercado dividido en dos etapas: exploratoria y concluyente, en la etapa exploratoria se consultaron fuentes secundarias y primarias.

Para el caso de las fuentes secundarias se encontraron los reportes sectoriales de INEI, APEIM, Euro monitor internacional. Del mismo modo se recogieron datos de diarios: El Comercio y Gestión.

En cuanto a las fuentes primarias se recurrió a diversas herramientas de investigación. Se empleó el juicio de expertos como médicos de diferentes especialidades. Se realizó un grupo de enfoque segmentado en función de los hábitos de consumo de productos saludables (frutas deshidratadas).

Tabla $\mathbf{N}^{\circ}$ 2: Ficha técnica del grupo de enfoque.

\begin{tabular}{|l|l|}
\hline Duración & 60 minutos \\
\hline Cantidad de personas & 5 personas \\
\hline Rango de edad & De 22 a 37 \\
\hline Sexo & Hombres y mujeres \\
\hline
\end{tabular}

Fuente: Elaboración propia 
Finalmente en la etapa concluyente se realizaron 384 encuestas. Las encuestas fueron realizadas de manera virtual y presencial.

Tabla $\mathbf{N}^{\circ}$ 3: Ficha técnica de la encuesta.

\begin{tabular}{|l|l|}
\hline \multicolumn{1}{|c|}{ Técnica empleada } & \multicolumn{1}{c|}{ Encuestas } \\
\hline Universo de estudio & $\begin{array}{l}\text { Personas naturales, residentes en Lima } \\
\text { Metropolitana de los NSE A y B }\end{array}$ \\
\hline Cobertura geográfica & Lima Metropolitana \\
\hline Tamaño de la muestra & 384 \\
\hline Tipo de muestreo & No probabilístico por juicio \\
\hline Filtros & $\begin{array}{l}\text { Disposición para consumir una nueva bebida } \\
\text { saludable }\end{array}$ \\
\hline Encuestas presenciales & Del 01/09/17 y 15/09/17 \\
\hline Encuestas online & Del 01/09/17 al 30/09/17 \\
\hline
\end{tabular}

Fuente: Elaboración propia

\subsection{Validación de la hipótesis}

En la fase exploratoria, con el fin de validar las tendencias y oportunidades del negocio se planteó la siguiente hipótesis:

Hi: Los consumidores reemplazarán con bebidas saludables a base de frutas su consumo de otras bebidas comerciales.

Ho: Los consumidores no reemplazarán con bebidas saludables a base de frutas su consumo de otras bebidas comerciales.

Para validar el juicio de expertos referimos las siguientes notas de médicos de diferentes especialidades:

\section{Fuente: Médico Interno, Oncólogo y en Salud Pública Dr. Elmer Huerta}

Diversos estudios han demostrado que el exceso en el consumo de azúcar está relacionado a una serie de problemas de salud, principalmente obesidad y enfermedades crónicas. Uno de los elementos que contribuye a ese problema (además de falta de actividad física, exceso de comida y alimentos procesados) es el consumo de bebidas excesivamente azucaradas como gaseosas, jugos de frutas artificiales, bebidas energizantes y deportivas.

Ante eso, mucha gente cree que al tener "cero calorías" las bebidas dietéticas, "light" o de dieta son una alternativa saludable al consumo de las bebidas azucaradas. Pero una reciente revisión, publicada en PloS Medicine por investigadores ingleses y brasileños, pone en duda esa aseveración y demuestra que las bebidas dietéticas no tienen nada de saludables. 


\section{Fuente: Nutricionista Yácomo Casas de la Cruz}

Una alimentación sana y equilibrada es fácilmente compatible con el sol y el calor si seguimos una serie de pautas básicas: "Las ensaladas de verduras y frutas constituyen también un aliado fundamental en estas fechas, además de aportar vitaminas y minerales. Frescas y deliciosas, es el mejor modo de alimentarse y refrescarse durante un día intenso de calor".

\section{Fuente: Endocrinólogo Jesús Rocca}

Como explica el endocrinólogo Jesús Rocca, de la clínica Ricardo Palma, el azúcar se absorbe rápidamente en el intestino, produciendo una gran liberación de insulina, que puede inducir en niños con predisposición a la diabetes u obesidad a un mayor depósito de grasa debajo de la piel y en las vísceras abdominales, lo cual predispone, a futuro, a diabetes mellitus, enfermedad cardiovascular y a arteriosclerosis.

Ojalá este artículo nos motive a echarle un poco menos de azúcar al café de la mañana, a la leche y a los jugos. Es cuestión de acostumbrarse a los sabores naturales de los alimentos; además, no olvidemos que tenemos un buen aporte de azúcar natural (sana) en las frutas.

\subsection{Muestreo poblacional}

Para estimar la demanda potencial de K'isa Té, se estableció como universo la población de Lima Metropolitana sin incluir el Callao, 9`147,116 habitantes. Posteriormente, se acotó dicho número considerando únicamente a las personas entre 18 y 35 años de edad pertenecientes a los niveles socioeconómicos A y B de la Zona 7 considerada como Lima Moderna ${ }^{4}$ (aproximadamente 308 mil personas). Para hallar el público objetivo de $\mathrm{K}$ 'isa Té, sólo se consideraron a aquellas personas que poseen un hábito de consumo saludable, las cuales representan el $63 \%$ de las personas pertenecientes a los NSE A y B (Datum Internacional, 2013).

Una vez obtenido nuestro público objetivo, 193,839 personas, se diseñó un filtro en función a tres variables clave en el consumo potencial de K'isa Té, para cada variable se determinaron porcentajes de captación resultantes del nivel de aprobación señalado en cada pregunta de la encuesta, estas variables fueron: valoración de productos saludables $(91.7 \%)$, intención de compra $(58.3 \%)$ y, finalmente precio a pagar $(66.2 \%)^{5}$.

\footnotetext{
${ }^{4}$ Los distritos considerados dentro de la Zona 7: Surco, San Isidro, San Borja, Miraflores, La Molina ${ }^{5}$ Porcentajes en base a la encuesta realizada, para mayor detalle ver Anexo 1: preguntas 11, 8 y 12 , respectivamente.
} 
Siguiendo este proceso, se obtuvo un porcentaje de captación de $1.0 \%{ }^{6}$ sobre el total del público objetivo; lo cual equivale a un nivel de captación de 2,010 personas. Considerando que la venta se hará por caja y la frecuencia de compra será quincenal, se obtuvo una demanda potencial anual de 1,205,930 cajas (48,237 cajas mensuales) y, una proyección de ventas de 964,744 cajas en el primer año de operación.

\subsection{Análisis de tendencias y patrones}

Para tener una buena salud es importante consumir agua a diario, $60 \%$ del cuerpo humano está compuesto de agua, su consumo es necesario para el buen funcionamiento de los órganos, se recomienda hidratarlo con bebidas saludables como agua natural, té, agua de hierbas o jugos naturales.

En el Perú el consumo de agua embotellada se encuentra rezagado frente al de otros países a pesar de que la producción industrial ha crecido notablemente en los últimos 10 años, según el informe del Instituto de estudios Económicos y Sociales de la Sociedad Nacional de Industrias como se muestra en el gráfico 3 (Instituto de Estudios Economicos y Sociales, 2017).

Gráfico N’3: Producción Nacional de Agua Embotellada de mesa, principales empresas 2012 2017 (Millones de Litros)
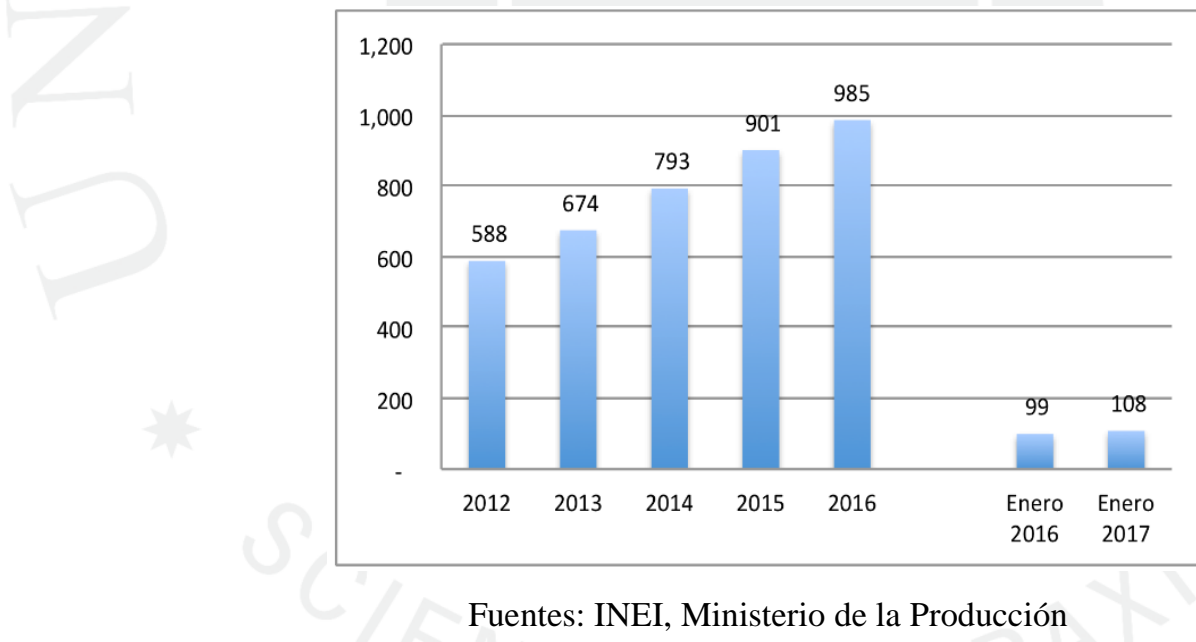

Fuentes: INEI, Ministerio de la Producción Elaboración: Propia

Según el estudio realizado el incremento en promedio del $10.9 \%$, se debió a una mayor demanda de las familias por consumir productos que favorezcan la salud.

En esa misma orientación el diario Gestión en su artículo ¿Cuáles son las nuevas tendencias del consumidor de alimentos especializados en EEUU? comenta que en la última edición de The Winter Fancy Food Show 2017, feria más grande de productos

\footnotetext{
${ }^{6}$ La captación se determina aplicando un porcentaje de descuento a cada variable de consumo considerada, en función de la importancia obtenida.
} 
gourmet de los Estados Unidos quedó claro y definido lo siguiente: "Las tendencias definen el futuro cercano y en esta ocasión, los productos saludables y especializados con autenticidad de marca e innovación en el empaque son los que están generando una demanda significativa en el Mercado”. A su vez destacó como de última tendencia y de gran interés las bebidas saludables, clasificándolas de acuerdo con el uso dado: para la desintoxicación del organismo o para mejorar el rendimiento físico (Gestion, 2017).

"Hay una tendencia mundial de los consumidores hacia los productos saludables y naturales, bajos en calorías y ricos en antioxidantes; el Perú no es ajeno a esta tendencia, y la categoría de té bebibles cumple con lo que demandan los consumidores; de ahí su potencial de crecimiento en penetración" (Gestión, 2015).

En base al estudio de Arellano Marketing observamos que el consumidor peruano muy saludable incluye un rango de edad de entre 16 a 60 años, se caracteriza por incluir en su dieta diaria frutas y verduras, practica ejercicio y en general se preocupa por mantener un equilibrio entre su vida física y laboral (Palomino, 2017).

\section{Gráfico N²: Hábitos Saludables entre los peruanos}

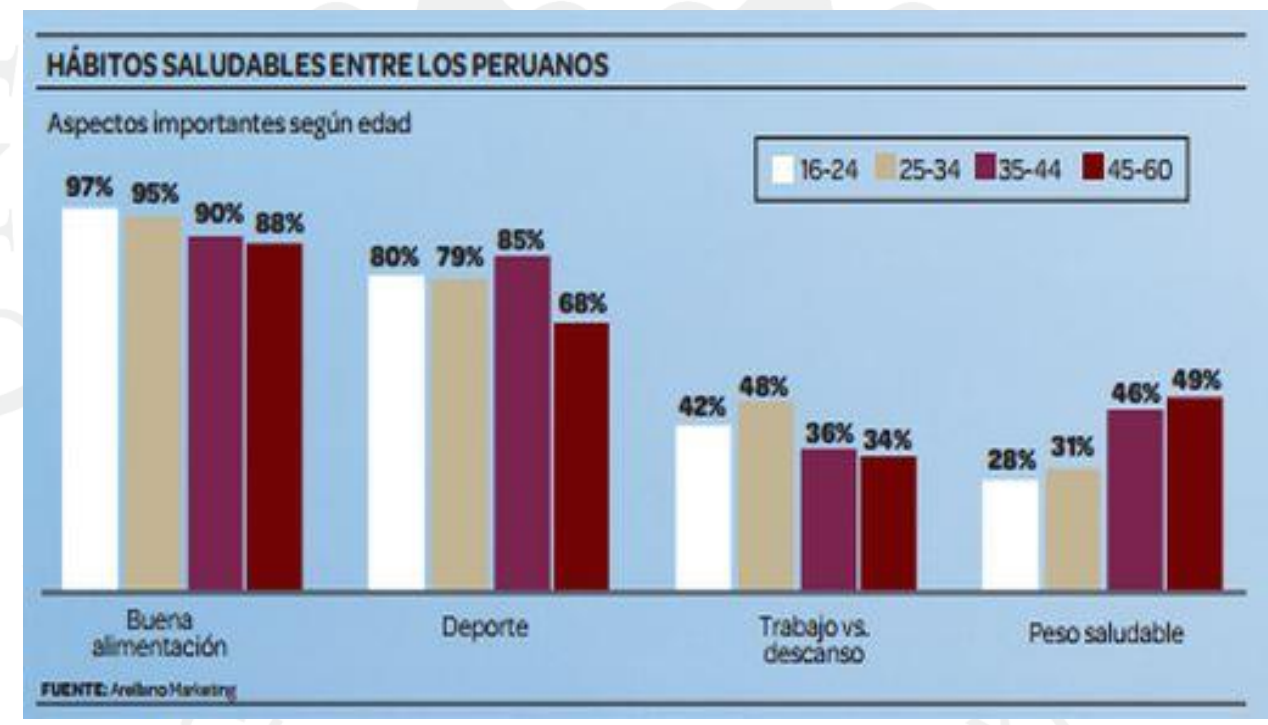

Fuente: Elaboración Arellano Marketing

\subsection{Validación de la propuesta}

En la fase concluyente, se validó la hipótesis con la pregunta $\mathrm{N}^{\circ} 8$ de la encuesta circulada a la muestra poblacional. Para mayor detalle del cuestionario realizado ver Anexo 1. Asimismo se presentan los resultados de la investigación de campo:

\section{Consumo}

- $83 \%$ de los encuestados considera importante hidratarse 
- $52 \%$ de los encuestados está dispuesto a consumir productos nuevos

\section{$\underline{\text { Preferencias }}$}

- $73 \%$ de los encuestados cuenta ya en su consumo con algún producto saludable.

- $56 \%$ de la muestra prefiere consumir agua para hidratarse

\section{Propuesta}

- $58 \%$ de la muestra estaría dispuesto a consumir un té de fruta deshidratada.

- $56 \%$ de los encuestados le gustaría encontrar el producto en los supermercados.

\subsection{Canvas del modelo de negocio}

Para el modelo de negocio de nuestra investigación el modelo Canvas nos permite describir la lógica de cómo nuestro proyecto crea y entrega un valor, una vez que se identifiquen los nueve elementos que lo conforman.

\section{Tabla N${ }^{\circ}$ : Modelo CANVAS}

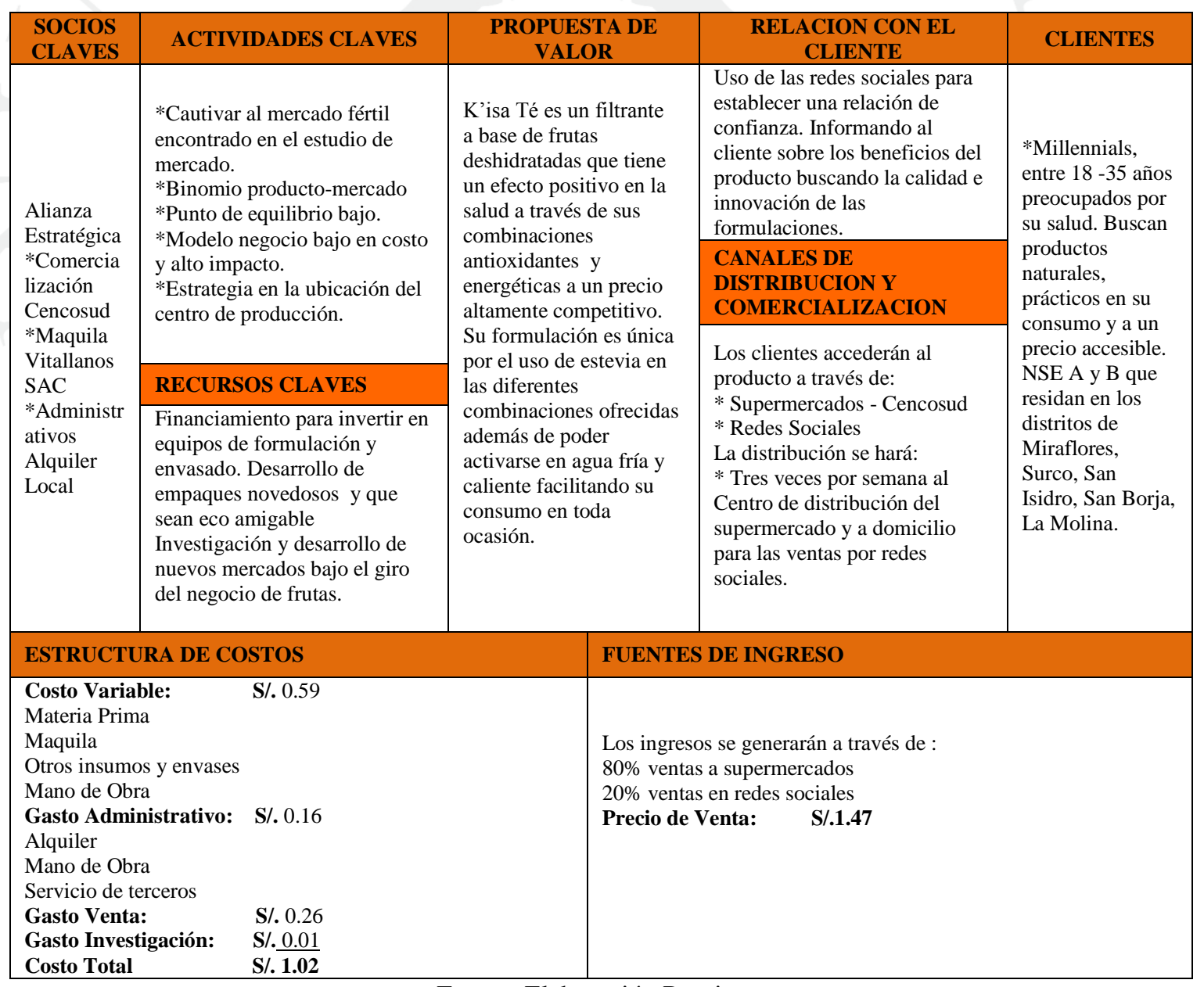




\subsection{Conclusiones}

Luego de evaluar la solución que brindará K’isa Té se puede concluir que es una idea de negocio atractiva y con un amplio potencial de crecimiento. Según la investigación realizada, hoy en día existe un fuerte interés de los Millennials por llevar una vida saludable siendo uno de los pilares: la industria de las bebidas.

Los expertos en temas de nutrición y la salud reconocen el rol clave que cumple la buena elección de hidratación pues en el mercado existe una amplia oferta de bebidas carbonatadas, light y procesadas que lejos de ser nutritivas deterioran la salud por su alto nivel de azúcar.

Es por ese motivo, que K'isa Té encuentra la oportunidad para brindar una solución: un té filtrante natural a base de fruta deshidratada y endulzado con estevia para la hidratación diaria sin descuidar el buen sabor, variedad y precio accesible para el consumidor.

Gracias al crecimiento de las plataformas de supermercados, la masificación de redes sociales y el crecimiento de espacios de educación nutricional, hemos encontrado la oportunidad de utilizar dichos canales para dar a conocer K'isa Té a gran alcance y cobertura geográfica. Asimismo, con ayuda de la tecnología, ofrecer al consumidor la practicidad de un filtrante que se activa en agua fría y caliente. 


\section{CAPÍTULO III: PLANEAMIENTO ESTRATÉGICO}

\subsection{Visión}

"Ser una empresa líder que inspire un consumo saludable, innovando permanentemente a través de la creación, investigación, y lanzamiento de nuevos productos y sus derivados".

\subsection{Misión}

Ofrecer productos naturales de alta calidad a través de nuestro compromiso con la seguridad alimentaria, alimentación saludable.

\subsection{Valores y ética}

Los valores de "Al Sol S.A.C." están íntimamente relacionados justamente con nuestro eslogan "Te nutre, te envuelve". A través de nuestro té natural obtendremos un beneficio que será sostenible en el tiempo sin afectar el medio ambiente. Es así que entendemos que todas nuestras operaciones con nuestros socios estratégicos deben regirse bajo el irrestricto uso de principios éticos.

Los valores que nos definen son:

1. Integridad: congruencia entre lo que se dice y se hace.

2. Confianza: entregar a nuestro consumidor lo que ofrecemos y a nuestros colaboradores la oportunidad de desarrollarse dentro de la organización a través de capacitación.

3. Justicia: tanto en el ámbito interno entre nuestros colaboradores a través de la delegación de funciones y carga laboral, así como en el ámbito externo a través del pago de nuestras obligaciones y en el retorno obtenido.

4. Transparencia: veracidad en la comunicación interna y externa.

5. Ecología: compromiso adquirido con el planeta ya que toda nuestra operación y el producto que ofrecemos lleva ese sello.

\subsection{Cultura Organizacional}

En "Al Sol S.A.C." promoveremos el uso de la dirección por valores, teniendo como eje central la ética la cual será transversal a toda la organización.

Nuestros valores ya definidos representan el cómo se hacen o deben hacer las cosas dentro de la organización y por lo tanto están al servicio de la misión y visión de la empresa. 


\subsection{Objetivos Estratégicos}

A partir de la misión y visión de K’isa Té, se presentan los objetivos estratégicos:

Tabla $\mathbf{N}^{\circ}$ 5: Objetivos Estratégicos

\begin{tabular}{|l|l|l|}
\hline \multicolumn{1}{|c|}{ OBJETIVO } & \multicolumn{2}{c|}{ INDICADOR } \\
\hline $\begin{array}{l}\text { Posicionarse en la mente del consumidor } \\
\text { como el mejor té filtrante del mercado. }\end{array}$ & $80 \%$ de satisfacción en el consumidor. \\
\hline $\begin{array}{l}\text { Establecer una relación duradera con el } \\
\text { proveedor de maquila. }\end{array}$ & $\begin{array}{l}\text { Evaluación semestral de control de } \\
\text { calidad. }\end{array}$ \\
\hline $\begin{array}{l}\text { Introducir una nueva línea cada dos años. } \\
\text { Resultados de la encuesta de } \\
\text { investigación al consumidor. }\end{array}$ \\
\hline $\begin{array}{l}\text { Lograr una rentabilidad no menor a 30\% } \\
\text { sobre las ventas }\end{array}$ & \begin{tabular}{l} 
Margen EBITDA / ventas \\
\hline Alcanzar crecimiento anual
\end{tabular} & Tasa anual de crecimiento compuesto \\
\hline
\end{tabular}

Fuente Elaboración Propia.

\subsection{Análisis Externo: PESTEL}

\subsubsection{Político - Legal}

En nuestro país el CEPLAN (Centro Nacional de Planeamiento Estratégico) recoge ya en su publicación PLAN BICENTENEARIO - El Perú hacia el 2021, como Políticas de Estado del Acuerdo Nacional: La Promoción de la seguridad alimentaria y la nutrición, Competitividad, productividad y formalización económica, Desarrollo sostenible y gestión ambiental (CEPLAN, 2011).

El objetivo principal de hacer negocios en el Perú, es la promoción e impulso de la mediana y pequeña empresa. Según el Doing Business el Perú ocupa el puesto 54 de 189 países con facilidad para hacer negocio y dentro de Latinoamérica está posicionado en el tercer puesto (BM, 2017).

Tabla $N^{\circ}$ 6: Ranking Doing Business de Latino América

\begin{tabular}{|c|c|}
\hline \multicolumn{2}{|c|}{ DOING BUSINESS } \\
\hline Ranking para Latino América \\
\hline País & Posición \\
\hline Colombia & 53 \\
\hline Perú & 54 \\
\hline Uruguay & 90 \\
\hline Paraguay & 106 \\
\hline Ecuador & 114 \\
\hline Argentina & 116 \\
\hline Brasil & 123 \\
\hline Bolivia & 149 \\
\hline Venezuela, RB & 187 \\
\hline Fuente: Banco Mundial Doing Business 2016 \\
\hline Elaboración Propia \\
\hline
\end{tabular}




\subsubsection{Económico}

A lo largo de la última década, Perú ha sido una de las economías de más rápido crecimiento en la región, con una tasa de crecimiento promedio de 5.9 por ciento en un contexto de baja inflación (promediando 2.9 por ciento). La presencia de un entorno externo favorable, políticas macroeconómicas prudentes y reformas estructurales en diferentes áreas, crearon un escenario de alto crecimiento y baja inflación.

Por un lado, el sólido crecimiento en empleo e ingresos redujo considerablemente las tasas de pobreza. La pobreza moderada (US\$4 por día con un PPA del 2005) cayó de 45.5 por ciento en el 2005 a 19.3 por ciento en el 2015. Esto equivale a decir que 6.5 millones de personas salieron de la pobreza durante ese periodo. La pobreza extrema (US\$2.5 por día con un PPA del 2005) disminuyó de 27.6 por ciento a 9 por ciento en ese mismo periodo (BM, 2017).

Por otro lado, el 74\% de las medianas y pequeñas empresas confían en que su negocio crecerá en los próximos seis meses. Ello, en línea con las expectativas positivas que el $61 \%$ de las medianas y pequeñas empresas tuvo para la economía nacional en el 2017 (Ministerio de la Produccion, 2017).

Es decir, existe una mayor disponibilidad de dinero para el consumo familiar e inversión por parte de la mediana y pequeña empresa. Asimismo, un mayor acceso a créditos y las altas expectativas conllevan a proyectos de expansión de empresas para su crecimiento y desarrollo. No obstante, también implica un aumento en el número de empresas y por ende de la competencia en los sectores que se desarrollen.

\subsubsection{Demografía}

El crecimiento por nivel socio económico en el 2015 y agosto 2017 es de $6 \%$ para el nivel "A" y 1\% para el nivel "B". Dicho esto, y la concentración de los "NSE A y B" en la población de Lima Moderna, indica una tendencia positiva en la adopción de nuevos hábitos o costumbres lo que propiciaría a una mayor cantidad de potenciales clientes para el producto (APEIM, 2015).

\subsubsection{Socio - Cultural}

La tendencia del público Millennial ${ }^{7}$ por consumir productos sin procesos químicos es una variable que impacta al consumo de $\mathrm{K}$ 'isa Té pues este tiene como objetivo contribuir a la salud como una bebida hidratante natural.

\footnotetext{
${ }^{7}$ Millennial: Generación "Y”, son los nacidos entre los ochenta y 2000
} 
De igual forma, el acceso a masivas cantidades de información a través de las redes sociales permite al consumidor realizar una compra informada u educada. También, se tiene que tener en cuenta que actúan de manera impredecible por lo que sus hábitos y costumbres tienen que ser identificados a tiempo para cubrir sus expectativas y ofrecer nuevos productos en el plazo correcto (Gestión, 2016).

\subsubsection{Tecnológico}

Los avances en la tecnología van en pro de un mejor futuro, es así que los paneles solares marcarán la pauta en la generación de energía renovable. Por esta razón existe un valor agregado explicito para todos los productos que contribuyen con el ambiente. El proceso de la deshidratación de fruta aprovechará esta tendencia en la implementación del proceso de maquila.

\subsubsection{Ecológico}

Con el fin de evitar la contaminación por el uso de las fuentes de energía actuales como el petróleo, gas natural o carbón; hoy en día existen fuentes de empleo de energía renovable como eólica, geotérmica, hidráulica, mareomotriz y la más conocida la energía solar. Por otro lado, el uso de té filtrante en vez del consumo de bebidas embotelladas permite reducir los desechos de plásticos.

\subsection{Análisis de Porter}

\subsubsection{Rivalidad de Competidores}

En la industria de bebidas entraríamos dentro del CIIU 1549 - Elaboración de otros productos alimenticios n.c.p. Actualmente no hay en el mercado un producto como $\mathrm{K}$ 'isa Té, cien por ciento natural y a base de fruta deshidratada.

Sin embargo, hay una gran presencia de té importado que se venden en supermercados y tiendas a altos costos sin conocer a profundidad su formulación. Entre las marcas que consideramos nuestra competencia directa, tenemos a: Bigelow, Nature's Heart y Lipton. Luego, los competidores indirectos que se encuentran en el mismo punto de venta y categoría encontramos a las marcas nacionales como: Herbi, McCollins u otros filtrantes.

Dentro de esta categoría no hay una marca que tenga un elevado posicionamiento, por todo ello la rivalidad entre competidores es alta y la tendencia de consumir productos naturales representa una oportunidad de diferenciación. 
Tabla $\mathrm{N}^{\circ}$ 7: Lista de Competidores

\begin{tabular}{|c|c|c|c|c|c|c|}
\hline Competidor & & Producto & Plaza & Precio S/. & Sabores & Compañía \\
\hline LAn & $\begin{array}{c}\text { NATURE'S } \\
\text { HEART }\end{array}$ & $\begin{array}{l}\text { Fusión de Té con trozos de fruta } \\
\text { deshidratada, su presentación es de } \\
\text { caja de } 6 \text { sobres } 10 \mathrm{~g} \mathrm{c} / \mathrm{u}\end{array}$ & \multirow{3}{*}{$\begin{array}{c}\text { Supermercados: } \\
\text { Wong }\end{array}$} & 13.1 & $\begin{array}{l}\text { Frutas Tropicales } \\
\text { Manzana y Canela }\end{array}$ & \begin{tabular}{|c|} 
TERRAFERT \\
IL \\
COLOMBIA
\end{tabular} \\
\hline$=$ & STEEP & $\begin{array}{l}\text { Té organico sembrado en campos } \\
\text { selectos. Su presentación es de caja } \\
20 \text { sobres } 1.25 \mathrm{~g} \mathrm{c} / \mathrm{u}\end{array}$ & & 26.9 & $\begin{array}{l}\text { Frutas tropicales } \\
\text { Hibiscus, Kion }\end{array}$ & $\begin{array}{l}\text { BIGELOW } \\
\text { USA }\end{array}$ \\
\hline & STASH & $\begin{array}{l}\text { Té herbal y con mezcla té negro sin } \\
\text { cafeina. Su presentación es de caja } \\
20 \text { o } 18 \text { sobres } 1.90 \mathrm{~g} \mathrm{c} / \mathrm{u}\end{array}$ & & 22.9 & \begin{tabular}{|c|} 
Frutas \\
clasicas,tropicales,g \\
ranada,maracuya,
\end{tabular} & $\begin{array}{c}\text { STASH TEA } \\
\text { USA }\end{array}$ \\
\hline & $\begin{array}{c}\text { LA } \\
\text { FIDELIA }\end{array}$ & $\begin{array}{c}\text { Fusión de Té con frutas flores y } \\
\text { otras hierbas. Caja de } 15 \text { unidades } \\
\text { de } 2.5 \mathrm{gr} \mathrm{c} / \mathrm{u}\end{array}$ & $\begin{array}{c}\text { Cafeterias San } \\
\text { Antonio, } \\
\text { Maminos,Sarcletti }\end{array}$ & 45.0 & $\begin{array}{l}\text { Atado ancestral, } \\
\text { maracuya, té verde, } \\
\text { negro, aguaymanto, }\end{array}$ & $\begin{array}{l}\text { LA FIDELIA } \\
\text { PERUANA }\end{array}$ \\
\hline
\end{tabular}

Fuente: Elaboración propia

\subsubsection{Amenaza de nuevos entrantes}

Como barrera de entrada tenemos la maquila del proceso de deshidratación de la fruta pues debe realizarse en grandes cantidades además de conocer del proceso a detalle para evitar merma en la materia prima.

La logística de distribución y las alianzas estratégicas con que inicia el proyecto, resultan ser una palanca para asegurar la venta del producto. Por ende, la amenaza de nuevos entrantes es media, porque se requiere de tiempo y dinero para ingresar al mercado, siendo K'isa Té el primero en penetrar el mercado.

\subsubsection{Poder de Negociación de Proveedores}

El proveedor con mayor poder de negociación es Vitallanos Perú S.A.C. quien realiza la maquila del proceso de deshidratado de frutas. Es la empresa de mayor capacidad de producción en Lima y su reemplazo sería un conjunto de medianas empresas donde la capacidad de producción es limitada; por lo que el poder de negociación es media.

Los vendedores del Mercado mayorista de frutas son un proveedor importante y su poder de negociación es medio pues son proveedores de la materia prima pero al estar localizados en un punto de comercio es fácil la comparación en términos de calidad del producto y precio ofertado.

Finalmente, la cadena de supermercado tiene un poder de negociación alto pues dada su ventaja y posicionamiento en el mercado cuenta ya con acuerdos comerciales establecidos y términos de comercialización que no son negociables. Dada la cobertura de puntos de venta, la empresa ha de adecuarse. 


\subsubsection{Poder de Negociación del Comprador}

El poder de negociación del comprador es alto porque pueden comparar el producto con otros en el punto de venta ya sea por calidad o precio.

El comprador al que vamos dirigidos es del nivel socioeconómico A y B donde el $63 \%$ prefieren mantener una dieta saludable, y se informan antes de realizar la compra por lo que el poder adquisitivo y educación del comprador son las característica que mayor influencia tienen en la compra.

\subsubsection{Amenaza de sustitutos}

Los productos que pueden ser adquiridos en lugar del té filtrante en base a frutas deshidratas son diversos y todos se encuentran en el mismo punto de venta, es por ello la amenaza de productos sustitutos es alta entre los que mencionamos:

- Té embotellado.

- Agua envasada con sabor a fruta.

El plan de contingencia radica en lograr la diferenciación en términos de innovación de las formulaciones y el precio accesible.

\subsection{Análisis FODA}

Tabla $\mathbf{N}^{\circ}$ 8: Análisis FODA

\section{FORTALEZA \\ Producto saludable y combinaciones en \\ función a su aporte al organismo \\ Equipo enfocado en hacer negocios ecológicos \\ Producto innovador porque no existe en el mercado una bebida filtrante con estas características \\ Cumplimiento de Normas Sanitarias y estandarización en técnicas BPM} DEBILIDAD

Control constante sobre proveedor de maquila de fruta

Demora en la implementación de los equipos y planta elevando costos.

Menor tiempo de vida del producto en anaquel por no uso de conservantes

\section{OPORTUNIDAD}

Mercado en crecimiento, demanda de productos saludables en especial bebidas Alta variedad de frutas, biodiversidad en nuestro país sobre todo las Súper frutas Los competidores del mercado tienen un precio alto y no hay certeza de que sean productos naturales

Estilo de vida actual, consumidores buscan productos prácticos.

\section{AMENAZA}

Nuevo marco regulatorio para productos saludables MAP.

Competidores nuevos imitando el producto.

Bajo poder de negociación con los

Supermercados para la comercialización

Temporada de Fruta en diferentes épocas del año.

Fuente: Elaboración Propia 


\section{CAPÍTULO IV: PLAN DE MARKETING}

La oportunidad de negocio que encontramos en la venta de K'isa Té resulta ser atractiva económicamente. Sin embargo, su posicionamiento en el mercado implica calar en la mente del consumidor limeño para cambiar la idea de que él té solo puede ser consumido con agua caliente y en época de invierno. Es decir se debe destacar las características de ser un producto natural con nuevas formulaciones de sabor exquisito y con la posibilidad de activarse en agua caliente y fría.

\subsection{Planeamiento de objetivos generales de marketing}

Los objetivos considerados ara el plan de marketing son:

Tabla $N^{\circ}$ 9: Objetivos de Marketing

\begin{tabular}{|c|c|}
\hline Objetivo & Indicador \\
\hline $\begin{array}{l}\text { Lograr ventas anuales por } 1.4 \text { millones de } \\
\text { soles. }\end{array}$ & Ventas netas del periodo en evaluación \\
\hline Lograr un margen EBITDA anual de $59 \%$ & EBITDA / Ventas del año \\
\hline Lograr una recordación de marca de $80 \%$ & $\begin{array}{l}\text { Consumidores encuestados que relacionan } \\
\text { té filtrante saludable con K'isa Té / } \\
\text { Consumidores de K'isa Té encuestados }\end{array}$ \\
\hline $\begin{array}{l}\text { Posicionarse como el mejor te filtrante y } \\
\text { saludable }\end{array}$ & $\begin{array}{l}\text { Encuestados que recomiendan K'isa Té } \\
\text { como el mejor te filtrante saludable / } \\
\text { Consumidores de K'isa Té encuestados }\end{array}$ \\
\hline $\begin{array}{l}\text { Lanzar } 2 \text { sabores de K'isa Té cada dos } \\
\text { años }\end{array}$ & $\begin{array}{l}\text { Número de nuevos sabores lanzados cada } \\
\text { dos años }\end{array}$ \\
\hline $\begin{array}{l}\text { Lograr una cobertura de distribución en } x \\
\text { puntos de venta }\end{array}$ & $\begin{array}{l}\text { Número de puntos de venta en los cuales } \\
\text { K'isa Té tiene presencia }\end{array}$ \\
\hline $\begin{array}{l}\text { Incrementar la frecuencia de consumo de } \\
\text { K'isa Té }\end{array}$ & Frecuencia de consumo \\
\hline $\begin{array}{l}\text { Lograr la satisfacción del consumidor } \\
\text { final en } 95 \%\end{array}$ & $\begin{array}{l}\text { Encuestados satisfecho con K'isa Té / } \\
\text { Numero de encuestados }\end{array}$ \\
\hline
\end{tabular}

Elaboración propia

\subsection{Estrategia de marketing}

\subsubsection{Segmentación y Perfil del cliente}

La segmentación reúne personas consideradas como Millennials de entre 18 a 35 años de edad del NSE AB de Lima Metropolitana.

Del nivel socioeconómico A y B nos enfocaremos en un 63\% (Datum Internacional, 2013) de las personas preocupadas por su salud alimenticia de los distritos de: La Molina, Surco, San Borja, San Isidro y Miraflores que equivale a 193,839. A este universo se aplicó un factor de aceptación de nuestro producto basado en las respuestas obtenidas de la encuesta realizada equivalente a $1.04 \%$ obteniendo un público objetivo de 2,010 personas. Se considera que los mismos tendrán una frecuencia de compra quincenal. 


\section{PERFIL DEL CLIENTE}

Hombres y mujeres de 18 a 35 años.- Millennials, preocupados por su salud localizados en el NSE AB de los distritos considerados como Lima Moderna, trabajan llevan un ritmo de vida acelerado que no les permite comer de manera tradicional con poder adquisitivo que se informan y realizan compras en los medios digitales.

\subsubsection{Posicionamiento y ventaja competitiva}

Dentro de nuestra estrategia de posicionamiento realizaremos campañas incisivas como:

- Pauta en radio de 20 segundos por 23 días 8 veces diarias.

- Redes sociales con reconocimiento de palabras claves como té y natural que medirán el crecimiento orgánico.

Presencia en carrera deportiva RPP y feria fitness "BOOM".

\subsection{Mercado Objetivo}

\subsubsection{Tendencia de mercado}

Hoy en día los consumidores buscan lo mejor para su cuerpo. El consumidor se informa sobre la procedencia de los alimentos y prefiere los que no son industrializados. La prevención a enfermedades crónicas y el cuidado es la mayor motivación para elegir productos saludables. Esta búsqueda de la salud se extiende a la preferencia por empresas que no atentan contra el medio ambiente. Finalmente, el tiempo también es un factor determinante para optar por un producto práctico de llevar y consumir.

\subsubsection{Tamaño de mercado}

El tamaño del mercado al que nos dirigimos de acuerdo a lo mencionado en el punto 4.2.1 es de 193,839 personas.

\subsubsection{Mercado Objetivo}

El mercado objetivo corresponde a las personas dispuestas a tomar bebidas en base de fruta deshidratadas como se muestra en el cuadro siguiente: 
Tabla $N^{\circ}$ 10: Estimación de la Demanda

\begin{tabular}{|c|c|c|}
\hline & POBLACION & $\%$ \\
\hline POBLACION PERUANA & $32,019,925$ & 100 \\
\hline POBLACION LIMA SIN CALLAO & $9,147,116$ & $29 \%$ \\
\hline \multicolumn{3}{|l|}{ NSE } \\
\hline NSE A & 439,062 & $5 \%$ \\
\hline NSE B & $2,268,485$ & $25 \%$ \\
\hline TOTAL NSE AB & $2,707,546$ & $30 \%$ \\
\hline \multicolumn{3}{|c|}{ ZONA 7 ( MIRAFLORES,SAN ISI DRO,SAN BORJA,SURCO, LA MOLINA) } \\
\hline NSE A & 153,232 & $35 \%$ \\
\hline NSE B & $1,043,503$ & $46 \%$ \\
\hline TOTAL NSE AB & $1,196,735$ & $44 \%$ \\
\hline \multicolumn{3}{|l|}{ RANGO ETARIO } \\
\hline De 18 a 25 años & 143,728 & $12 \%$ \\
\hline De 26 a 30 años & 82,575 & $7 \%$ \\
\hline De 31 a 35 años & 81,378 & $7 \%$ \\
\hline TOTAL ENTRE 18 A 35 AÑOS & 307,681 & $26 \%$ \\
\hline \multicolumn{3}{|l|}{ CUIDAN SU SALUD ALIMENTICIA } \\
\hline Personas preocupadas AB $\quad$ Fuente Datum & 193,839 & $63 \%$ \\
\hline \multicolumn{3}{|c|}{ DISPUESTOSA TOMAR BEBIDAS DE FRUTA DESHIDRATADA } \\
\hline \multirow{2}{*}{ Encuesta \% Per sonas dispuestasa consumir } & 2,010 & $1 \%$ \\
\hline & & \\
\hline CONSUMO PERCAPITA FILTRANTE $2.5 \mathrm{Gr}$. & 1 & \\
\hline CONSUMO ESTIM ADO POR PERSONA & 2,010 & \\
\hline
\end{tabular}

Fuente: Elaboración Propia

\subsubsection{Identificación de agentes}

Clientes, usuarios, compradores, prescriptores, intermediarios, mayoristas, minoristas, comisionistas.

\subsubsection{Potencial de crecimiento del mercado}

El crecimiento anual estimado en el escenario base es de $1.5 \%$.

\subsubsection{Rivalidad, competidores y Potencial de ventas}

En el mercado limeño encontramos varios filtrantes que se ofertan como bebidas calientes, entre los que destacan los relajantes y algunas infusiones con aromas frutales, cabe resaltar que todos estos productos son procesados industrialmente y por lo tanto no son naturales.

Encontramos un nicho de mercado grande para tener ventas potenciales, al tener presente el binomio producto- mercado pero hay que recordar que al ser Océano Azul también tenemos que invertir en investigación y desarrollo de nuevas formulaciones para conseguir clientes fidelizados y encantados con el producto. 


\subsection{Desarrollo y estrategia del marketing mix}

\subsubsection{Política de gestión del cliente}

Las políticas que la empresa implementará para tener factores diferenciadores frente a la competencia y otros, se basan en el estudio de mercado donde se encontró:

- Al preferir las compras por canales digitales, se establecerá un mínimo de pedido para llevarlo sin cargo por entrega.

- Se buscará incentivar la compra por las redes sociales, generando interacción por tener más "me gusta" o compartir la imagen del día con más personas.

\subsubsection{Estrategia de productos:}

Las especificaciones del producto a ofrecer consisten principalmente en un sobre de 2.5 gramos de una formulación que contiene fruta deshidratada, la cual al ser diluida en agua fría o caliente se puede consumir como una bebida en todo momento conservando las características propias de la fruta, como su sabor y vitaminas.

La calidad de producto se asegura por el proceso de deshidratación de la fruta, al pasar por este proceso no se pierde ninguna de las propiedades de la fruta, el proveedor de la maquila deberá cumplir con las especificaciones establecidas para evitar la oxidación estando sujeto a control de calidad de acuerdo al contrato firmado.

La variabilidad se sustenta en las diferentes frutas que se utilizarán en el proceso de deshidratación y estacionalidad de la fruta. En un inicio se trabajará con fresa, piña, manzana y arándano.

La diversificación de nuestro producto esperará hasta que se logre un posicionamiento en el mercado, dado que el crecimiento será de integración vertical, para no perder el foco del negocio

\subsubsection{Estrategia de precios: análisis de costos y precios.}

El análisis de costos se ha realizado satisfactoriamente, ya que en Lima contamos con el mercado de frutas donde se encuentra amplia oferta de materia prima de excelente calidad y bajo precio.

El porcentaje de rendimiento de la materia prima es del $35 \%$ ya que en el proceso de deshidratación se pierde el $65 \%$.

El precio del kilo de fruta elegido oscila entre S/.1.00 y S/.3.50 soles.

El precio de venta una vez deducido el margen del canal de distribución es de S/. 1.47 soles por unidad y de S/. 36.70 soles por caja. 


\subsubsection{Política comercial}

Dentro de las políticas de precios que se establecerán para un correcto funcionamiento de la empresa se plantea lo siguiente: los objetivos de venta se han establecido en base al flujo de venta anual, donde se toma el $80 \%$ del público estimado.

Condiciones de venta: Por la alianza estratégica con la cadena de supermercados CENCOSUD, se establece un periodo de pago de 30 días al ser considerada como pequeña empresa. Las ventas a través de redes sociales se harán en efectivo de manera que tengamos un flujo mínimo para gestionar las compras en la operación.

Condiciones de pago: Para el inicio de operaciones se ha estimado un capital de trabajo de 30 días lo cual nos permitirá realizar las compras en efectivo respetando el mecanismo del mercado de frutas y por ser nuevos no podremos gestionar un periodo de crédito con proveedores.

Canales de venta: Se ha establecido el canal moderno como medio de comercialización. La alianza con la cadena de supermercado CENCOSUD nos permitirá vender el ochenta por ciento de nuestra producción dejando el veinte por ciento restante a la venta a través de redes sociales en donde se podrá encontrar información del producto, la entrega a domicilio se hará con un monto mínimo de compra.

\subsubsection{Estrategia comunicacional y canal}

Las estrategias de comunicación que se usarán para cautivar y hacer que se posicione la marca serán las redes sociales como Facebook, Instagram, WhatsApp así como la pauta radial contratada en una emisora en el espacio de mayor audiencia del público objetivo. También se contará con la web de la empresa para dar a conocer los beneficios del producto y datos relevantes.

\subsubsection{Estrategia de distribución}

Para la distribución de nuestro producto, se cuenta con el alquiler de un camión tres veces por semana en un horario de ocho horas para cumplir con la carga de las compras entrega al proveedor de maquila, recojo de la fruta procesada, entrega en nuestra planta de donde se procederá a distribuir el producto terminado al centro de distribución de CENCOSUD y/o a los destinos por distrito de acuerdo a los pedidos por redes sociales.

\subsection{Plan de ventas y Proyección de la Demanda}

Nuestro plan de ventas en el escenario base considera una venta quincenal por persona determinada en el punto 4.3.3. Mercado Objetivo: 2,010 personas. 
Tabla $N^{\circ}$ 11: Proyección de la demanda Anual - Escenario Base

\begin{tabular}{|c|c|c|c|c|c|}
\hline \multirow[b]{3}{*}{ PARTICIPACION DE MERCADO } & \multicolumn{5}{|c|}{$\begin{array}{l}\text { Caso Base } \\
\text { DEM ANDA ESTIM ADA POR HABITANTE }\end{array}$} \\
\hline & AÑO 1 & ANOO 2 & ANO 3 & AÑO 4 & AÑO 5 \\
\hline & $80 \%$ & $81.5 \%$ & $83.0 \%$ & $84.5 \%$ & $86.0 \%$ \\
\hline UNIDADES MENSUALES & 80,395 & 81,903 & 83,410 & 84,918 & 86,425 \\
\hline UNIDADESANUALES & 964,744 & 982,833 & $1,000,922$ & $1,019,011$ & $1,037,100$ \\
\hline PRODUCCION DI ARI A POR AÑO & 3,682 & 3,751 & 3,820 & 3,889 & 3,958 \\
\hline GRAM OSPOR PAQUETESANUALES & $2,411,860$ & $2,457,082$ & $2,502,305$ & $2,547,527$ & $2,592,750$ \\
\hline KILOS REQUERIDOS DE MATERIA PRIMA & 2,412 & 2,457 & 2,502 & 2,548 & 2,593 \\
\hline
\end{tabular}

Fuente: Elaboración propia

\subsection{Proyección de ventas}

Elaborado en base al proyectado de la demanda considerando solo el $80 \%$ del potencial consumo de nuestro producto de acuerdo al público objetivo y con un crecimiento de $1.5 \%$ cada año, tenemos:

Tabla $N^{\circ} 12$ : Proyección de las Ventas

\begin{tabular}{|c|c|c|c|c|c|c|}
\hline \multicolumn{7}{|c|}{ ESCENARIO BASE } \\
\hline \multirow{5}{*}{ VENTAS } & & AÑo 1 & AÑo 2 & AÑo 3 & AÑO 4 & AÑo 5 \\
\hline & S/. & & & & & \\
\hline & CREDITO & $1,414,851$ & $1,441,379$ & $1,467,908$ & $1,494,436$ & $1,520,964$ \\
\hline & DCTO CANAL & $(28,297)$ & $(28,828)$ & $(29,358)$ & $(29,889)$ & $(30,419)$ \\
\hline & & $1,386,554$ & $1,412,552$ & $1,438,549$ & $1,464,547$ & $1,490,545$ \\
\hline
\end{tabular}

Fuente: Elaboración propia 


\section{CAPÍTULO V: PLAN DE OPERACIONES}

El plan de operaciones de nuestra empresa contempla la gestión de manera óptima de todo el ciclo productivo de manera que nuestro costo operativo refleje en cifras justamente el elemento diferenciador de nuestro producto. Se deberá de poner énfasis en el control de calidad de nuestro té filtrante así como también en el desarrollo de nuevas formulaciones de acuerdo a las exigencias de nuestro consumidor.

Los objetivos planteados para un área tan sensible como la operativa son:

Tabla $N^{\circ}$ 13: Objetivos de Operaciones

\begin{tabular}{|l|l|}
\hline \multicolumn{1}{|c|}{ Objetivo } & \multicolumn{1}{c|}{ Indicador } \\
\hline $\begin{array}{l}\text { Lograr un margen operativo de } 5 \% \% \text { en la empresa } \\
\text { minimizar los costos unitarios por el servicio de }\end{array}$ & $\begin{array}{l}\text { Utilidad bruta / Ventas } \\
\text { Costo Maquila / Costo de Venta }\end{array}$ \\
\hline $\begin{array}{l}\text { Lograr la satisfacción de 95\% de clientes } \\
\text { encuestados }\end{array}$ & Clientes satisfechos / Clientes Atendidos \\
\hline $\begin{array}{l}\text { Incrementar la cobertura de entrega de productos } \\
\text { para las ventas online }\end{array}$ & Pedido Atendidos / Total de pedidos \\
\hline $\begin{array}{l}\text { Realizar un 100\% de entregas a tiempo } \\
\text { Lograr altos estándares de calidad }\end{array}$ & \begin{tabular}{l} 
Entrega a tiempo / Total de Entregas \\
\hline Minimizar los desechos prácticas de producción y manipulación \\
de productos naturales
\end{tabular} \\
\hline Cantidad de Desechos / Total de la producción \\
\hline
\end{tabular}

\subsection{Políticas Operacionales}

\subsubsection{Calidad:}

Los consumidores y clientes son cada vez más exigentes y nuestro producto tiene por meta calar en la mente del consumidor bajo la premisa de ser un producto de "calidad" y que esto no signifique que su costo sea elevado, sino más bien que se adapta en características y precio a lo que busca el cliente.

Para garantizar la gestión de calidad en procesos y producto nos regiremos bajo la Norma ISO 9000 que refuerzan situaciones contractuales con los proveedores.

\subsubsection{Procesos:}

Contamos con procesos pensados en optimizar tiempo y horas de trabajo para lograr tener una rotación rápida del inventario y lograr ventas recurrentes. Ver Anexo 2. 
Gráfico N`5: Flujo de Procesos

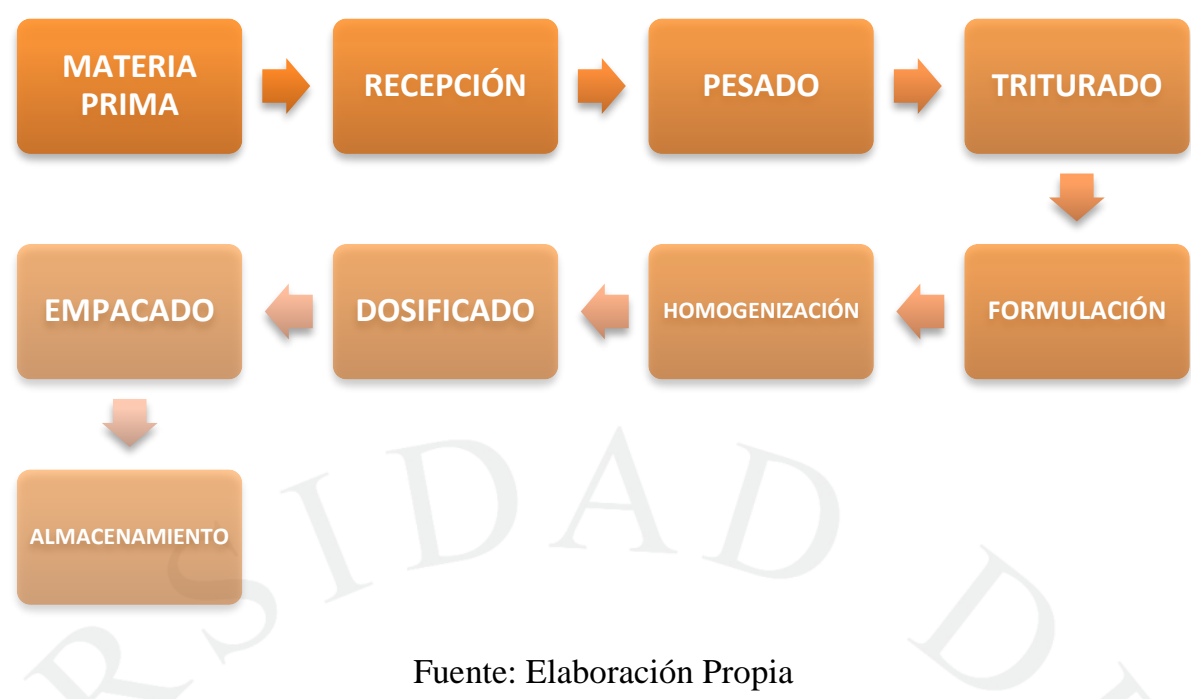

\subsubsection{Planificación:}

Realizamos la planificación a corto plazo para el análisis de la producción, distribución y comercialización del producto a ofrecer, considerado los siguientes:

- Capacidad para producir de acuerdo a demanda generada.

- Capacidad para conservación del producto envasado.

- Rentabilidad al final del ejercicio esperado versus el obtenido.

- Desarrollo de actividades laborales para tener el personal mínimo óptimo para cubrir todas las actividades.

\subsubsection{Inventarios:}

Al representar los inventarios el mayor costo de la inversión se establecen las siguientes políticas:

- Inventario Inicial y Final: Información de materia prima adquirida para envío a tercero y realice la transformación en producto final. (Tercero realiza el proceso de deshidratación). Esta información es para el área de producción.

- PEPS: Significa "Primero en entrar, Primero en salir", con esto se quiere establecer que lo primero comprado sea lo primero que se venda y en almacén quede las compras recientes. Esta información es para el área de compras.

- Implementar las 5S: Seiri (clasificar), Seiton (organizar), Seiso (limpiar), Seiketsu (normalizar), Shitsuke (preservar). 


\subsection{Equipos, actividades y procesos}

\subsubsection{Diseño y capacidad de instalaciones}

La empresa "AL SOL S.A.C.” está debidamente organizada para atender su volumen productivo. El diseño de planta cuenta con un área de 93.54 metros cuadrados, que comprende: área de proceso y recepción, almacén y/o depósito, vestidores, S.S. H.H., área control de calidad, cochera y oficina de administración. Ver Anexo 3.

Gráfico $N^{\circ}$ 6: Diseño de las áreas de la empresa

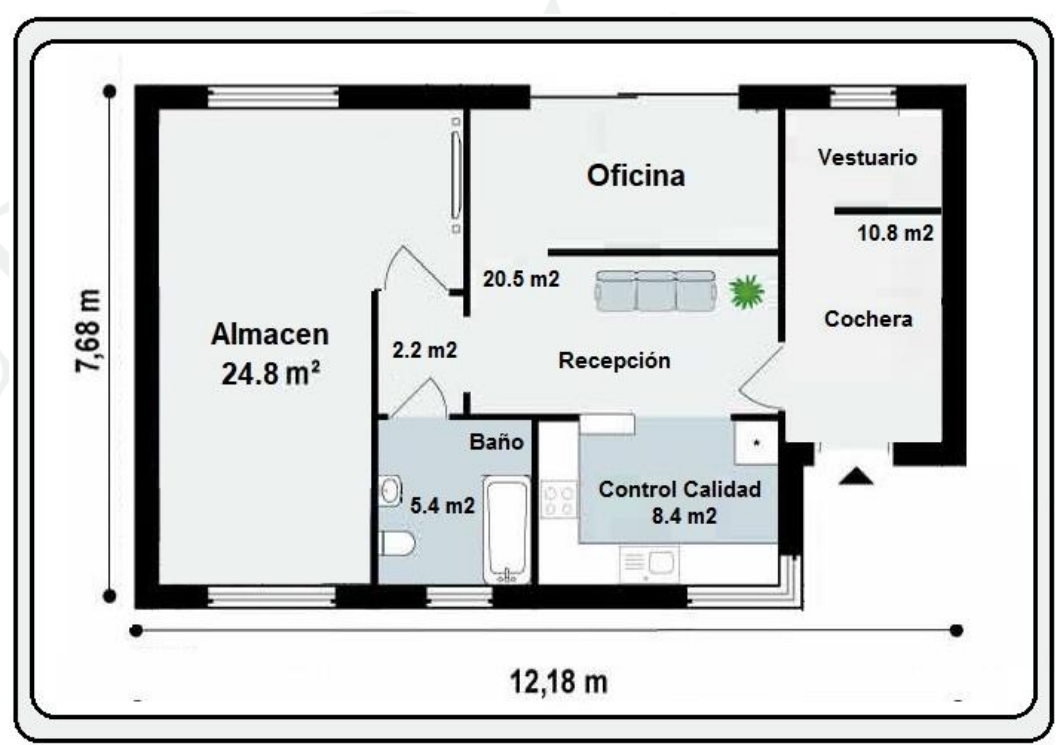

Fuente: Elaboración Propia

\subsubsection{Equipos de trabajo $y$ apoyo}

Gráfico $N^{\circ}$ 7: Equipos de trabajo y apoyo

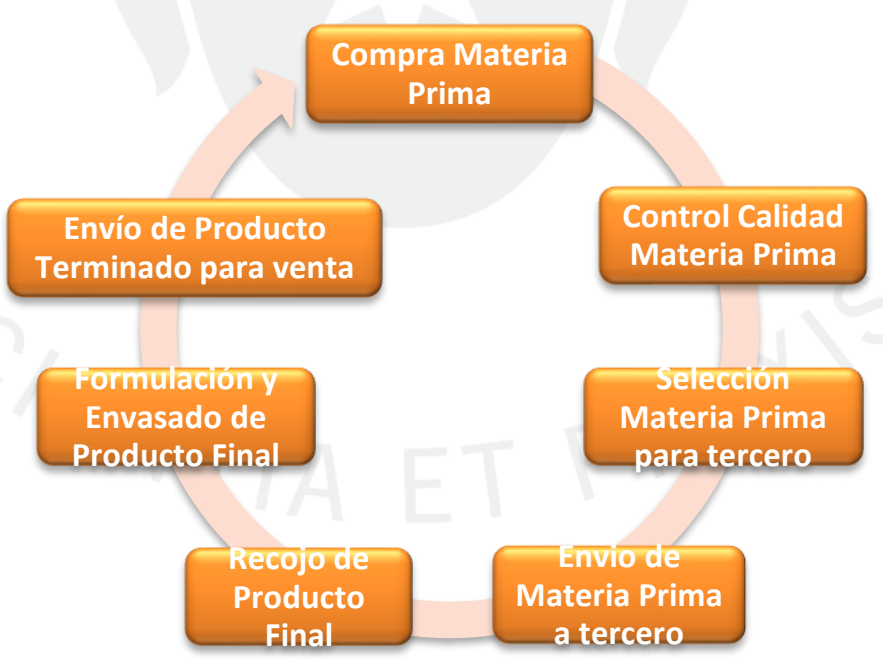

Fuente: Elaboración propia

La responsabilidad es por área, la misma indicada en el siguiente cuadro en base a la imagen arriba descrita. 


\section{Gráfico Nº: Áreas de trabajo}

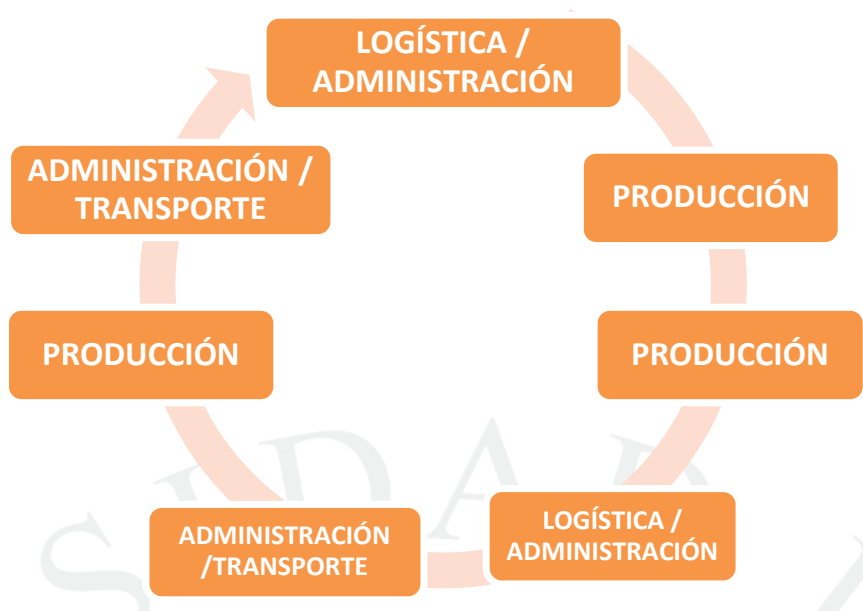

Fuente: Elaboración propia

Este ciclo es continuo, se inicia con la compra de la fruta (materia prima) y se procede a revisar lo comprado para separarlo por pesos y enviarlo a la empresa que hace el proceso de deshidratación de la fruta y entrega del producto final para envase en nuestra planta y distribución para venta. Así mismo tenemos identificados la maquinaria con la que realizaremos el trabajo:

Tabla $N^{\circ} 14$ Requerimiento de Maquinaria

\begin{tabular}{|c|c|}
\hline Equipos & Descripción \\
\hline $\begin{array}{l}\text { Máquina empacadora para } \\
\text { filtrante }\end{array}$ & $\begin{array}{l}\text { Capacidad de envasado } 90 \text { bolsas } / \mathrm{min} \\
\text { Dosis máx. de materia prima } 8 \mathrm{~cm} 2 \\
\text { Dimensiones de la bolsa } 62.5 \mathrm{~mm} \text { x } 50 \mathrm{~mm} \\
\text { Dimensiones del sobre } 75 \mathrm{~mm} \text { x } 65 \mathrm{~mm} \\
\text { Dimensiones de la etiqueta } 28 \mathrm{~mm} \text { x } 24 \mathrm{~mm} \\
\text { Longitud del hilo } 210 \mathrm{~mm} \\
\text { Fuente de energía AC } 380 \mathrm{~V} \\
\text { Potencia total } 1.65 \mathrm{~kW} \\
\text { Peso } 570 \mathrm{~kg} \text {. } \\
\text { Peso bruto } 730 \mathrm{~kg} \text {. } \\
\text { Dimensiones generales: } 1,700 \mathrm{~mm} \times 900 \mathrm{~mm} \times \\
2,000 \mathrm{~mm}\end{array}$ \\
\hline Balanza de plataforma & Capacidad $500 \mathrm{~kg}$. \\
\hline Balanza digital & Capacidad 3000 gr. \\
\hline Mesas de acero inoxidable & acero inoxidable AISI $304,1 \mathrm{mx} 2 \mathrm{~m}$ \\
\hline Mezclador tipo V & $\begin{array}{l}\text { Acero inoxidable AISI 304, permite obtener } \\
\text { mezcla homogénea. }\end{array}$ \\
\hline $\begin{array}{l}\text { Molino de martillo } \\
\text { (Triturado) }\end{array}$ & $100 \mathrm{~kg}$. Por hora \\
\hline
\end{tabular}

Fuente: Elaboración propia

\subsubsection{Gestión de proveedores, compras y stock}

El principal proveedor será el mercado de frutas, donde se ira tres veces a la semana para la compra de la materia prima y con pago en efectivo. 
Los insumos por comprar son:

Tabla $N^{\circ} 15$ : Requerimiento de Compras

\begin{tabular}{|l|l|}
\hline INSUMOS & Precio $\mathrm{kg} \mathrm{S} /$ \\
\hline Fruta (promedio) & 2.13 \\
\hline Estevia & 8.00 \\
\hline Té negro & 8.00 \\
\hline Té verde & 8.00 \\
\hline Saborizante polvo & 15.00 \\
\hline Total & $\mathbf{4 1 . 1 3}$ \\
\hline
\end{tabular}

Fuente: Elaboración propia

Para complementos del producto final, artículos de limpieza y de oficina realizaremos la compra en Makro y las compras serán mensuales en efectivo.

Alquilaremos un camión tres veces a la semana para realizar las compras en el mercado mayorista, entregar la fruta para el proceso de deshidratación y el reparto del producto a nuestros clientes de acuerdo con el plan de ruta establecido.

\subsubsection{Tercerización $o$ integración de procesos}

Realizaremos tercerización para el proceso de deshidratación de la materia prima - fruta. El costo del servicio por deshidratar el kilo de fruta es de S/.12.00 soles.

\subsubsection{Implementación de las actividades de la cadena de valor}

Dentro de nuestras actividades se encuentran etapas de desarrollo identificadas para un completo análisis de nuestra cadena de valor, las mismas que se detalla en el siguiente cuadro

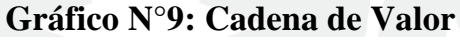

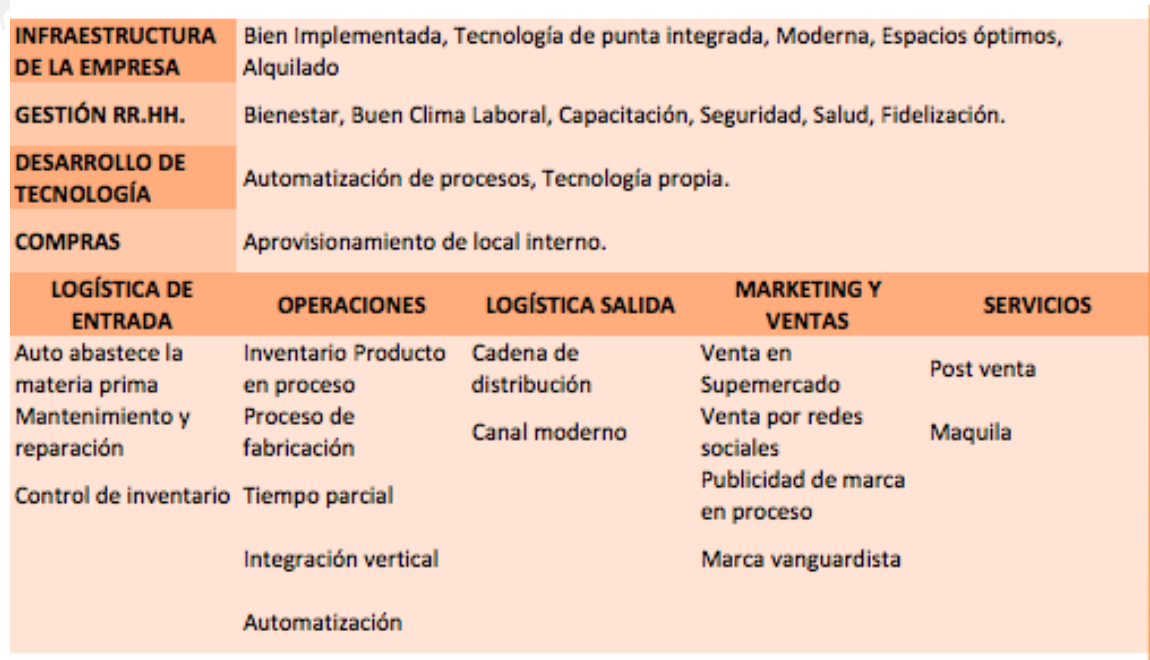

Fuente: Elaboración propia

\subsubsection{Proceso de elaboración de bienes y/o prestación de servicio.}

Nuestro principal proceso que consiste en la deshidratación de la fruta ha sido tercerizado, este proceso de maquila dura diez horas aproximadamente. 
El producto es entregado listo para realizar la mezcla con los ingredientes complementarios a la fruta para que perdure el aroma y el sabor artesanal al que nos enfocamos.

El proceso de envasado consiste en mezclar la fruta deshidratada con los demás ingredientes con medidas ya especificadas y separar los 2.5 gr. para cada presentación a vender.

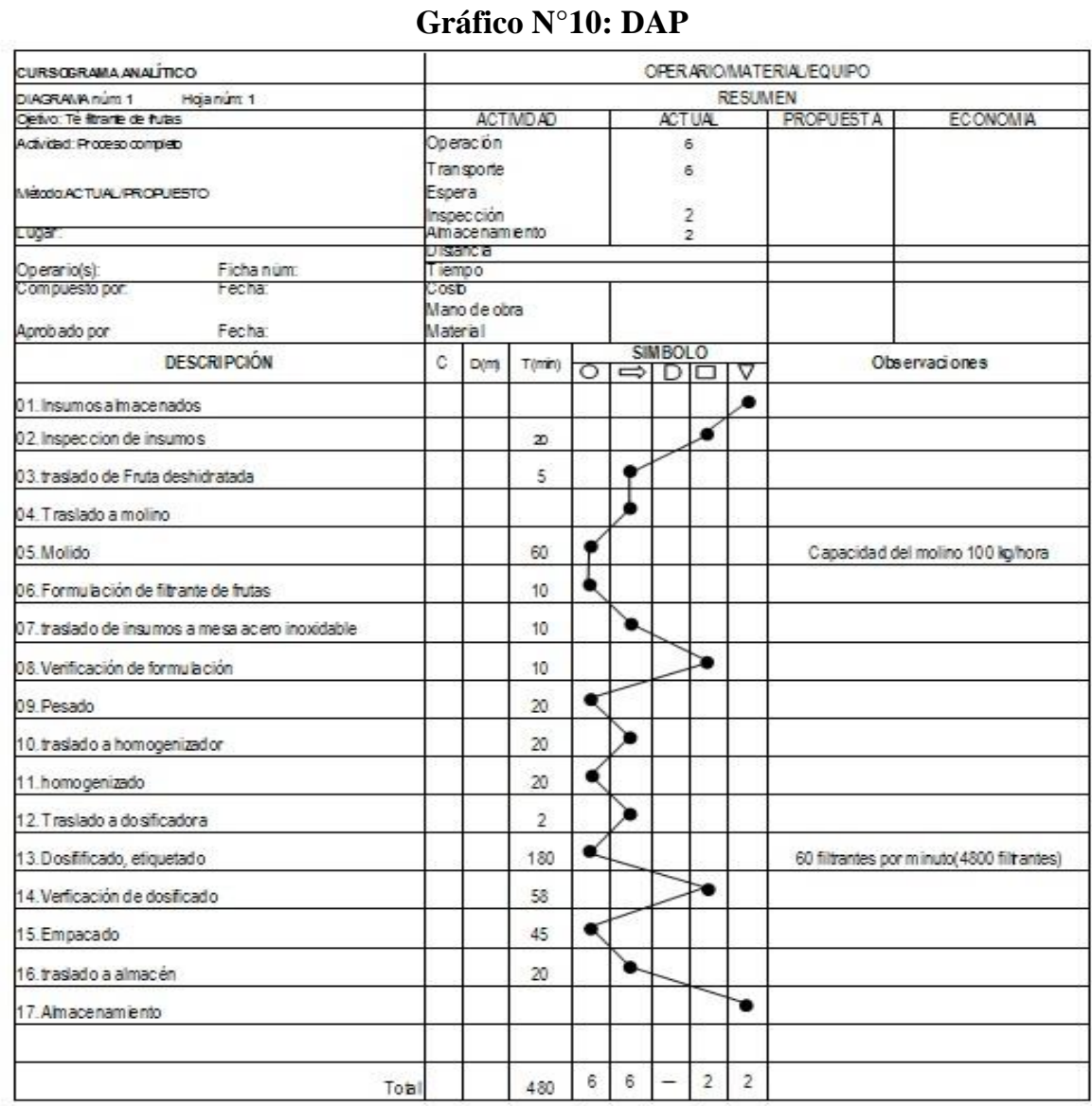

Fuente: Elaboración propia

Presentación del Filtrante de "K'isa Té":

- Presentación: en bolsas de papel filtrantes de $2.5 \mathrm{~g}$

- Envase primario: será de papel filtro

- Envase secundario: etiqueta

- Envase terciario: cajas de 25 unidades

- Almacenamiento: lugares fresco, seco y ventilado. 


\subsubsection{Políticas de transformación de la actividad}

Hemos diseñado el siguiente cuadro para correcto análisis y entendimiento de nuestro proceso de elaboración y venta de producto.

Gráfico $N^{\circ}$ 11: Proceso de Venta

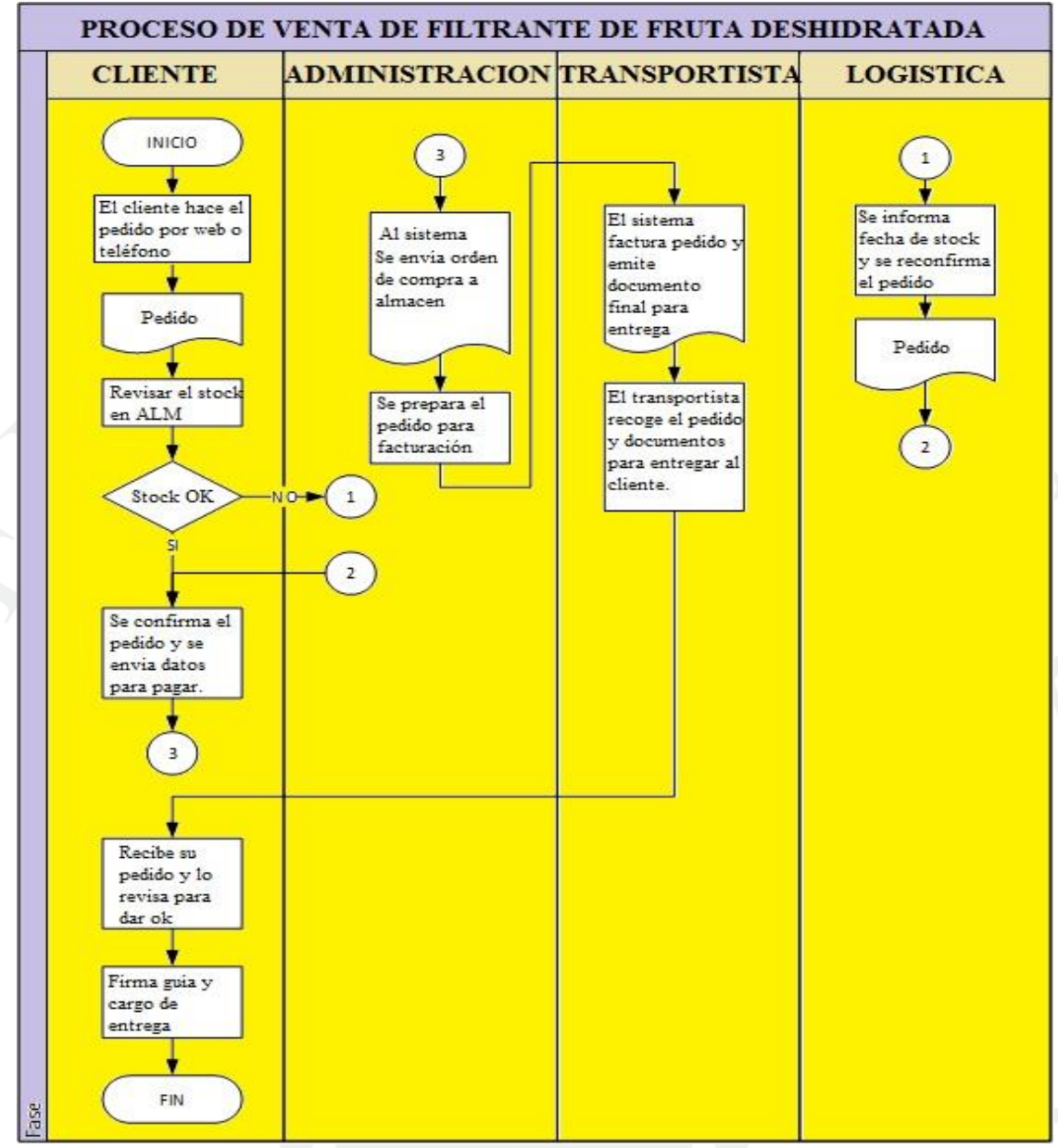

Fuente: Elaboración propia

\subsubsection{Flujograma de la actividad y Diagrama de decisiones PERT}

Usamos el cuadro de tiempo el cual consta de tres procesos: compra de materia prima, tercerización para tratamiento de materia prima y el producto final listo para distribución y venta.

Gráfico $\mathrm{N}^{\circ}$ 12: Flujograma de la actividad

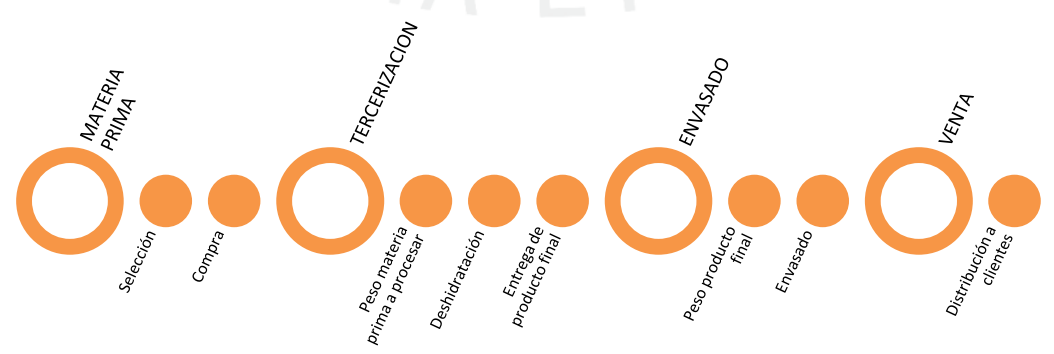

Fuente: Elaboración propia 


\section{EI Diagrama de decisiones de PERT.}

Para nuestro proyecto teníamos que decidir si realizaríamos todos los procesos de producción o lo tercerizamos, por ello usamos el diagrama de PERT para evaluar tiempos y costos y lograr un producto final con las mismas características.

\section{Gráfico Nº 13: Diagrama de PERT}

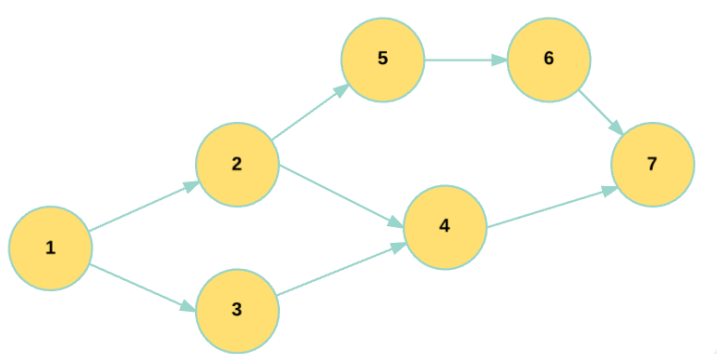

Fuente: Elaboración propia

\section{Leyenda del Diagrama de PERT:}

1. Compra de materia prima.

2. Clasificación y partición de materia prima para proceso de deshidratación.

3. Entrega a proveedor (tercero) para proceso deshidratación

4. Transformación de la materia prima por el proveedor (tercero)

5. Deshidratación de la fruta por el proveedor (tercero).

6. Formulación y envasado del producto final.

7. Distribución y venta del producto final.

\begin{tabular}{|c|c|c|}
\hline Gráfico $\mathbf{N}^{\circ}$ 14: Cuadro de tiempo \\
\hline Actividad & Duracion (dias) & $\begin{array}{c}\text { Actividad Predecesor } \\
\text { Inmediato }\end{array}$ \\
\hline 1 & 1 & - \\
\hline 2 & 3 & 1 \\
\hline 3 & 1 & 1 \\
\hline 4 & 7 & 2,3 \\
\hline 5 & 10 & 2 \\
\hline 6 & 3 & 5 \\
\hline 7 & 1 & 4,6 \\
\hline \multicolumn{3}{|c|}{ Fuente: Elaboración Propia } \\
\end{tabular}

Ante lo antes mencionado el camino $1-3-4-7$ optimiza el tiempo de producción sin encarecer el producto final. 


\subsubsection{Balance Scorecard: control de gestión por indicadores.}

El objetivo de "Al Sol S.A.C." es la obtención de productos sanos no contaminantes y económicos.

Gráfico $\mathbf{N}^{\circ}$ 15: Balance Scorecard
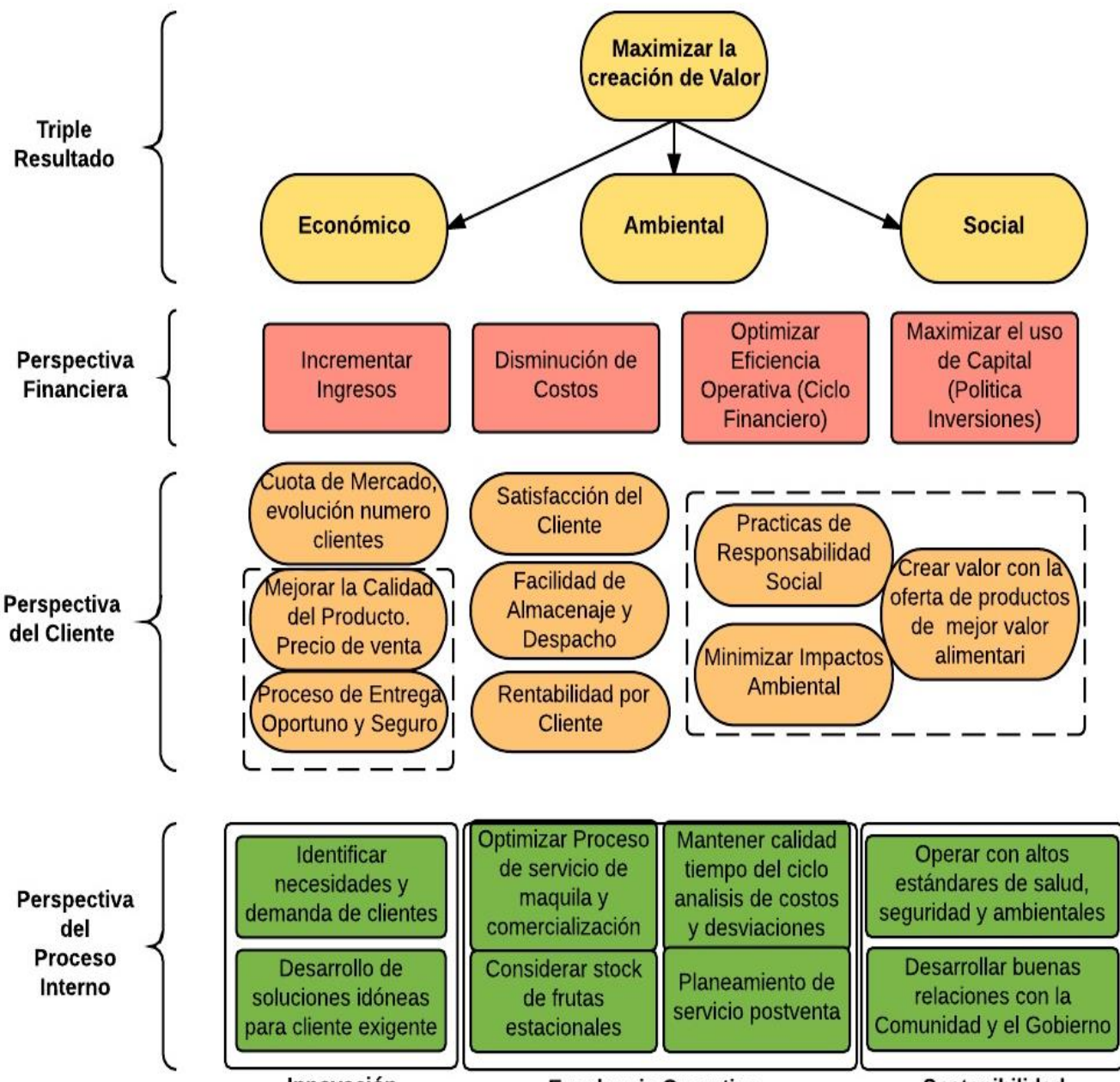

Innovación Excelencia Operativa

Sostenibilidad

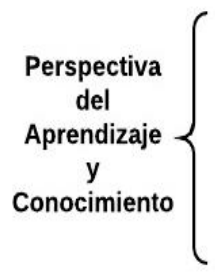

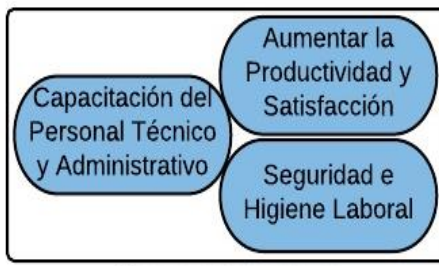

Recursos Humanos

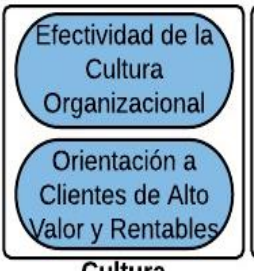

Cultura

Corporativa

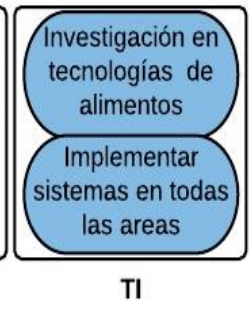

Fuente Elaboración propia 


\section{CAPÍTULO VI: ESTRUCTURA ORGANIZACIONAL Y RECURSOS HUMANOS}

El plan de Organización y de Recursos Humanos analiza, selecciona, evalúa y controla el talento humanos de la empresa. Estableciendo un organigrama en donde se definen los puestos, responsabilidades y perfil de cada posición. Es importante definir las políticas de reclutamiento, selección, contratación y formación del colaborador.

Los objetivos planteados para la gestión del recurso humano son:

Tabla $N^{\circ}$ 16: Objetivos de RRHH

\begin{tabular}{|l|l|}
\hline \multicolumn{1}{|c|}{ Objetivo } & \multicolumn{1}{c|}{ Indicador } \\
\hline Generar una satisfacción del clima laboral de "80\%". & $\begin{array}{l}\text { "80\%"de satisfacción del clima } \\
\text { laboral. }\end{array}$ \\
\hline $\begin{array}{l}\text { Lograr un rendimiento promedio de } \\
\text { colaborador. }\end{array}$ & Calificación de la evaluación. \\
\hline $\begin{array}{l}\text { Potenciar habilidades comerciales y habilidades blandas. } \\
\quad \text { Elaboración propia }\end{array}$ & $\mathrm{N}^{\mathbf{o}}$ de capacitaciones recibidas. \\
\hline
\end{tabular}

\subsection{Objetivos Organizacionales}

\subsubsection{Naturaleza de la Organización}

"Al Sol" SAC es una empresa que nace con el fin de obtener un rendimiento en la venta de un té filtrante a base fruta deshidratada, producto de alta calidad para nuestro público objetivo asumiendo el compromiso de la seguridad alimentaria saludable (nueva ley regulatoria MAP, vigencia Mayo 2018)

\subsubsection{Organigrama}

Dentro de nuestra empresa se han designado las funciones bajo los siguientes cargos: Administrador-Gerente, Ingeniero de planta, Ingeniero de Control de Calidad y cuatro operarios. Ver Anexo 4.

6.1.3. Diseño estructural por proyectos: campaña de difusión, búsqueda de patrocinadores y campañas de concientización.

Desde la gestión de actividades de se promueve los siguientes puntos:

- Alianzas Estratégicas: Presencia en eventos deportivos carrera RPP y en la feria fitness Boom. En ambos eventos encontramos a nuestro público objetivo. También contactar con reconocidos expertos en la salud quienes resaltaran los beneficios de nuestro producto y lo promocionaran por sus redes sociales.

- Marketing Boca a Boca, en reuniones de trabajo y sociales, contando experiencias propias y ofreciendo muestras con data para contacto y posterior compra.

- Fan Page y Redes Sociales en el lanzamiento del producto y contacto directo con el cliente final. 


\subsection{Diseño de Puestos y Responsabilidades}

El propósito del Manual de Organización y Funciones es constituirse en un instrumento de gestión que permita regular las funciones y responsabilidades que corresponda desempeñar a los diferentes órganos gerenciales, administrativos, operativos y de apoyo. Ver Anexo 5.

Dentro de las funciones básicas para todas las áreas tenemos: planificar, organizar, coordinar sus labores en la empresa para el correcto funcionamiento de todos los procesos establecidos.

Dentro de las funciones específicas por cargos tenemos: Administrador-Gerente (puesto ocupado por una de las socias), Ingeniero de Planta, Ingeniero de Control de Calidad y cuatro operarios.

\subsection{Políticas Organizacionales}

Con la misma importancia que tratamos a nuestro cliente externo también nos preocupamos por nuestro cliente interno para que el ambiente donde desarrolla sus labores sea agradable y en pro de su mejora personal.

\subsubsection{Política de incentivos:}

Ofrecemos beneficios en compensación a su labor como, por ejemplo:

- EPS: Un sistema privado de salud, donde el colaborador asume un porcentaje del costo total.

- Almuerzo en el día de su profesión

- Día libre remunerado

- Horario de Verano, puede salir el viernes a la 1:00 p.m.

Estas acciones fidelizan al colaborador y lo motivan a desarrollar sus actividades de manera tranquila y motivadora.

\subsubsection{Política de responsabilidad social}

Implementaremos las siguientes medidas dentro de nuestra organización:

- Mensajes en los empaques: Ayudamos a difundir esta cultura e informar los beneficios a largo plazo que conseguiremos.

- Movilidad al centro de labores en bicicleta: Esto incentiva a mantener un estado físico óptimo y destreza de habilidades por la sincronización y concentración para desplazarse. 
- La hora del planeta: Dentro de nuestras actividades, se promueve el ahorro de energía, desenchufar los equipos electrónico, uso de los mismos en hora no punta entre otros.

- Correcto uso del agua: Evitar el desperdicio de agua.

- Eliminación de Desechos: En alianza con la municipalidad fomentaremos la difusión de los beneficios de discriminar mejor los desechos estableciendo puntos de reciclaje con tachos de basura de plásticos, papel, orgánicos, los mismos que la municipalidad podrá identificar al recoger la basura.

\subsubsection{Política de reconocimiento}

El área de recursos humanos evalúa no solo los perfiles que requiere la empresa, sino también un plan de fidelización para que el colaborador perdure en le organización:

- EDP: Evaluación de desempeño personal basada en objetivos trazados al inicio del año, lo cual implicaría un incremento en su salario de ser satisfactorio su rendimiento.

\subsubsection{Política de compra:}

- Producto: La fruta se compra en el día y se entrega para maquila

- Proveedores: Por inicio de actividades la compra es personal en el Mercado de Frutas, se tienen a garantía de abastecimiento y calidad del producto.

- Sistema de Información: Iniciamos operaciones con base de datos en Excel para el correcto control de la mercadería adquirida y el stock de los mismos.

- Logística: Verificar el cumplimiento de las órdenes de compra. Evitar duplicidad y desperdicios de los materiales comprados. Revisar base de datos.

\subsubsection{Política de venta:}

Dentro de nuestras políticas de venta es importante mantener un compromiso con el cliente para dar la seguridad de la compra:

Para ello hemos establecido los siguientes requisitos:

- Orden de compra con datos principales del cliente y del producto solicitado. Datos personales, Datos a quien se emite el comprobante, numero de contacto.

- Se pide la firma de la orden de compra como conformidad de ambas partes.

- La entrega del producto es en un plazo de dos días, luego del pago del 50\% de la mercadería en efectivo o vía transferencia bancaria.

- La entrega del producto es en el domicilio que informe, solo en Lima Moderna y por un máximo en valor de S/.100.00 soles. 
Respetando ambas partes lo antes mencionado, se genera una relación con el cliente de confianza y seguridad.

\subsubsection{Política de Ética:}

Tener comportamiento ético es fundamental y subyace a toda la organización. “A1 Sol" operará de manera honesta, equitativa e integra.

\subsection{Gestión de talento}

\subsubsection{Selección y contratación:}

Selección de personal: trabajaremos con los siguientes referentes:

- Bumeran: Basados en experiencias de reclutamiento se ha elegido esta empresa que es líder en el mercado local para reclutamiento de personal.

- I Partner: Especialistas en centrales de riesgos e información sensible del postulante como policial y legal.

Contratación de personal: es uno de los costos más importantes de la empresa, en base al perfil del puesto y funciones a realizar se fideliza desde el primer momento.

- Brindar seguridad con el contrato de trabajo por un periodo mínimo de seis meses y periodo de evaluación de tres meses para evaluar su desempeño y compromiso con la empresa.

- Cumplir con los beneficios sociales como pago de remuneración en fecha, jornada de ocho horas de acuerdo a ley, días de descanso, vacaciones, licencias y capacitaciones.

- Información de políticas de despido o separación de la empresa.

\subsubsection{Remuneración y desempeño: Escala salarial}

Nuestra escala salarial se ha diseñado bajo el rango que se maneja en el mercado y por las cualidades y calificaciones del personal que cumple con el perfil que requerimos.

Tabla N¹7: Planilla Mensual

\begin{tabular}{|c|c|c|}
\hline NRO & AREA & SUELDO BÁSICO \\
\hline 1 & ADMINISTRADOR-GERENTE & 3000.00 \\
\hline 2 & ING. PLANTA & 2500.00 \\
\hline 3 & ING. CONTROL CALIDAD & 2500.00 \\
\hline 4 & OPERARIO x 4 & 3400.00 \\
\hline & TOTAL & $\mathbf{1 1 4 0 0 . 0 0}$ \\
\hline
\end{tabular}

Fuente: Elaboración propia

\subsubsection{Empoderamiento y reconocimiento:}

Se establecerá una reunión mensual para conversar de los alcances que ha tenido la empresa y revisar la meta de venta propuesta para superar el punto de equilibrio, 
informando lo importante de la labor de cada uno de los colaboradores para lograr esta meta.

Generar una competencia sana para que logren ser el colaborador del mes, hecho que se promocionará no solo dentro de la empresa sino también en las redes sociales para que lo pueda compartir con sus familiares y amigos.

\subsubsection{Capacitación, motivación y desarrollo:}

El área de producción es la más sensible de la empresa, por lo que se programa dos capacitaciones anuales en los temas de BPM (Buenas prácticas de manufactura).

\subsection{Estructura de gastos de Recursos Humanos}

La estructura salarial que se ha establecido en la organización, es la siguiente:

Tabla $N^{\circ}$ 18: Presupuesto de Recursos Humanos

\begin{tabular}{|c|c|c|c|c|c|c|c|}
\hline \multirow[b]{2}{*}{$\begin{array}{l}O \\
\text { z }\end{array}$} & \multirow[t]{2}{*}{ AREA } & \multirow{2}{*}{$\begin{array}{l}\text { SUELDO } \\
\text { BASICO }\end{array}$} & \multicolumn{2}{|c|}{ DESCUENTOS } & \multirow{2}{*}{$\begin{array}{c}\text { OTRO } \\
\text { DSCT } \\
\text { O }\end{array}$} & \multirow{2}{*}{$\begin{array}{l}\text { RENT } \\
\text { A 5TA }\end{array}$} & \multirow{2}{*}{$\begin{array}{l}\text { REM. } \\
\text { NETA }\end{array}$} \\
\hline & & & APF/ONP & MONTO & & & \\
\hline 1 & ADM. GERENTE & 3000.00 & HT MX & 387.30 & & 94.60 & 2518.10 \\
\hline 2 & ING. PLANTA & 2500.00 & HT MX & 322.75 & & & 2177.25 \\
\hline 3 & ING. CONTROL Q & 2500.00 & HT MX & 322.75 & & & 2177.25 \\
\hline 4 & OPERARIO & 850.00 & INT MX & 99.79 & & & 750.21 \\
\hline 5 & OPERARIO & 850.00 & INT MX & 99.79 & & & 750.21 \\
\hline 6 & OPERARIO & 850.00 & INT MX & 99.79 & & & 750.21 \\
\hline 7 & OPERARIO & 850.00 & INT MX & 99.79 & & & 750.21 \\
\hline & TOTAL & 11400.00 & & 1431.96 & 0.00 & 0.00 & 9968.04 \\
\hline
\end{tabular}

Fuente: Elaboración propia 


\section{CAPÍTULO VII: PLAN ECONÓMICO - FINANCIERO}

Se plantean los siguientes objetivos para el plan económico - financiero:

Tabla $N^{\circ}$ 19: Objetivos Financieros

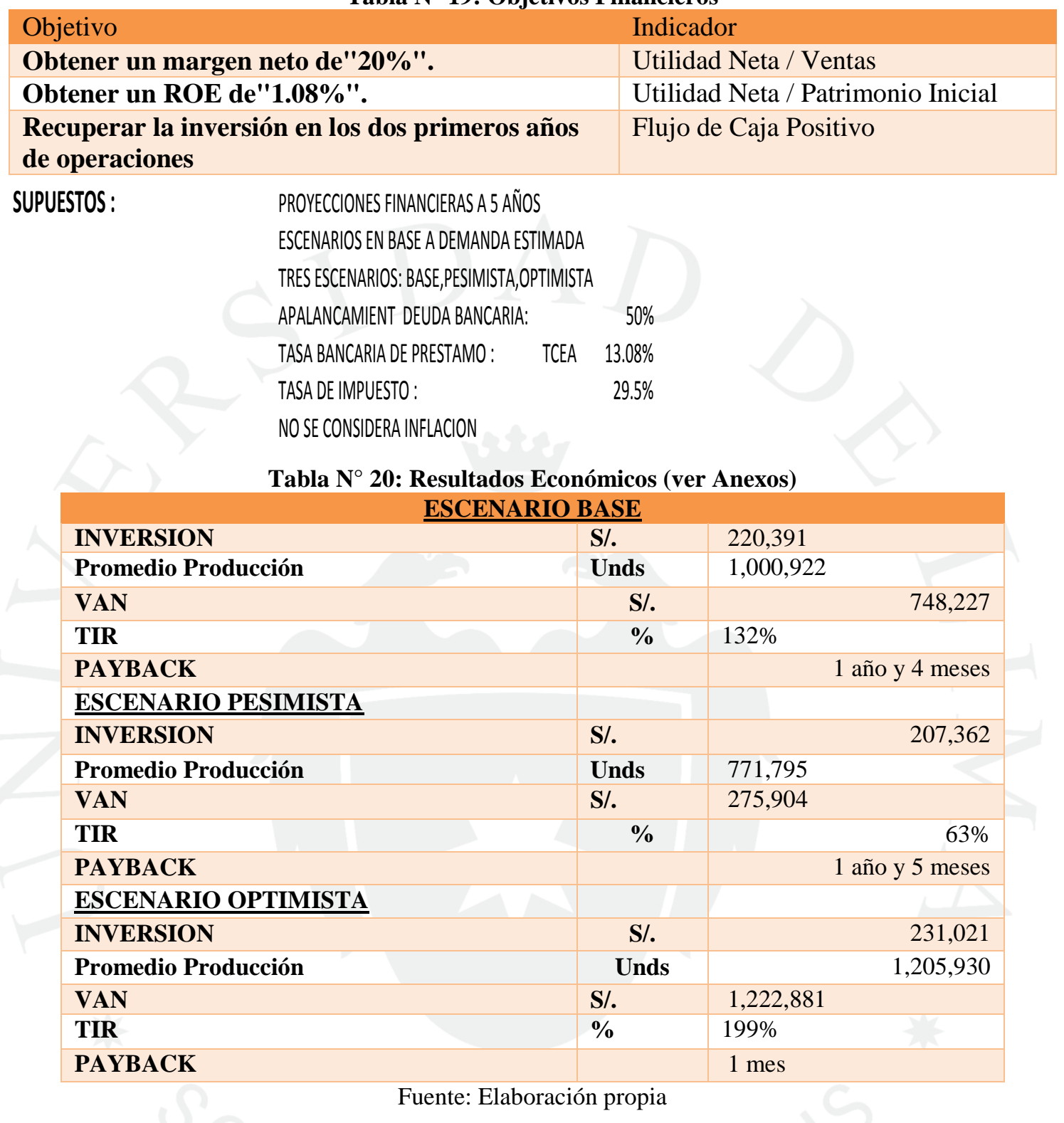

\subsection{Plan de Contingencia}

Tabla $\mathrm{N}^{\circ}$ 21: Plan de Contingencia

\begin{tabular}{|c|c|}
\hline Circunstancias & Táctica planteada \\
\hline $\begin{array}{l}\text { Falta de fruta de formulaciones } \\
\text { más solicitadas por } \\
\text { estacionalidad }\end{array}$ & $\begin{array}{l}\text { Se debe contar con una lista de proveedores que almacenen fruta } \\
\text { en Lima con las condiciones adecuadas de salubridad. Se tiene } \\
\text { contactos con La Gran Fruta. }\end{array}$ \\
\hline $\begin{array}{l}\text { Aumento de demanda en } \\
\text { Supermercado }\end{array}$ & $\begin{array}{l}\text { Establecer en el contrato con Vitallanos SAC esta posibilidad } \\
\text { asegurando una mayor cantidad de producción en su planta para } \\
\text { poder responder de manera rápida. }\end{array}$ \\
\hline $\begin{array}{l}\text { Ingreso de nuevos tés } \\
\text { embotellados }\end{array}$ & $\begin{array}{l}\text { Incrementar el presupuesto de marketing promocionando en } \\
\text { puntos de venta de supermercados la practicidad del uso de } \\
\text { nuestro filtrante y la contribución con el planeta al disminuir los } \\
\text { desechos de PETS con nuestro consumo. }\end{array}$ \\
\hline
\end{tabular}

Fuente Elaboración propia 


\section{CONCLUSIONES Y RECOMENDACIONES}

- Existe una tendencia mundial creciente hacia mantener un estilo vida saludable en donde la alimentación juega el rol principal. La preferencia es hacia alimentos bajos en grasa y bebidas libres de azúcar lo cual se expresa en el mayor consumo de productos saludables y por ende un mayor gasto en esta categoría. Si consideramos que más del 20\% de las calorías que consumimos provienen de las bebidas y que después del agua el té embotellado es percibido como la alternativa más saludable. Entonces presentamos a K'isa Té que nace con la intención de ser la primera línea de té filtrantes hechos a base de fruta deshidratada que busca posicionarse como líder en su categoría por la calidad del producto que ofrece y ante la ausencia de una marca líder. Un punto fundamental para K'isa Té es la innovación constante de sus formulaciones por la demanda creciente de bebidas saludables, lo que la hace una categoría altamente competitiva; por este motivo se evaluará periódicamente a los consumidores, buscando nuevas inquietudes en formulaciones y necesidades a satisfacer. Esto será posible gracias al destino del $1 \%$ de sus ventas al rubro de investigación y desarrollo, participando de Ferias Internacionales y a la alianza estratégica con el proveedor de la maquila Vitallanos SAC en su compromiso por mantener la calidad de la fruta procesada.

- Finalmente el proyecto demuestra ser rentable por su bajo costo de producción y el alto valor percibido por el consumidor. Así mismo es sostenible en el tiempo ya que es una idea de negocio escalable hacia otros giros de negocio como los snacks saludables a base de frutas deshidratadas.

- Lo recomendable para un producto como K'isa Té es ingresar en el corto plazo al mercado. Si bien en Lima el consumo de filtrantes obtiene un porcentaje de aceptación del 57\% aún queda un público por atender. Así se debe evaluar el ingreso a provincias donde esta categoría aún no es de gran tamaño. También se tendría que evaluar la puesta en marcha de una planta de producción propia al ampliar las líneas de producto. Se obtendrían economías de escala, por ende un menor costo de maquila que permitirían atender más pedidos.

- Finalmente, K'isa Té es un proyecto que surge en respuesta a una nueva tendencia. Propone calar en el consumidor entregando a nuestro cliente el binomio productomercado que busca salud con buen sabor. 


\section{REFERENCIAS}

- Lic. Nutrición - Julio Medina - In Motion

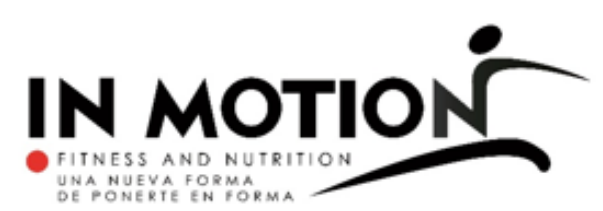

Me parece una extraordinaria propuesta la de las infusiones de frutas deshidratadas pues es una propuesta diferente y original para el mercado peruano mucho sabor, aroma y repletas de propiedades.

Los procesos que se usan para deshidratar las frutas, las cuales pierden un gran contenido de agua para ser conservadas, favorecen la conservación de muchas de sus propiedades nutricionales como su contenido de carbohidratos, el contenido de antioxidantes y otros minerales exacerban su sabor y aroma.

Otra de las ventajas de estas infusiones novedosas es su combinación con el té negro y el té verde de las cuales ya son muy conocidos su poder para regular la presión arterial, prevención de cardiopatías y ahora último su poder curativo en procesos inflamatorios y cancerígenos.

Y si a todo esto le agregamos el uso del Kion o jengibre con grandes poderes des inflamatorios usado mucho en tratamientos de problemas respiratorios pues tenemos un producto, bajo en calorías, rico en antioxidantes, relacionado con la prevención de varias patologías y además de buen sabor y aroma.

Lic. En Nutrición Julio Medina Maestría en Deporte y Salud 


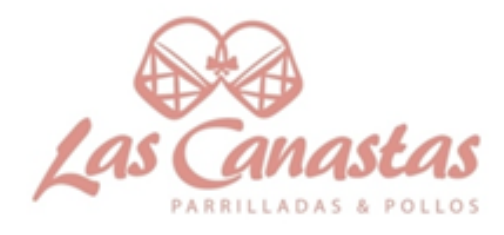

Lima, 05 de noviembre de 2017

Estimada Denisse:

Agradecemos la presentación de tu proyecto, el mismo que nos ha dejado gratamente entusiasmados y con deseos de iniciar lo más pronto posible.

Esto básicamente porque tenemos en desarrollo de la campaña de verano con el lanzamiento de bebidas frías como el Ice Tea, y de iniciar un vínculo de negocio la promoción publicitaria que desarrollaremos ira de la mano con este nuevo producto "K’isa Te", que por su proceso natural de deshidratación de la fruta calza con nosotros y con el propósito de consolidarnos como una empresa socialmente responsable en el rubro y da pie a un gran inicio de año. Estamos a tu disposición para una nueva reunión y definir el contrato de trabajo y los temas comerciales.

Atentamente.

RICARDO ZORRILLA

SUPERVISOR DE CALIDA

GRUPO LAS CANASTAS 


\section{BIBLIOGRAFIA}

APEIM. (Julio de 2015). Asociación Peruana de Empresas de Investigación de Mercados. Recuperado el 15 de Octubre de 2017, de Niveles Socioeconomicos 2015: http://www.apeim.com.pe/wp-content/themes/apeim/docs/nse/APEIMNSE-2015.pdf

Austria, X. (9 de Enero de 2015). 10 ideas de responsabilidad social para tu empresa. Recuperado el 2 de Diciembre de 2017, de Alto Nivel: https://www.altonivel.com.mx/48410-10-ideas-de-responsabilidad-social-paratu-empresa/

Barletta, F., Pereira, M., Robert, V., \& Yoguel, G. (2013). Argentina: dinámica reciente del sector de software y servicios informáticos. Revista de la CEPAL (110), 137155.

BM. (17 de Abril de 2017). Perú Panorama General. Recuperado el 20 de Abril de 2017, de BM en Perú: http://www.bancomundial.org/es/country/peru/overview\#1

Breast Cancer Organization. (28 de 06 de 2013). Obtenido de http://www.breastcancer.org

Choy, M., \& Chang, G. (2014). Medidas macroprudenciales aplicadas en el Perú. Lima: Banco Central de Reserva del Perú.

CNN Español. (2 de Junio de 2016). La agroindustria en Perú: entre la innovación y los retos de la competitividad. Recuperado el 20 de Abril de 2017, de CNN - Fuerz en movimiento: http://cnnespanol.cnn.com/2016/06/02/el-exito-de-laagroindustria-en-peru-entre-la-innovacion-y-los-retos-de-la-competitividad/

Datum Internacional. (2013). Hábitos de consumo saludables. Lima.

Dommarco, J. R. (27 de 10 de 2014). BID MEJORANDO VIDAS. Recuperado el 2 de Enero de 2017, de https://blogs.iadb.org/salud/2014/10/27/alimentacion/

García Nieto, J. P. (2013). Consturye tu Web comercial: de la idea al negocio. Madrid: RA-MA.

Gestion. (28 de Setiembre de 2016). Demanda de productos orgánicos peruanos se incrementó en 17\%. Recuperado el 5 de Mayo de 2017, de Gestión: https://gestion.pe/economia/demanda-productos-organicos-peruanosincremento-17-147961

Gestion. (2 de Febrero de 2017). ¿Cuáles son las nuevas tendencias del consumidor de alimentos especializados en EE.UU.? Recuperado el 15 de Abril de 2017, de Gestión: https://gestion.pe/economia/son-nuevas-tendencias-consumidoralimentos-especializados-ee-uu-127880

Gestión. (29 de Mayo de 2016). CBC y AJE revelan su interés por ampliar su portafolio en bebidas más saludables. Recuperado el 15 de Noviembre de 2017, de Gestión: https://gestion.pe/economia/empresas/cbc-aje-revelan-interes-ampliarportafolio-bebidas-saludables- 122046

Gestión. (29 de Marzo de 2015). Mercado de té bebibles crecería 15\% este año. Recuperado el 15 de Noviembre de 2017, de Gestión: https://gestion.pe/economia/empresas/mercado-bebibles-creceria-15-ano-152624

Instituto de Estudios Economicos y Sociales. (2017). Elaboración de Agua Embotellada. Lima: Sociedad Nacional de Industrias.

Lampadia. (24 de Mayo de 2017). Las grandes tendencias que definirán el nuevo mundo. Recuperado el 15 de Mayo de 2017, de Lampadia - Globalización: http://www.lampadia.com/analisis/globalizacion/las-grandes-tendencias-quedefiniran-el-nuevo-mundo 
Ministerio de la Produccion. (2017). Anuario Estadistico Industrial, MIPYME y Comercio Interno 2015. Lima.

OMS. (2017). Estrategia mundial sobre régimen alimentario, actividad física y salud. Recuperado el 15 de Mayo de 2017, de OS - Programas y proyectos: http://www.who.int/dietphysicalactivity/goals/es/

Palomino, S. (5 de Mayo de 2017). Radiografía de la vida sana. el perfil del peruano saludable. Recuperado el 15 de Abril de 2017, de Gestión: https://gestion.pe/tendencias/radiografia-vida-sana-perfil-peruano-saludable145987

Wittmann, R. (2006). ¿Hubo una revolución en la lectura a finales del siglo XVIII? En G. Cavallo, \& R. Chartier, Historia de la lectura en el mundo occidental (págs. 435-472). México D.F.: Santillana. 
ANEXOS 
ANEXO 1: ENCUESTA Y TABULACION

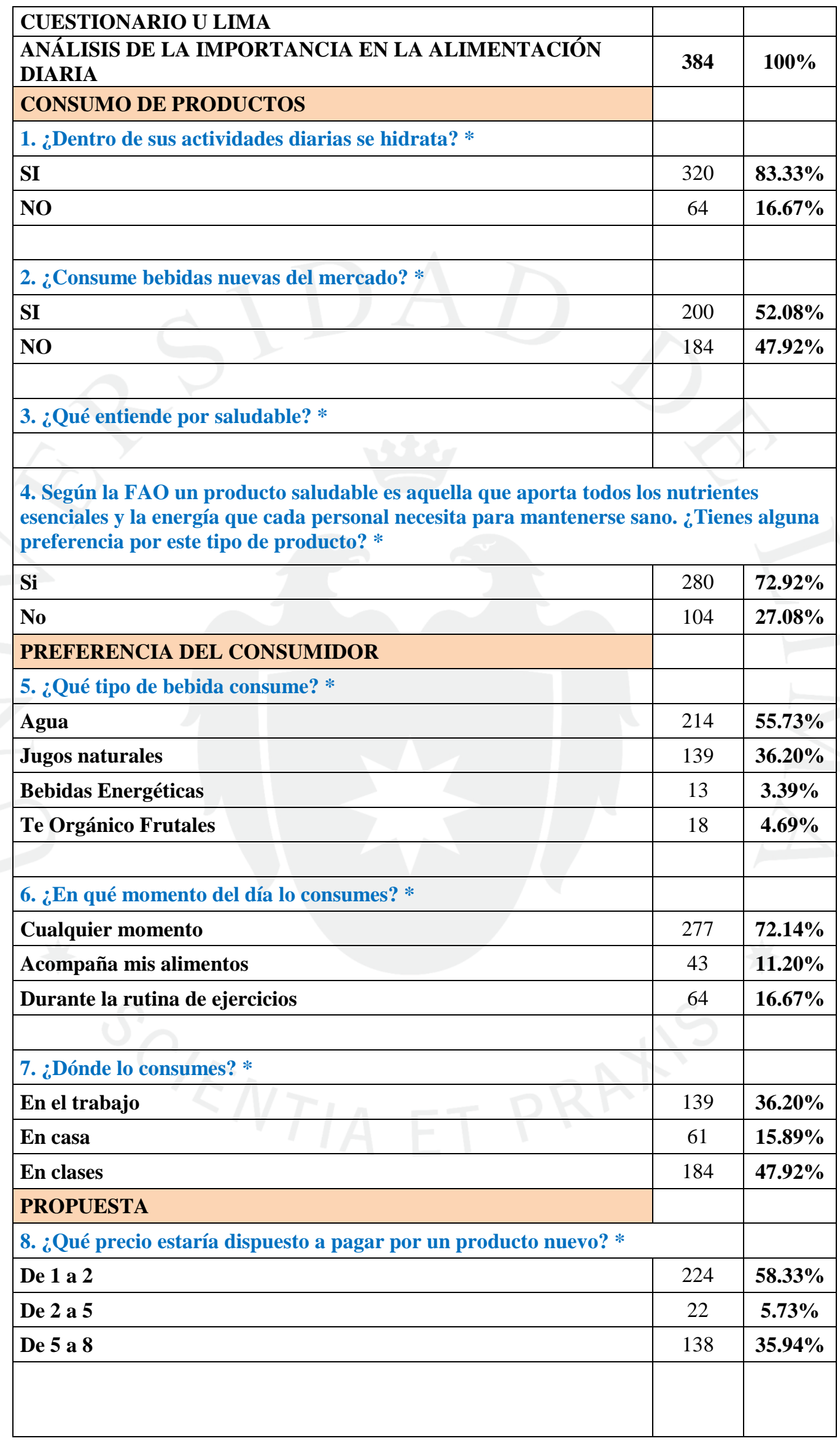




\begin{tabular}{|l|c|c|}
\hline 9. ¿Dónde comprarías? $*$ & & \\
\hline Tienda cercana & 10 & $\mathbf{2 . 6 0 \%}$ \\
\hline Supermercados & 214 & $\mathbf{5 5 . 7 3 \%}$ \\
\hline Pedido por delivery & 160 & $\mathbf{4 1 . 6 7 \%}$ \\
\hline & & \\
\hline 10. ¿Valoras que el producto sea natural? * & \\
\hline Sí & 352 & $\mathbf{9 1 . 6 7 \%}$ \\
\hline No & 32 & $\mathbf{8 . 3 3 \%}$ \\
\hline & & \\
\hline 11. ¿Qué bebida reemplazarías de tu consumo? * & \\
\hline Gaseosa & 200 & $\mathbf{5 2 . 0 8 \%}$ \\
\hline Agua & 85 & $\mathbf{2 2 . 1 4 \%}$ \\
\hline Bebidas comerciales & 99 & $\mathbf{2 5 . 7 8 \%}$ \\
\hline & & \\
\hline 12. ¿Consumiría un té fruta deshidratada? $*$ & & \\
\hline SI & 224 & $\mathbf{5 8 . 3 3 \%}$ \\
\hline NO & 160 & $\mathbf{4 1 . 6 7 \%}$ \\
\hline & & \\
\hline 13. ¿Qué fruta prefieres? $*$ & & \\
\hline Plátano, Naranja, Papaya & 88 & $\mathbf{2 2 . 9 2 \%}$ \\
\hline Fresa, Piña, Manzana, Arándano & 214 & $\mathbf{5 5 . 7 3 \%}$ \\
\hline Tuna, Melón, Sandia & 82 & $\mathbf{2 1 . 3 5 \%}$ \\
\hline
\end{tabular}




\section{ANEXO 2: PROCESOS}

- Materia Prima: Una vez que las materias primas llegan a la planta, el jefe de planta recepciona los documentos del proveedor y verifica el número de empaques y su estado, comparándolo con la información de la compra recibida.

- Recepción y pesado:

- Si está correcto se recibe la materia prima y se firma los documentos del proveedor. Si hay alguna diferencia en cantidad se detalla en el mismo documento del proveedor y se comunica a compras, en caso de encontrar materia prima en mal estado se comunica al laboratorio.

- Recibida la materia prima los operarios la ubican en el almacén.

- Triturado: se tritura la fruta deshidrata con un molino de martillos de capacidad de $100 \mathrm{~kg} / \mathrm{hora}$.

- Formulación: se realiza la formulación del filtrante de frutas con frutas deshidratadas molidas, té, estevia.

- Homogenizado: las frutas trituradas, estevia, té y saborizante se colocan en un mezclador tipo V para obtener una mezcla homogénea.

- Dosificado: la máquina se encarga de dosificar, embolsar en papel filtro con hilo $210 \mathrm{~mm}$ de longitud y colocado con etiquetas que tienen el logo del producto y los datos de la empresa. Los filtrantes tendrán el peso de 2.5 gr. el contenido es de frutas trituradas con estevia y té.

- Empacado: con máquina encelofanadora empaca las cajas de presentación de 25 unidades.

Almacenamiento: en un lugar limpio y seco. Debidamente registrado y ordenado por lotes de producción. 


\section{ANEXO 3: DISEÑO Y CAPACIDAD DE INSTALACIONES}

- Área de ingreso y egreso: Esta área se divide en 2: la primera para ingreso y egreso peatonal, con previa autorización del personal administrativo; en la segunda es la vía vehicular por donde fluyen el vehículo privado y de carga (materia prima, insumos, producto terminado, entre otros).

- Guardianía: Se tiene una seguridad nocturna. Se implementa un ambiente al cierre de las operaciones en la cochera, optimizando espacios, la cual está en contacto directo con el público y personas ajenas a la misma.

- Área de control de calidad: Esta construido en base a un área ideal para el trabajo, aquí algunas especificaciones:

Paredes. Enchapado con mayólica las 3/4 partes de la pared desde el suelo. El color de las paredes es color blanco humo.

Las mesas de trabajo de acero inoxidable para mejor limpieza y presentación. Pisos. Construidas de material resistente e impermeable, enchapadas con mayólica antideslizante y sobre el mismo piso de jebe antideslizante también para fácil limpieza.

Iluminación. Cuenta con una ventana de buen tamaño que asegura una buena iluminación y a la vez ventilación.

- Luminarias. El número de luminarias será con focos led y dos por espacio para brindar buena iluminación.

- Sistema de cañería. Constará de una pileta ubicadas estratégicamente.

- Vestidores:

- Piso. Recubierto de cerámico para mejor limpieza.

- Paredes. Recubiertas con mayólica o cerámico hasta una altura de 3/4. Las paredes serán pintadas de color claro para mejor claridad de ambientes.

- Casilleros. Cada operador dispondrá de su propio casillero con la vestimenta y botas adecuadas para el trabajo en planta.

\section{- Servicios higiénicos:}

- Piso. Preferentemente estará recubierto de cerámico para mejor limpieza. 
- Paredes. Recubiertas con mayólica o cerámico hasta una altura de 3/4. Las paredes serán pintadas de color claro para mejor claridad de ambientes.

- Inodoro. Dispondrá de un urinario para hombre y un inodoro para damas.

- Duchas. Una ducha que para damas y varones que dispondrán todo el tiempo de agua fría y agua caliente.

- Lavatorio. Incluido para aseo personal básico. 
ANEXO 4: ORGANIGRAMA

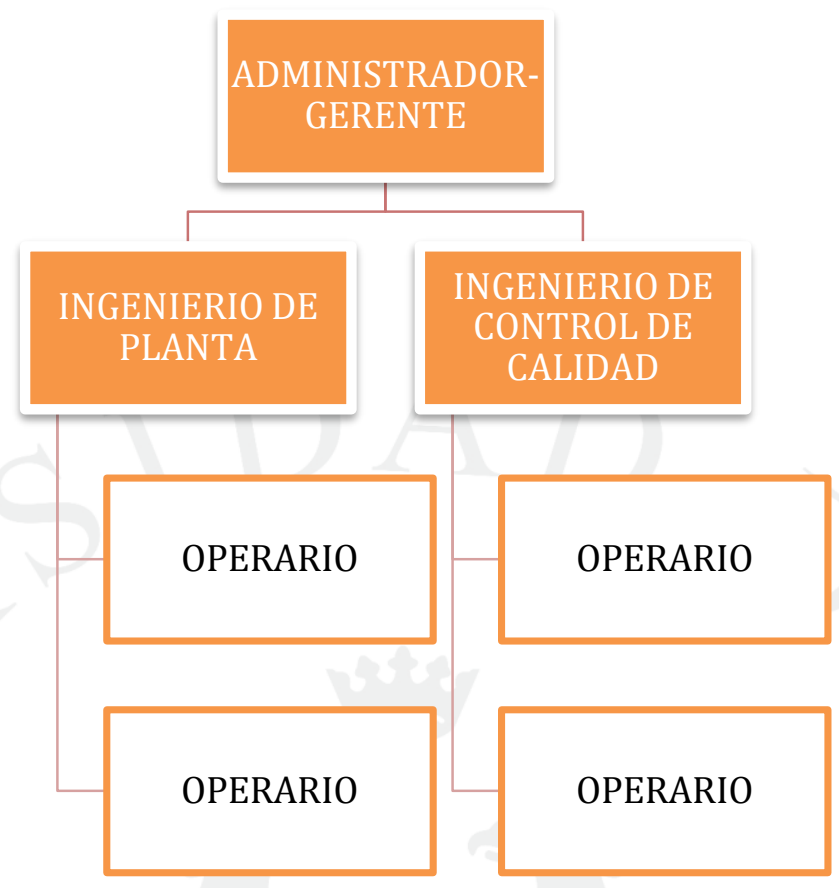




\section{ANEXO 5: DISEÑO DE PUESTOS Y \\ RESPONSABILIDADES}

CÓDIGO: 001 Gestión y Desarrollo Humano

NOMBRE DEL PUESTO

SECCIÓN

\section{FUNCIONES ESPECÍFICAS:}

- Revisar todas las áreas y confirmar que todo esté bien y listo para inicio de operaciones.

- Verificar la correcta presentación del personal.

- Verificar que todas las áreas estén abastecidas de lo necesario para desempeñar bien su labor.

- Supervisar al personal en todo momento con la intención de que se optimicen las horas de trabajo.

- Realizar la lista de productos para compra en coordinación con almacén.

- Llevar control del personal (descansos, horario de ingreso y salida, permisos, premios, etc.)

CÓDIGO: 002 Gestión y Desarrollo Humano

NOMBRE DEL PUESTO

: OPERARIO DE ALMACEN

SECCIÓN

\section{: LOGISTICA}

REPORTA A

: ADMINISTRADOR-GERENTE

FUNCIONES ESPECÍFICAS:

- Limpiar y mantener ordenado el almacén.

- Autorizar el ingreso y salida de los productos, insumos, materiales, equipos y herramientas; verificando el buen estado de los mismos y firmando los documentos respectivos.

- Recibir y cuidar todos los productos que ingresen al área.

- Recepcionar y despachar los requerimientos de todas las secciones.

- Recepcionar y gestionar las órdenes de compra.

- Inventariar constantemente el almacén para que no falte ningún producto. 
CÓDIGO: 003 Gestión y Desarrollo Humano

NOMBRE DEL PUESTO

: OPERARIO

SECCIÓN

: PRODUCCION

REPORTA A

: ADMINISTRADOR-GERENTE

FUNCIONES ESPECÍFICAS:

- Supervisar y verificar la adecuada limpieza de su área.

- Revisar los insumos que se compran para envío a maquila.

- Probar y verificar la calidad de los insumos.

- Verificar el adecuado funcionamiento de las herramientas, equipos, entre otros, utilizados en el área.

- Verificar el stock y la buena conservación de la materia prima.

- Preparar el producto final para envasado y distribución.

- Liderar el área proyectándose al crecimiento y desarrollo de la empresa.

CÓDIGO: 004 Gestión y Desarrollo Humano

NOMBRE DEL PUESTO

: VIGILANTE

SECCIÓN

: SEGURIDAD

REPORTA A

: ADMINISTRADOR-GERENTE

FUNCIONES ESPECÍFICAS:

- Llevar el registro de salida del personal.

- Limpia el área de estacionamiento vehicular.

- Vestir correctamente el uniforme limpio y mantener en todo momento higiene y aseo personal.

- Comportarse impecablemente durante las horas de trabajo y mientras lleve el uniforme, teniendo en consideración que es la imagen externa de la empresa.

- Tener al día su cuaderno de ocurrencias. 


\section{ANEXO 6: INVERSIÓN INICIAL}

\begin{tabular}{|c|c|c|c|c|c|}
\hline NRO & ITEM & CANTIDAD & C UNIT & TOTAL & $\begin{array}{l}\text { SUB TOTAL } \\
\text { ACTIVOS }\end{array}$ \\
\hline 1 & Máquina empacadora para filtrante & 1 & $25,000.00$ & $\mathrm{~S} / .25,000.00$ & \\
\hline 2 & Balanza de plataforma & 1 & $5,500.00$ & $\mathrm{~S} / .5,500.00$ & \\
\hline 3 & Balanza digital & 1 & $2,500.00$ & $\mathrm{~S} / .2,500.00$ & \\
\hline 4 & Selladora de bolsas & 1 & $2,500.00$ & $\mathrm{~S} / .2,500.00$ & \\
\hline 5 & Máquina encelofanadora & 1 & $5,000.00$ & $\mathrm{~S} / .5,000.00$ & \\
\hline 6 & Molino & 1 & $6,000.00$ & S/ $.6,000.00$ & \\
\hline 7 & Homogenizador tipo $\mathrm{v}$ & 1 & $5,000.00$ & $\mathrm{~S} / .5,000.00$ & $\mathrm{~S} / .51,500.00$ \\
\hline 8 & Mesas de acero inoxidable & 2 & $1,800.00$ & $\mathrm{~S} / .3,600.00$ & \\
\hline 9 & Tinas de acero inoxidable & 2 & 240.00 & $\mathrm{~S} / .480 .00$ & \\
\hline 10 & Bolsas de polietileno alta densidad & 100 & 2.00 & $\mathrm{~S} / .200 .00$ & \\
\hline 11 & Jabas para frutas & 10 & 25.00 & $\mathrm{~S} / .250 .00$ & \\
\hline 12 & Otros utensilios & 10 & 80.00 & $\mathrm{~S} / .800 .00$ & $\mathrm{~S} / \mathbf{5 , 3 3 0 . 0 0}$ \\
\hline 13 & Lap Top & 3 & $3,500.00$ & $\mathrm{~S} / .10,500.00$ & \\
\hline 14 & Impresora & 1 & 600.00 & $\mathrm{~S} / .600 .00$ & \\
\hline 15 & Estaciones administrativas (escritorio, silla) & 3 & $2,000.00$ & $\mathrm{~S} / .6,000.00$ & \\
\hline 16 & Mesa ovalada +6 sillas & 1 & $1,500.00$ & $\mathrm{~S} / .1,500.00$ & \\
\hline 17 & Ambientaciòn (tabiquerias almacen, oficinas) & 1 & $3,000.00$ & $\mathrm{~S} / .3,000.00$ & \\
\hline 18 & Refrigerador & 1 & $1,000.00$ & $\mathrm{~S} / .1,000.00$ & \\
\hline 19 & Horno Microhondas + cafetera & 1 & 300.00 & $\mathrm{~S} / .300 .00$ & \\
\hline 20 & Monitor para vigilancia (camaras de seguridad) & 1 & 150.00 & $\mathrm{~S} / .150 .00$ & \\
\hline 21 & Camaras de vigilancia & 3 & 266.67 & $\mathrm{~S} / .800 .00$ & $\mathrm{~S} / .23,850.00$ \\
\hline 22 & Paquete contable & 1 & $8,250.00$ & $\mathrm{~S} / .8,250.00$ & \\
\hline 23 & Registro sanitario (análisis + registro) & 1 & 750.00 & $\mathrm{~S} / .750 .00$ & \\
\hline 24 & Garantía de alquileres ( 2 meses) & 2 & $5,000.00$ & $\mathrm{~S} / .10,000.00$ & \\
\hline 25 & Licencias Office + antivirus & 3 & $1,470.00$ & $\mathrm{~S} / .4,410.00$ & \\
\hline 26 & Registro Indecopi & 1 & $1,000.00$ & $\mathrm{~S} / .1,000.00$ & \\
\hline 27 & Diseño $y$ arte de logo & 1 & 120.00 & $\mathrm{~S} / .120 .00$ & \\
\hline 28 & Diseño de empaque y bolsa & 1 & 550.00 & S/ .550 .00 & \\
\hline 29 & Desarrollo Pàgina Web & 1 & $2,520.00$ & $\mathrm{~S} / .2,520.00$ & \\
\hline 30 & Pieza gràfica & 1 & 350.00 & $\mathrm{~S} / .350 .00$ & \\
\hline 31 & Dominio Web (Godaddy) & 1 & 33.00 & $\mathrm{~S} / .33 .00^{\circ}$ & S/.27,983.00 \\
\hline 32 & Capital de trabajo & 1 & & $\mathrm{~S} / .111,728.14$ & S/.111,728.14 \\
\hline & & & TOTAL & S/.220,391.14 & S/.220,391.14 \\
\hline
\end{tabular}




\section{ANEXO 7: ACTIVOS Y DEPRECIACION}

\begin{tabular}{|c|c|c|c|c|c|c|c|c|}
\hline \multicolumn{9}{|c|}{ DEPRECIACION Y AMORTIZACION LINEAL 5 AÑOS } \\
\hline \multicolumn{9}{|c|}{ ESCENARIO BASE } \\
\hline & & & Aก๊o 1 & ANO 2 & AÑo 3 & AÑO 4 & AÑo 5 & TOTAL \\
\hline & TASA $\%$ & & $20 \%$ & $20 \%$ & $20 \%$ & $20 \%$ & $20 \%$ & INNERSION \\
\hline & TASA $\%$ & & $33 \%$ & $33 \%$ & $33 \%$ & & & \\
\hline 1 & MAQUINARIA Y EQUIPOS & 51,500 & 10,300 & 10,300 & 10,300 & 10,300 & 10,300 & 51,500 \\
\hline 2 & MUEBLES Y ENSERES OPERACIÓN & 5,330 & 1,066 & 1,066 & 1,066 & 1,066 & 1,066 & 5,330 \\
\hline 3 & EQUIPOS DE COMPUTO & 12,050 & 4,017 & 4,017 & 4,017 & & & 12,050 \\
\hline 4 & BIENES DE ESCRITORIO & 11,800 & 2,360 & 2,360 & 2,360 & 2,360 & 2,360 & 11,800 \\
\hline \multirow[t]{2}{*}{5} & AMORTIZACION & 17,983 & 3,597 & 3,597 & 3,597 & 3,597 & 3,597 & 17,983 \\
\hline & & 98,663 & 21,339 & 21,339 & 21,339 & 17,323 & 17,323 & 98,663 \\
\hline
\end{tabular}




\section{ANEXO 8: CAPITAL DE TRABAJO}

\section{DETERMINACION CAPITAL DE TRABAJO}

GASTOS OPERATIVOS - ESCENARIO BASE

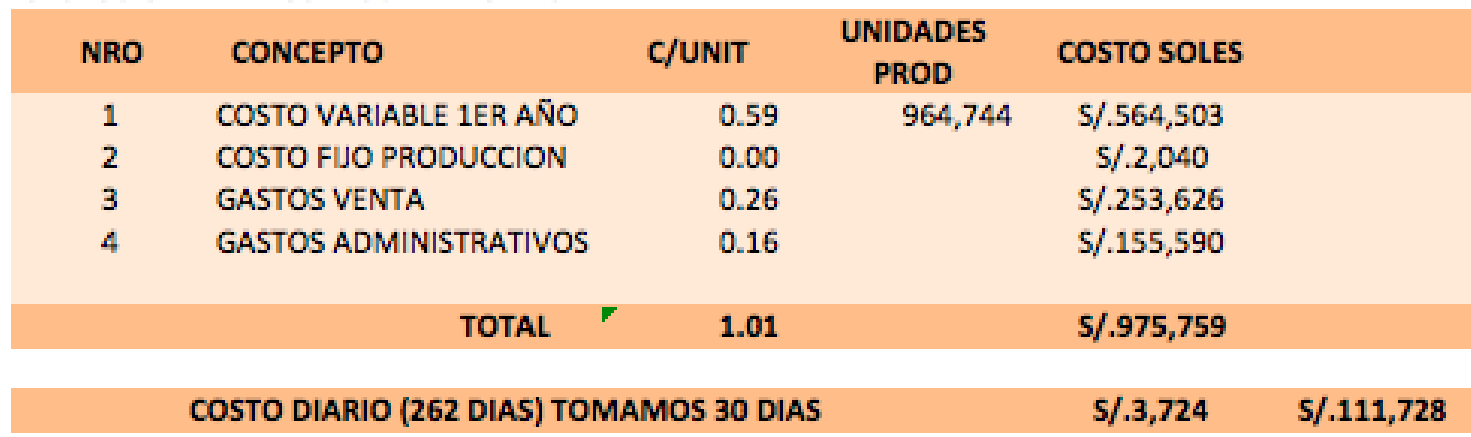

GASTOS OPERATIVOS - ESCENARIO PESIMISTA

\begin{tabular}{|c|c|c|c|c|c|}
\hline NRO & CONCEPTO & C/UNIT & $\begin{array}{l}\text { UNIDADES } \\
\text { PROD }\end{array}$ & COSTO SOLES & \\
\hline 1 & COSTO VARIABLE 1ER AÑO & 0.62 & 723,558 & $\mathrm{~S} / .450,712$ & \\
\hline 2 & COSTO FIJO PRODUCCION & 0.00 & & $5 / .2,040$ & \\
\hline 3 & GASTOS VENTA & 0.35 & & $S / .253,626$ & \\
\hline \multirow[t]{2}{*}{4} & GASTOS ADMINISTRATIVOS & 0.22 & & $\mathrm{~S} / .155,590$ & \\
\hline & TOTAL & 1.19 & & $5 / .861,968$ & \\
\hline & COSTO DIARIO (262 DIAS) TOM & AMOS 30 DIAS & & $5 / .3,290$ & $\$ / .98,699$ \\
\hline
\end{tabular}

GASTOS OPERATIVOS - ESCENARIO OPTIMISTA

\begin{tabular}{|c|c|c|c|c|c|}
\hline NRO & CONCEPTO & C/UNIT & $\begin{array}{l}\text { UNIDADES } \\
\text { PROD }\end{array}$ & COSTO SOLES & \\
\hline 1 & COSTO VARIABLE 1ER AÑO & 0.55 & $1,205,930$ & S/.657,334 & \\
\hline 2 & COSTO FIJO PRODUCCION & 0.00 & & $5 / .2,040$ & \\
\hline 3 & GASTOS VENTA & 0.21 & & $S / .253,626$ & \\
\hline 4 & GASTOS ADMINISTRATIVOS & 0.13 & & $\mathrm{~S} / .155,590$ & \\
\hline \multicolumn{6}{|l|}{5} \\
\hline & TOTAL & 0.89 & & $S / .1,068,590$ & \\
\hline & COSTO DIARIO (262 DIAS) TON & MOS 30 DIAS & & $5 / .4,079$ & $5 / .122,358$ \\
\hline
\end{tabular}




\section{ANEXO 9: ESTRUCTURA DE DEUDA Y APALANCAMIENTO}

\section{ESTRUCTURA DE DEUDA APALANCAMIENTO}

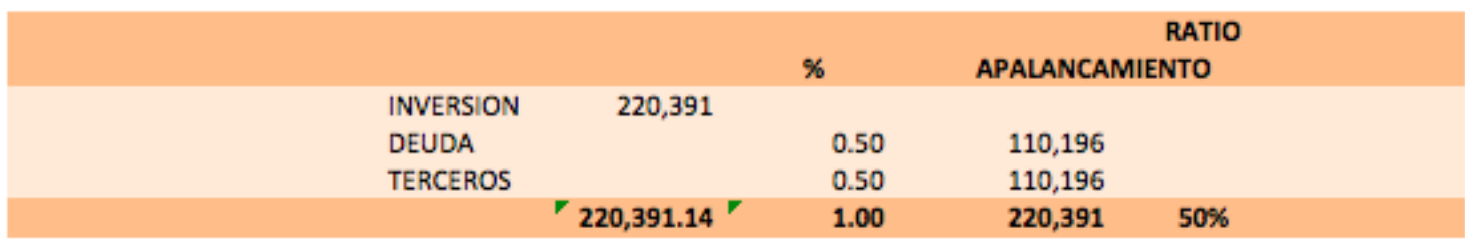

Calculo del COK

Tasa

\begin{tabular}{|c|c|c|}
\hline & & \\
\hline Rf (US treasury rate 3 yrs) & $2.74 \%$ & 30 años \\
\hline $\mathrm{Rm}$ & $15.05 \%$ & s\&.P 5 añ் \\
\hline Beta (Bebidas no alcoholicas) & 0.74 & \\
\hline Riesgo Peru & $1.77 \%$ & 5 aก̃os \\
\hline COK & $13.6 \%$ & \\
\hline
\end{tabular}

\begin{tabular}{|r|r|r|r|r|r|r|r|}
\hline $\mathrm{D} / \mathrm{D}+\mathrm{E}$ & $\mathrm{KD}$ & $\mathrm{Tl}$ & $\mathrm{R}$ & $\mathrm{D}$ & $\mathrm{E}$ & $\mathrm{D} / \mathrm{E}$ \\
\hline $10 \%$ & $13.08 \%$ & $29.5 \%$ & $2.74 \%$ & $15.05 \%$ & $10 \%$ & $90 \%$ & 0.11 \\
\hline $15 \%$ & $13.08 \%$ & $29.5 \%$ & $2.74 \%$ & $15.05 \%$ & $15 \%$ & $85 \%$ & 0.18 \\
\hline $20 \%$ & $13.08 \%$ & $29.5 \%$ & $2.74 \%$ & $15.05 \%$ & $20 \%$ & $80 \%$ & 0.25 \\
\hline $25 \%$ & $13.08 \%$ & $29.5 \%$ & $2.74 \%$ & $15.05 \%$ & $25 \%$ & $75 \%$ & 0.33 \\
\hline $30 \%$ & $13.08 \%$ & $29.5 \%$ & $2.74 \%$ & $15.05 \%$ & $30 \%$ & $70 \%$ & 0.43 \\
\hline $35 \%$ & $13.08 \%$ & $29.5 \%$ & $2.74 \%$ & $15.05 \%$ & $35 \%$ & $65 \%$ & 0.54 \\
\hline $40 \%$ & $13.08 \%$ & $29.5 \%$ & $2.74 \%$ & $15.05 \%$ & $40 \%$ & $60 \%$ & 0.67 \\
\hline $45 \%$ & $13.08 \%$ & $29.5 \%$ & $2.74 \%$ & $15.05 \%$ & $45 \%$ & $55 \%$ & 0.82 \\
\hline $50 \%$ & $13.08 \%$ & $29.5 \%$ & $2.74 \%$ & $15.05 \%$ & $50 \%$ & $50 \%$ & 1.00 \\
\hline
\end{tabular}

\begin{tabular}{|l|r|}
\hline \multicolumn{2}{|c|}{ BETA CON DEUDA DE "AL SOL" } \\
\hline & 0.80 \\
\cline { 2 - 2 } & 0.83 \\
\cline { 2 - 2 } & 0.87 \\
\cline { 2 - 2 } & 0.91 \\
\cline { 2 - 2 } & 0.96 \\
\cline { 2 - 2 } & 1.02 \\
\cline { 2 - 2 } & 1.09 \\
\cline { 2 - 2 } & 1.17 \\
\cline { 2 - 2 } & $\mathbf{1 . 2 6}$ \\
\hline
\end{tabular}

\begin{tabular}{|r|r|}
\hline \multicolumn{2}{|c|}{ COK } \\
\hline $12.56 \%$ & $20.56 \%$ \\
\hline $12.98 \%$ & $20.98 \%$ \\
\hline $13.45 \%$ & $21.45 \%$ \\
\hline $13.99 \%$ & $21.99 \%$ \\
\hline $14.60 \%$ & $22.60 \%$ \\
\hline $15.31 \%$ & $23.31 \%$ \\
\hline $16.13 \%$ & $24.13 \%$ \\
\hline $17.10 \%$ & $25.10 \%$ \\
\hline $18.27 \%$ & $26.27 \%$ \\
\hline
\end{tabular}

\begin{tabular}{|l|r|}
\hline \multicolumn{2}{|c|}{ WACC } \\
\hline \multirow{4}{*}{} & $19.43 \%$ \\
\cline { 2 - 3 } & $19.22 \%$ \\
\cline { 2 - 3 } & $19.01 \%$ \\
\cline { 2 - 3 } & $18.80 \%$ \\
\cline { 2 - 3 } & $18.59 \%$ \\
\cline { 2 - 3 } & $18.38 \%$ \\
\cline { 2 - 3 } & $18.17 \%$ \\
\cline { 2 - 3 } & $17.96 \%$ \\
\cline { 2 - 3 } & $17.75 \%$ \\
\hline
\end{tabular}


TASA PROPUESTA TEA \% 11.90 TCEA \% 13.08

DEUDA

110,196
$13 \%$ 0.13

$110,195.57$

Credito

Plazo Años

TCEA

Cuota

$\begin{array}{rr}110,195.57 & \\ 2 & 24 \\ 13.08 \% & 0.01029643 \\ \text { S/. } 5,205.61 & \end{array}$

Cronograma de Pagos

\begin{tabular}{|c|c|c|c|c|}
\hline Nro Cuota & Capital & Interes & Cuota & Amortizacion \\
\hline 1 & $110,195.57$ & $1,134.62$ & S/. 5,205.61 & $4,070.99$ \\
\hline 2 & $106,124.58$ & $1,092.70$ & S/. 5,205.61 & $4,112.91$ \\
\hline 3 & $102,011.67$ & $1,050.36$ & $5 / .5,205.61$ & $4,155.26$ \\
\hline 4 & $97,856.41$ & $1,007.57$ & S/. 5,205.61 & $4,198.04$ \\
\hline 5 & $93,658.37$ & 964.35 & S/. 5,205.61 & $4,241.27$ \\
\hline 6 & $89,417.11$ & 920.68 & $5 / .5,205.61$ & $4,284.94$ \\
\hline 7 & $85,132.17$ & 876.56 & S/. 5,205.61 & $4,329.06$ \\
\hline 8 & $80,803.12$ & 831.98 & S/. 5,205.61 & $4,373.63$ \\
\hline 9 & $76,429.49$ & 786.95 & S/. 5,205.61 & $4,418.66$ \\
\hline 10 & $72,010.83$ & 741.45 & 5/. 5,205.61 & $4,464.16$ \\
\hline 11 & $67,546.67$ & 695.49 & S/. 5,205.61 & $4,510.12$ \\
\hline 12 & $63,036.55$ & 649.05 & S/. 5,205.61 & $4,556.56$ \\
\hline 13 & $58,479.98$ & 602.13 & S/. 5,205.61 & $4,603.48$ \\
\hline 14 & $53,876.51$ & 554.74 & S/. 5,205.61 & $4,650.88$ \\
\hline 15 & $49,225.63$ & 506.85 & $5 / .5,205.61$ & $4,698.76$ \\
\hline 16 & $44,526.87$ & 458.47 & S/. 5,205.61 & $4,747.14$ \\
\hline 17 & $39,779.72$ & 409.59 & S/. 5,205.61 & $4,796.02$ \\
\hline 18 & $34,983.70$ & 360.21 & S/. 5,205.61 & $4,845.41$ \\
\hline 19 & $30,138.29$ & 310.32 & $5 / .5,205.61$ & $4,895.30$ \\
\hline 20 & $25,243.00$ & 259.91 & S/. 5,205.61 & $4,945.70$ \\
\hline 21 & $20,297.30$ & 208.99 & S/. 5,205.61 & $4,996.62$ \\
\hline 22 & $15,300.68$ & 157.54 & S/. 5,205.61 & $5,048.07$ \\
\hline 23 & $10,252.61$ & 105.57 & S/. 5,205.61 & $5,100.05$ \\
\hline \multirow[t]{2}{*}{24} & $5,152.56$ & 53.05 & S/. 5,205.61 & $5,152.56$ \\
\hline & & $14,739.12$ & $124,934.69$ & $110,195.57$ \\
\hline
\end{tabular}

S/. 5,205.61

24

\section{$\mathrm{N}=\mathbf{2 4}$}

$14,413.58$

14,414 $100 \%$ 
TASA PROPUESTA TEA \% 11.90 TCEA \% 13.08 DEUDA

103,681
$N=24$

$13 \%$

$14,413.58$

14,414

$100 \%$

$103,680.83$

Plazo Años

TCEA

Cuota

\$/. $4,897.86$

Cronograma de Pagos

\begin{tabular}{|c|c|c|c|c|}
\hline Nro Cuota & Capital & Interes & Cuota & Amortizacion \\
\hline 1 & $103,680.83$ & $1,067.54$ & S/. 4,897.86 & $3,830.32$ \\
\hline 2 & $99,850.52$ & $1,028.10$ & S/. 4,897.86 & $3,869.75$ \\
\hline 3 & $95,980.76$ & 988.26 & $5 / .4,897.86$ & $3,909.60$ \\
\hline 4 & $92,071.16$ & 948.00 & S/. 4,897.86 & $3,949.85$ \\
\hline 5 & $88,121.31$ & 907.33 & $5 / .4,897.86$ & $3,990.52$ \\
\hline 6 & $84,130.79$ & 866.25 & $5 / .4,897.86$ & $4,031.61$ \\
\hline 7 & $80,099.18$ & 824.74 & $5 / .4,897.86$ & $4,073.12$ \\
\hline 8 & $76,026.05$ & 782.80 & S/. 4,897.86 & $4,115.06$ \\
\hline 9 & $71,910.99$ & 740.43 & S/. 4,897.86 & $4,157.43$ \\
\hline 10 & $67,753.56$ & 697.62 & S/. 4,897.86 & $4,200.24$ \\
\hline 11 & $63,553.32$ & 654.37 & S/. 4,897.86 & $4,243.49$ \\
\hline 12 & $59,309.84$ & 610.68 & S/. 4,897.86 & $4,287.18$ \\
\hline 13 & $55,022.66$ & 566.54 & S/. 4,897.86 & $4,331.32$ \\
\hline 14 & $50,691.34$ & 521.94 & $5 / .4,897.86$ & $4,375.92$ \\
\hline 15 & $46,315.42$ & 476.88 & S/. 4,897.86 & $4,420.97$ \\
\hline 16 & $41,894.45$ & 431.36 & S/. 4,897.86 & $4,466.49$ \\
\hline 17 & $37,427.95$ & 385.37 & S/. 4,897.86 & $4,512.48$ \\
\hline 18 & $32,915.47$ & 338.91 & $5 / .4,897.86$ & $4,558.95$ \\
\hline 19 & $28,356.52$ & 291.97 & S/. 4,897.86 & $4,605.89$ \\
\hline 20 & $23,750.64$ & 244.55 & $5 / .4,897.86$ & $4,653.31$ \\
\hline 21 & $19,097.33$ & 196.63 & S/. 4,897.86 & $4,701.22$ \\
\hline 22 & $14,396.10$ & 148.23 & $5 / .4,897.86$ & $4,749.63$ \\
\hline 23 & $9,646.47$ & 99.32 & S/. 4,897.86 & $4,798.53$ \\
\hline \multirow[t]{2}{*}{24} & $4,847.94$ & 49.92 & S/. 4,897.86 & $4,847.94$ \\
\hline & & $13,867.75$ & $117,548.58$ & $103,680.83$ \\
\hline
\end{tabular}


TASA PROPUESTA TEA \% 11.90 TCEA \% 13.08 DEUDA
115,510

$13 \%$

\section{$N=24$}

$14,413.58$

\section{$14,414 \quad 100 \%$ \\ $115,510.31$ \\ 0.13}

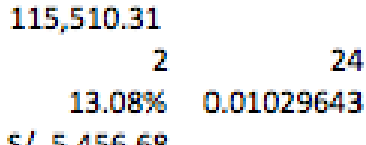

S/. $5,456.68$

Cronograma de Pagos

\begin{tabular}{|c|c|c|c|c|}
\hline Nro Cuota & Capital & Interes & Cuota & Amortizacion \\
\hline 1 & $115,510.31$ & $1,189.34$ & $5 / .5,456.68$ & $4,267.34$ \\
\hline 2 & $111,242.97$ & $1,145.41$ & S/. $5,456.68$ & $4,311.27$ \\
\hline 3 & $106,931.70$ & $1,101.01$ & S/. 5,456.68 & $4,355.66$ \\
\hline 4 & $102,576.03$ & $1,056.17$ & S/. $5,456.68$ & $4,400.51$ \\
\hline 5 & $98,175.52$ & $1,010.86$ & S/. 5,456.68 & $4,445.82$ \\
\hline 6 & $93,729.70$ & 965.08 & S/. 5,456.68 & $4,491.60$ \\
\hline 7 & $89,238.10$ & 918.83 & S/. 5,456.68 & $4,537.85$ \\
\hline 8 & $84,700.26$ & 872.11 & S/. 5,456.68 & $4,584.57$ \\
\hline 9 & $80,115.69$ & 824.91 & S/. 5,456.68 & $4,631.77$ \\
\hline 10 & $75,483.91$ & 777.21 & 5/. 5,456.68 & $4,679.46$ \\
\hline 11 & $70,804.45$ & 729.03 & S/. $5,456.68$ & $4,727.65$ \\
\hline 12 & $66,076.80$ & 680.35 & S/. 5,456.68 & $4,776.32$ \\
\hline 13 & $61,300.48$ & 631.18 & S/. 5,456.68 & $4,825.50$ \\
\hline 14 & $56,474.97$ & 581.49 & S/. 5,456.68 & $4,875.19$ \\
\hline 15 & $51,599.79$ & 531.29 & 5/. $5,456.68$ & $4,925.39$ \\
\hline 16 & $46,674.40$ & 480.58 & S/. 5,456.68 & $4,976.10$ \\
\hline 17 & $41,698.30$ & 429.34 & S/. 5,456.68 & $5,027.34$ \\
\hline 18 & $36,670.96$ & 377.58 & S/. 5,456.68 & $5,079.10$ \\
\hline 19 & $31,591.87$ & 325.28 & $5 / .5,456.68$ & $5,131.40$ \\
\hline 20 & $26,460.47$ & 272.45 & S/. 5,456.68 & $5,184.23$ \\
\hline 21 & $21,276.24$ & 219.07 & S/. 5,456.68 & $5,237.61$ \\
\hline 22 & $16,038.63$ & 165.14 & $5 / .5,456.68$ & $5,291.54$ \\
\hline 23 & $10,747.09$ & 110.66 & S/. $5,456.68$ & $5,346.02$ \\
\hline \multirow[t]{2}{*}{24} & $5,401.07$ & 55.61 & S/. 5,456.68 & $5,401.07$ \\
\hline & & $15,449.99$ & $130,960.30$ & $115,510.31$ \\
\hline
\end{tabular}




\section{ANEXO 10: ESTADO DE GANANCIAS Y PÉRDIDAS}

\author{
ESCENARIO BASE \\ VENTAS \\ COSTO DE VENTAS \\ UTILIDAD BRUTA \\ GASTOS DE VENTAS \\ GASTOS ADMINISTRATIVOS \\ GASTOS DE INVESTIGACION Y DESARROLLO \\ DEPRECIACION Y AMORTIZACION \\ UTILIDAD OPERATIVA \\ INTERESES DEUDA \\ UTILIDAD ANTES DE IMPUESTOS \\ IMPUESTOS \\ UTILIDAD NETA \\ EBITDA
}

ESCENARIO PESIMISTA

VENTAS

COSTO DE VENTAS

UTILIDAD BRUTA

GASTOS DE VENTAS

GASTOS ADMINISTRATIVOS

GASTOS DE INVESTIGACION Y DESARROLLO

DEPRECIACION Y AMORTIZACION

UTILIDAD OPERATIVA

INTERESES DEUDA

UTILIDAD ANTES DE IMPUESTOS

IMPUESTOS

UTILIDAD NETA

EBITDA

\begin{tabular}{|c|c|c|c|c|}
\hline $\begin{array}{c}\text { AN̂O 1 } \\
2018\end{array}$ & $\begin{array}{l}\text { ANO } 2 \\
2019\end{array}$ & $\begin{array}{l}\text { ANO } 3 \\
2020\end{array}$ & $\begin{array}{c}\text { ANo } 4 \\
2021\end{array}$ & $\begin{array}{l}\text { ANo } 5 \\
20222\end{array}$ \\
\hline $\begin{array}{c}1,386,554 \\
(566,543)\end{array}$ & $\begin{array}{c}1,412,552 \\
(573,505)\end{array}$ & $\begin{array}{c}1,438,549 \\
(580,468)\end{array}$ & $\begin{array}{c}1,464,547 \\
(587,430)\end{array}$ & $\begin{array}{r}1,490,545 \\
(594,392)\end{array}$ \\
\hline 820,011 & 839,046 & 858,082 & 877,117 & 896,153 \\
\hline$(253,626)$ & $(253,626)$ & $(253,626)$ & $(253,626)$ & $(253,626)$ \\
\hline$(155,590)$ & $(155,590)$ & $(155,590)$ & $(155,590)$ & $(155,590)$ \\
\hline$(13,866)$ & $(14,126)$ & $(14,385)$ & $(14,645)$ & $(14,905)$ \\
\hline$(21,339)$ & $(21,339)$ & $(21,339)$ & $(17,323)$ & $(17,323)$ \\
\hline$(444,421)$ & $(444,681)$ & $(444,941)$ & $(441,184)$ & $(441,444)$ \\
\hline 375,590 & 394,365 & 413,141 & 435,933 & 454,709 \\
\hline$(10,752)$ & $(3,987)$ & & & \\
\hline 364,838 & 390,378 & 413,141 & 435,933 & 454,709 \\
\hline$(107,627)$ & $(115,162)$ & $(121,877)$ & $(128,600)$ & $(134,139)$ \\
\hline $257,210.8$ & $275,216.5$ & $291,264.4$ & $307,332.9$ & $320,569.7$ \\
\hline 396,929 & 415,705 & 434,480 & 453,256 & 472,031 \\
\hline $59 \%$ & $59 \%$ & $60 \%$ & $60 \%$ & $60 \%$ \\
\hline
\end{tabular}

\begin{tabular}{rrrrr}
\multicolumn{1}{c}{\begin{tabular}{c} 
ANO 1 \\
\multicolumn{1}{c}{ ANO18 2 }
\end{tabular}} & \multicolumn{1}{c}{$\begin{array}{c}\text { ANO 3 } \\
\text { 2019 }\end{array}$} & \multicolumn{1}{c}{$\begin{array}{c}\text { ANO 4 } \\
\text { 2020 }\end{array}$} & \multicolumn{1}{c}{$\begin{array}{c}\text { ANO 5 } \\
\text { 2021 }\end{array}$} & \multicolumn{1}{c}{2022} \\
$1,039,915$ & $1,074,579$ & $1,109,243$ & $1,143,907$ & $1,178,571$ \\
$(452,752)$ & $(462,035)$ & $(471,318)$ & $(480,602)$ & $(489,885)$ \\
\hline 587,163 & 612,544 & 637,924 & 663,305 & 688,686 \\
& & & & \\
$(253,626)$ & $(253,626)$ & $(253,626)$ & $(253,626)$ & $(253,626)$ \\
$(155,590)$ & $(155,590)$ & $(155,590)$ & $(155,590)$ & $(155,590)$ \\
$(10,399)$ & $(10,746)$ & $(11,092)$ & $(11,439)$ & $(11,786)$ \\
$(21,339)$ & $(21,339)$ & $(21,339)$ & $(17,323)$ & $(17,323)$ \\
\hline$(440,954)$ & $(441,301)$ & $(441,648)$ & $(437,978)$ & $(438,324)$ \\
146,209 & 171,243 & 196,277 & 225,328 & 250,362 \\
$(10,116)$ & $(3,752)$ & & & \\
136,092 & 167,491 & 196,277 & 225,328 & 250,362 \\
$(40,147)$ & $(49,410)$ & $(57,902)$ & $(66,472)$ & $(73,857)$ \\
95,945 & 118,081 & 138,375 & 158,856 & 176,505 \\
& & & & \\
167,548 & 192,582 & 217,616 & 242,650 & 267,684 \\
$56 \%$ & $57 \%$ & $58 \%$ & $58 \%$ & $58 \%$
\end{tabular}




\section{ESCENARIO OPTIMISTA}

VENTAS

COSTO DE VENTAS

UTILIDAD BRUTA

GASTOS DE VENTAS

GASTOS ADMINISTRATIVOS

GASTOS DE INVESTIGACION Y DESARROLLO DEPRECIACION Y AMORTIZACION

UTILIDAD OPERATIVA

INTERESES DEUDA

UTILIDAD ANTES DE IMPUESTOS

IMPUESTOS

UTILIDAD NETA

EBITDA

\begin{tabular}{|c|c|c|c|c|}
\hline $\begin{array}{c}\text { AÑo } 1 \\
2018\end{array}$ & $\begin{array}{l}\text { AÑO } 2 \\
2019 \\
\end{array}$ & $\begin{array}{l}\text { AÑo } 3 \\
2020\end{array}$ & $\begin{array}{l}\text { AÑO } 4 \\
2021\end{array}$ & $\begin{array}{l}\text { AÑO } 5 \\
2022\end{array}$ \\
\hline $\begin{array}{r}1,733,192 \\
(659,374)\end{array}$ & $\begin{array}{r}1,733,192 \\
(659,374)\end{array}$ & $\begin{array}{r}1,733,192 \\
(659,374)\end{array}$ & $\begin{array}{r}1,733,192 \\
(659,374)\end{array}$ & $\begin{array}{r}1,733,192 \\
(659,374)\end{array}$ \\
\hline $1,073,818$ & $1,073,818$ & $1,073,818$ & $1,073,818$ & $1,073,818$ \\
\hline$(253,626)$ & $(253,626)$ & $(253,626)$ & $(253,626)$ & $(253,626)$ \\
\hline$(155,590)$ & $(155,590)$ & $(155,590)$ & $(155,590)$ & $(155,590)$ \\
\hline$(17,332)$ & $(17,332)$ & $(17,332)$ & $(17,332)$ & $(17,332)$ \\
\hline$(21,339)$ & $(21,339)$ & $(21,339)$ & $(17,323)$ & $(17,323)$ \\
\hline$(447,887)$ & $(447,887)$ & $(447,887)$ & $(443,871)$ & $(443,871)$ \\
\hline 625,931 & 625,931 & 625,931 & 629,948 & 629,948 \\
\hline$(11,270)$ & $(4,180)$ & & & \\
\hline 614,661 & $621,751 \mathrm{~V}$ & $625,931 \mathbf{V}$ & $629,948 \nabla$ & 629,948 \\
\hline$(181,325)$ & $(183,417)$ & $(184,650)$ & $(185,835)$ & $(185,835)$ \\
\hline $433,335.8$ & $438,334.7$ & $441,281.4$ & $444,113.1$ & $444,113.1$ \\
\hline 647,270 & 647,270 & 647,270 & 647,270 & 647,270 \\
\hline $62 \%$ & $62 \%$ & $62 \%$ & $62 \%$ & $62 \%$ \\
\hline
\end{tabular}




\section{ANEXO 11: BALANCE GENERAL}

\begin{tabular}{|c|c|c|c|c|c|c|}
\hline & & $\begin{array}{c}\text { AÑo } 1 \\
2018\end{array}$ & $\begin{array}{l}\text { AÑO } 2 \\
2019\end{array}$ & $\begin{array}{c}\text { AÑo } 3 \\
2020\end{array}$ & $\begin{array}{l}\text { ANo } 4 \\
2021\end{array}$ & $\begin{array}{l}\text { AÑO 5 } \\
2022\end{array}$ \\
\hline \multicolumn{7}{|l|}{ ACTIVOS } \\
\hline CAJA Y BANCOS & 111,728 & 338,563 & 576,638 & 889,242 & $1,213,898$ & $1,551,790$ \\
\hline GASTOS PAGADOS POR ANTICIPADO & 10,000 & 10,000 & 10,000 & 10,000 & 10,000 & 10,000 \\
\hline TOTAL ACTIVO CORRIENTE & 121,728 & 348,563 & 586,638 & 899,242 & $1,223,898$ & $1,561,790$ \\
\hline INMUEBLES MAQUINARIA Y EQUIPO & 98,663 & 98,663 & 98,663 & 98,663 & 98,663 & 98,663 \\
\hline DEPRECIACION Y AMORTIZACION ACUMULADA & & $(21,339)$ & $(42,679)$ & $(64,018)$ & $(81,340)$ & $(98,663)$ \\
\hline TOTAL ACTIVO NO CORRIENTE & 98,663 & 77,324 & 55,984 & 34,645 & 17,323 & - \\
\hline $\begin{array}{l}\text { TOTAL ACTIVO } \\
\text { PASIVO Y PATRIMONIO }\end{array}$ & 220,391 & 425,886 & 642,623 & 933,887 & $1,241,220$ & $1,561,790$ \\
\hline \multicolumn{7}{|l|}{$\begin{array}{l}\text { PASIVO Y PATRIMONIO } \\
\text { PASIVO }\end{array}$} \\
\hline DEUDA CORRIENTE & 51,716 & 58,480 & $\cdot$ & & & \\
\hline $\begin{array}{l}\text { TOTAL PASIVO CORRIENTE } \\
\text { DEUDA LARGO PLAZO }\end{array}$ & $\begin{array}{l}51,716 \\
58,480\end{array}$ & 58,480 & - & - & - & - \\
\hline $\begin{array}{l}\text { TOTAL PASIVO NO CORRIENTE } \\
\text { PATRIMONIO }\end{array}$ & 58,480 & - & - & - & - & - \\
\hline CAPITAL SOCIAL & 110,196 & 110,196 & 110,196 & 110,196 & 110,196 & 110,196 \\
\hline UTILIDADES RETENIDAS & & 257,211 & 532,427 & 823,692 & $1,131,025$ & $1,451,594$ \\
\hline TOTAL PATRIMONIO & 110,196 & 367,406 & 642,623 & 933,887 & $1,241,220$ & $1,561,790$ \\
\hline \multirow[t]{2}{*}{ TOTALPASIVO Y PATRIMONIO } & 220,391 & 425,886 & 642,623 & 933,887 & $1,241,220$ & $1,561,790$ \\
\hline & - & - & - & - & - & - \\
\hline \multicolumn{7}{|l|}{ RATIOS } \\
\hline EVA & & 189,211 & 163,985 & 125,532 & 87,060 & 43,407 \\
\hline$R O E=(E B I T / E)$ & & 1.08 & 0.65 & 0.47 & 0.37 & 0.30 \\
\hline ROIC $=E B T(1-t) / E$ & & 0.72 & 0.43 & 0.31 & 0.25 & 0.21 \\
\hline
\end{tabular}




\section{ANEXO 12: FLUJO DE CAJA E INDICADORES ECONOMICOS (VAN, TIR Y PERIODO DE REPAGO)}

\section{FLUJO FINANCIERO - ESCENARIO BASE}

\begin{tabular}{|c|c|c|c|c|c|c|c|}
\hline $\begin{array}{l}\text { TE FRUTA DESHIDRATADA } \\
\text { FITRANTES } 2.5 \text { GR. }\end{array}$ & & ANOO 0 & $\begin{array}{l}\text { AÑO } 1 \\
80 \%\end{array}$ & $\begin{array}{l}\text { ANO } 2 \\
82 \%\end{array}$ & $\begin{array}{l}\text { ANO } 3 \\
83 \%\end{array}$ & $\begin{array}{l}\text { ANNO } 4 \\
85 \%\end{array}$ & $\begin{array}{l}\text { ANO } 5 \\
86 \%\end{array}$ \\
\hline Venta mensual & & & 80,395 & 81,903 & 83,410 & 84,918 & 86,425 \\
\hline Venta anual & & & 964,744 & 982,833 & $1,000,922$ & $1,019,011$ & $1,037,100$ \\
\hline PRODUCCION & & & 964,744 & 982,833 & $1,000,922$ & $1,019,011$ & $1,037,100$ \\
\hline VENTA & & & ANO 1 & ANO 2 & ANO 3 & ANO 4 & ANO 5 \\
\hline \multicolumn{8}{|l|}{ TE FRUTA DESHIDRATADA } \\
\hline Cantidad & & & 964,744 & 982,833 & $1,000,922$ & $1,019,011$ & $1,037,100$ \\
\hline Precio & & & S/.1.44 & $S / .1 .44$ & S/.1.44 & $\mathrm{S} / .1 .44$ & S/.1.44 \\
\hline INGRESOS TOTALES & & & $\mathrm{S} / .1,386,554$ & $5 / .1,412,552$ & $5 / .1,438,549$ & $5 / .1,464,547$ & $5 / .1,490,545$ \\
\hline costos & & & ANO 1 & ANO 2 & ANO 3 & ANO 4 & ANO 5 \\
\hline \multicolumn{8}{|l|}{ TE FRUTA DESHIDRATADA } \\
\hline Costos de Producción & & & 564,503 & 571,465 & 578,428 & 585,390 & 592,352 \\
\hline GIF & & & 2,040 & 2,040 & 2,040 & 2,040 & 2,040 \\
\hline Gastos de Ventas & & & 253,626 & 253,626 & 253,626 & 253,626 & 253,626 \\
\hline Gastos Administrativos & & & 155,590 & 155,590 & 155,590 & 155,590 & 155,590 \\
\hline Gastos Investigación y Desarrollo & & & 13,866 & 14,126 & 14,385 & 14,645 & 14,905 \\
\hline \multirow[t]{2}{*}{ COSTO DE PRODUCCION } & & & $5 / .989,625$ & $5 / .996,847$ & $5 / .1,004,069$ & $5 / .1,011,291$ & S/.1,018,514 \\
\hline & & ANO 0 & ANO 1 & ANO2 & ANO 3 & ANO 4 & ANO 5 \\
\hline Maquinaria & 51,500 & 51,500 & & & & & \\
\hline Utensilios & 5,330 & 5,330 & & & & & \\
\hline Capital Trabajo & 111,728 & 111,728 & & & & & \\
\hline Equipos e implementacion & 23,850 & 23,850 & & & & & \\
\hline Intangibles & 27,983 & 27,983 & & & & & \\
\hline \multirow[t]{2}{*}{ INVERSION } & 220,391 & 220,391 & - & - & - & - & - \\
\hline & & ANO 0 & ANO 1 & ANO 2 & ANO 3 & ANO 4 & ANO 5 \\
\hline Maquinaria y Equipos & D. 5 años & & 10,300 & 10,300 & 10,300 & 10,300 & 10,300 \\
\hline Muebles y Enseres & D. 5 años & & 1,066 & 1,066 & 1,066 & 1,066 & 1,066 \\
\hline Equipos de Computo & D. 3años & & 4,017 & 4,017 & 4,017 & 0 & 0 \\
\hline Bienes escritorio & D. 5 años & & 2,360 & 2,360 & 2,360 & 2,360 & 2,360 \\
\hline Amortizaciòn & D. 5 años & & 3,597 & 3,597 & 3,597 & 3,597 & 3,597 \\
\hline DEPRECIACION Y AMORTIZACION & & - & 21,339 & 21,339 & 21,339 & 17,323 & 17,323 \\
\hline
\end{tabular}




\begin{tabular}{|c|c|c|c|c|c|c|c|}
\hline \multirow[t]{2}{*}{ FINANCIAMIENTO } & VALOR CUOTA & $\begin{array}{r}110,196 \\
5,206\end{array}$ & $\begin{array}{c}13.08 \% \\
0.010\end{array}$ & $\begin{array}{l}\text { TCEA } \\
\text { TCEM }\end{array}$ & & & \\
\hline & & ANO 0 & ANO 1 & ANO 2 & ANO 3 & ANO 4 & ANO 5 \\
\hline Principal & & 110,196 & 110,196 & 58,480 & - & & \\
\hline Amortización & & & 51,716 & 58,480 & & & \\
\hline Saldo & & & 58,480 & - & & & \\
\hline Intereses & & & 10,752 & 3,987 & & & \\
\hline Escudo tributario & & & 3,172 & 1,176 & & & \\
\hline FC Financiamiento & & 110,196 & 59,296 & 61,291 & & & \\
\hline PERDIDAS Y GANANCIAS & & ANOO 0 & ANO 1 & ANO2 & ANO 3 & ANO 4 & ANo 5 \\
\hline Ingresos & & & $1,386,554$ & $1,412,552$ & $1,438,549$ & $1,464,547$ & $1,490,545$ \\
\hline \multicolumn{8}{|l|}{ Costos: } \\
\hline Operativos & & & 989,625 & 996,847 & $1,004,069$ & $1,011,291$ & $1,018,514$ \\
\hline Depreciación & & & 21,339 & 21,339 & 21,339 & 17,323 & 17,323 \\
\hline EBIT & & & 375,590 & 394,365 & 413,141 & 435,933 & 454,709 \\
\hline Intereses & & & 10,752 & 3,987 & - & - & - \\
\hline \multicolumn{8}{|l|}{ Ganancias extraordinarias } \\
\hline Utilidad antes de IR & & & 364,838 & 390,378 & 413,141 & 435,933 & 454,709 \\
\hline IR & $29.5 \%$ & & 107,627 & 115,162 & 121,877 & 128,600 & 134,139 \\
\hline Utilidad Neta & & & 257,211 & 275,216 & 291,264 & 307,333 & 320,570 \\
\hline \multicolumn{8}{|l|}{ FLUJO DE CAJA } \\
\hline & & $\begin{array}{c}0 \\
\text { Inversión }\end{array}$ & 1 & 2 & 3 & 4 & 5 \\
\hline Ingresos & & & $1,386,554$ & $1,412,552$ & $1,438,549$ & $1,464,547$ & $1,490,545$ \\
\hline Costos operativos & & & $-1,010,964$ & $-1,018,186$ & $-1,025,408$ & $-1,028,614$ & $-1,035,836$ \\
\hline EBIT & & & 375,590 & 394,365 & 413,141 & 435,933 & 454,709 \\
\hline EBIT $(1-t)$ & & & $-110,799$ & $-116,338$ & $-121,877$ & $-128,600$ & $-134,139$ \\
\hline Cambio en KL & & 1 & & & & & \\
\hline Inversiòn & & $-220,391$ & - & - & - & - & - \\
\hline Flujo de caja económico & & $-220,391$ & 286,130 & 299,367 & 312,604 & 324,656 & 337,892 \\
\hline Flujo de financiamiento & & 110,196 & $-59,296$ & $-61,291$ & - & - & - \\
\hline \multirow[t]{6}{*}{ Flujo de caja financiero } & & $-110,196$ & 226,834 & 238,076 & 312,604 & 324,656 & 337,892 \\
\hline & VANE & 748,227 & & coK & $26.3 \%$ & & \\
\hline & TIRE & $132 \%$ & & WACC & $17.7 \%$ & & \\
\hline & VAN & 763,856 & & & & & \\
\hline & $\operatorname{TIR}$ & $215 \%$ & & & & & \\
\hline & PAY BACK & 1 año y 4 meses & & & & & \\
\hline
\end{tabular}


FLUJO FINANCIERO - ESCENARIO PESIMISTA

\begin{tabular}{|c|c|c|c|c|c|c|c|}
\hline $\begin{array}{l}\text { TE FRUTA DESHIDRATADA } \\
\text { FILTRANTES } 2.5 \text { GR. }\end{array}$ & & AÑO 0 & $\begin{array}{l}\text { ANO 1 } \\
60 \%\end{array}$ & $\begin{array}{l}\text { ANNO } 2 \\
62 \%\end{array}$ & $\begin{array}{l}\text { ANO } 3 \\
64 \%\end{array}$ & $\begin{array}{l}\text { AÑO } 4 \\
66 \%\end{array}$ & $\begin{array}{l}\text { ANO5 } 5 \\
68 \%\end{array}$ \\
\hline Venta mensual & & & 60,297 & 62,306 & 64,316 & 66,326 & 68,336 \\
\hline Venta anual & & & 723,558 & 747,677 & 771,795 & 795,914 & 820,032 \\
\hline PRODUCCION & & & 723,558 & 747,677 & $\mathbf{7 7 1 , 7 9 5}$ & 795,914 & 820,032 \\
\hline VENTA & & & ANO 1 & ANO 2 & ANO 3 & ANO 4 & ANO 5 \\
\hline \multicolumn{8}{|l|}{ TE FRUTA DESHIDRATADA } \\
\hline Cantidad & & & 723,558 & 747,677 & 771,795 & 795,914 & 820,032 \\
\hline Precio & & & S/.1.44 & S/.1.44 & S/.1.44 & S/.1.44 & S/.1.44 \\
\hline INGRESOS TOTALES & & & \begin{tabular}{|l|}
$5 / .1,039,915$ \\
\end{tabular} & S/.1,074,579 & $\mathrm{S} / .1,109,243$ & $5 / .1,143,907$ & $S / .1,178,571$ \\
\hline $\operatorname{costos}$ & & & ANO 1 & ANO2 & ANO 3 & ANO 4 & ANO 5 \\
\hline \multicolumn{8}{|l|}{ TE FRUTA DESHIDRATADA } \\
\hline Costos de Producción & & & 450,712 & 459,995 & 469,278 & 478,562 & 487,845 \\
\hline GIF & & & 2,040 & 2,040 & 2,040 & 2,040 & 2,040 \\
\hline Gastos de Ventas & & & 253,626 & 253,626 & 253,626 & 253,626 & 253,626 \\
\hline Gastos Administrativos & & & 155,590 & 155,590 & 155,590 & 155,590 & 155,590 \\
\hline Gastos Investigación y Desarrollo & & & 10,399 & 10,746 & 11,092 & 11,439 & 11,786 \\
\hline \multirow[t]{2}{*}{ COSTO DE PRODUCCION } & & & $5 / .872,367$ & S/.881,997 & $5 / .891,627$ & S/.901,257 & $5 / .910,886$ \\
\hline & & ANO 0 & ANO 1 & ANO 2 & ANO 3 & ANO 4 & ANO 5 \\
\hline Maquinaria & 51,500 & 51,500 & & & & & \\
\hline Utensilios & 5,330 & 5,330 & & & & & \\
\hline Capital Trabajo & 98,699 & 98,699 & & & & & \\
\hline Equipos e implementacion & 23,850 & 23,850 & & & & & \\
\hline Intangibles & 27,983 & 27,983 & & & & & \\
\hline \multirow[t]{2}{*}{ INVERSION } & 207,362 & 207,362 & - & - & - & - & - \\
\hline & & ANO 0 & ANO 1 & ANO 2 & ANO 3 & ANO 4 & ANO 5 \\
\hline Maquinaria y Equipos & D. 5 años & & 10,300 & 10,300 & 10,300 & 10,300 & 10,300 \\
\hline Muebles y Enseres & D. 5 años & & 1,066 & 1,066 & 1,066 & 1,066 & 1,066 \\
\hline Equipos de Computo & D. 3años & & 4,017 & 4,017 & 4,017 & 0 & 0 \\
\hline Bienes escritorio & D. 5 años & & 2,360 & 2,360 & 2,360 & 2,360 & 2,360 \\
\hline Amortizaciòn & D. 5 años & & 3,597 & 3,597 & 3,597 & 3,597 & 3,597 \\
\hline DEPRECIACION Y AMORTIZACION & & - & 21,339 & 21,339 & 21,339 & 17,323 & 17,323 \\
\hline \multirow[t]{3}{*}{ FINANCIAMIENTO } & & 103,681 & $13.08 \%$ & TCEA & & & \\
\hline & VALOR CUOTA & 4,898 & 0.010 & TCEM & & & \\
\hline & & ANO 0 & ANO 1 & ANO 2 & ANO 3 & ANO 4 & ANO 5 \\
\hline Principal & & 103,681 & 103,681 & 55,023 & & & \\
\hline Amortización & & & 48,658 & 55,023 & & & \\
\hline Saldo & & & 55,023 & - & & & \\
\hline Intereses & & & 10,116 & 3,752 & & & \\
\hline Escudo tributario & & & 2,984 & 1,107 & & & \\
\hline FC Financiamiento & & \begin{tabular}{l|l|}
103,681 \\
\end{tabular} & 55,790 & 57,668 & - & - & - \\
\hline PERDIDAS Y GANANCIAS & & ANO 0 & ANO 1 & ANO 2 & ANO 3 & ANO 4 & ANO 5 \\
\hline Ingresos & & & $1,039,915$ & $1,074,579$ & $1,109,243$ & $1,143,907$ & $1,178,571$ \\
\hline \multicolumn{8}{|l|}{ Costos: } \\
\hline Operativos & & & 872,367 & 881,997 & 891,627 & 901,257 & 910,886 \\
\hline Depreciación & & & 21,339 & 21,339 & 21,339 & 17,323 & 17,323 \\
\hline EBIT & & & 146,209 & 171,243 & 196,277 & 225,328 & 250,362 \\
\hline Intereses & & & 10,116 & 3,752 & - & - & - \\
\hline \multicolumn{8}{|l|}{ Ganancias extraordinarias } \\
\hline Utilidad antes de IR & & & 136,092 & 167,491 & 196,277 & 225,328 & 250,362 \\
\hline IR & $29.5 \%$ & & 40,147 & 49,410 & 57,902 & 66,472 & 73,857 \\
\hline Utilidad Neta & & & 95,945 & 118,081 & 138,375 & 158,856 & 176,505 \\
\hline \multicolumn{8}{|l|}{ FLUJO DE CAJA } \\
\hline & & $\begin{array}{c}0 \\
\text { Inversión }\end{array}$ & 1 & 2 & 3 & 4 & 5 \\
\hline Ingresos & & & $1,039,915$ & $1,074,579$ & $1,109,243$ & $1,143,907$ & $1,178,571$ \\
\hline Costos operativos & & & $-893,707$ & $-903,336$ & $-912,966$ & $-918,579$ & $-928,209$ \\
\hline EBIT & & & 146,209 & 171,243 & 196,277 & 225,328 & 250,362 \\
\hline EBIT $(1-t)$ & & & $-43,132$ & $-50,517$ & $-57,902$ & $-66,472$ & $-73,857$ \\
\hline Cambio en KL & & 1 & & & & & \\
\hline Inversiòn & & $-207,362$ & - & - & - & - & - \\
\hline Flujo de caja económico & & $-207,362$ & 124,416 & 142,065 & 159,714 & 176,179 & 193,828 \\
\hline Flujo de financiamiento & & 103,681 & $-55,790$ & $-57,668$ & - & - & - \\
\hline \multirow[t]{6}{*}{ Flujo de caja financiero } & & $-103,681$ & 68,626 & 84,398 & 159,714 & 176,179 & 193,828 \\
\hline & VANE & 275,904 & & $\mathrm{COK}$ & $26.3 \%$ & & \\
\hline & TIRE & $63 \%$ & & WACC & $17.7 \%$ & & \\
\hline & VAN & 290,609 & & & & & \\
\hline & TIR & $90 \%$ & & & & & \\
\hline & PAY BACK [ & 1 año y 5 meses & & & & & \\
\hline
\end{tabular}


FLUJO FINANCIERO - ESCENARIO OPTIMISTA

\begin{tabular}{|c|c|c|c|c|c|c|c|}
\hline $\begin{array}{l}\text { TE FRUTA DESHIDRATADA } \\
\text { FILTRANTES } 2.5 \mathrm{GR} \text {. }\end{array}$ & & AÑO 0 & $\begin{array}{l}\text { AÑO } 1 \\
100 \%\end{array}$ & $\begin{array}{l}\text { AÑO } 2 \\
100 \%\end{array}$ & $\begin{array}{l}\text { AÑo } 3 \\
100 \%\end{array}$ & $\begin{array}{l}\text { AÑo } 4 \\
100 \%\end{array}$ & $\begin{array}{l}\text { AÑO5 } \\
100 \%\end{array}$ \\
\hline Venta mensual & & & 100,494 & 100,494 & 100,494 & 100,494 & 100,494 \\
\hline Venta anual & & & $1,205,930$ & $1,205,930$ & $1,205,930$ & $1,205,930$ & $1,205,930$ \\
\hline PRODUCCION & & & $1,205,930$ & $1,205,930$ & $1,205,930$ & $1,205,930$ & $1,205,930$ \\
\hline VENTA & & & ANO 1 & ANO 2 & ANO 3 & ANO 4 & ANo 5 \\
\hline \multicolumn{8}{|l|}{ TE FRUTA DESHIDRATADA } \\
\hline Cantidad & & & $1,205,930$ & $1,205,930$ & $1,205,930$ & $1,205,930$ & $1,205,930$ \\
\hline Precio & & & S/.1.44 & S/.1.44 & S/.1.44 & S/.1.44 & S/.1.44 \\
\hline INGRESOS TOTALES & & & $5 / .1,733,192$ & $5 / .1,733,192$ & $5 / .1,733,192$ & $S / .1,733,192$ & $5 / .1,733,192$ \\
\hline costos & & & ANO 1 & ANO 2 & ANO 3 & ANO 4 & ANO 5 \\
\hline \multicolumn{8}{|l|}{ TE FRUTA DESHIDRATADA } \\
\hline Costos de Producción & & & 657,334 & 657,334 & 657,334 & 657,334 & 657,334 \\
\hline GIF & & & 2,040 & 2,040 & 2,040 & 2,040 & 2,040 \\
\hline Gastos de Ventas & & & 253,626 & 253,626 & 253,626 & 253,626 & 253,626 \\
\hline Gastos Administrativos & & & 155,590 & 155,590 & 155,590 & 155,590 & 155,590 \\
\hline Gastos Investigación y Desarrollo & & & 17,332 & 17,332 & 17,332 & 17,332 & 17,332 \\
\hline \multirow[t]{2}{*}{ COSTO DE PRODUCCION } & & & $5 / .1,085,922$ & $5 / .1,085,922$ & $5 / .1,085,922$ & $5 / .1,085,922$ & $5 / .1,085,922$ \\
\hline & & ANO 0 & ANO 1 & ANO 2 & ANO 3 & ANO 4 & ANO 5 \\
\hline Maquinaria & 51,500 & 51,500 & & & & & \\
\hline Utensilios & 5,330 & 5,330 & & & & & \\
\hline Capital Trabajo & 122,358 & 122,358 & & & & & \\
\hline Equipos e implementacion & 23,850 & 23,850 & & & & & \\
\hline Intangibles & 27,983 & 27,983 & & & & & \\
\hline \multirow[t]{2}{*}{ INVERSION } & 231,021 & 231,021 & - & - & - & - & - \\
\hline & & ANO 0 & ANO 1 & ANO 2 & ANO 3 & ANO 4 & ANO 5 \\
\hline Maquinaria y Equipos & D. 5 años & & 10,300 & 10,300 & 10,300 & 10,300 & 10,300 \\
\hline Muebles y Enseres & D. 5 años & & 1,066 & 1,066 & 1,066 & 1,066 & 1,066 \\
\hline Equipos de Computo & D. 3años & & 4,017 & 4,017 & 4,017 & 0 & 0 \\
\hline Bienes escritorio & D. 5 años & & 2,360 & 2,360 & 2,360 & 2,360 & 2,360 \\
\hline Amortizaciòn & D. 5 años & & 3,597 & 3,597 & 3,597 & 3,597 & 3,597 \\
\hline DEPRECIACION Y AMORTIZACION & & - & 21,339 & 21,339 & 21,339 & 17,323 & 17,323 \\
\hline
\end{tabular}




\begin{tabular}{|c|c|c|c|c|c|c|c|}
\hline \multirow[t]{3}{*}{ FINANCIAMIENTO } & & 115,510 & $13.08 \%$ & TCEA & & & \\
\hline & VALOR CUOTA & 5,457 & 0.010 & TCEM & & & \\
\hline & & ANOO 0 & ANO 1 & ANO2 2 & ANO 3 & Añ 4 & ANO 5 \\
\hline Principal & & 115,510 & 115,510 & 61,300 & & & \\
\hline Amortización & & & 54,210 & 61,300 & & & \\
\hline Saldo & & & 61,300 & - & & & \\
\hline Intereses & & & 11,270 & 4,180 & & & \\
\hline Escudo tributario & & & 3,325 & 1,233 & & & \\
\hline FC Financiamiento & & \begin{tabular}{|l|l|}
115,510 & \\
\end{tabular} & 62,155 & 64,247 & - & - & - \\
\hline PERDIDAS Y GANANCIAS & & ANOO 0 & ANO 1 & ANO 2 & ANO 3 & AnO 4 & ANo 5 \\
\hline Ingresos & & & $1,733,192$ & $1,733,192$ & $1,733,192$ & $1,733,192$ & $1,733,192$ \\
\hline \multicolumn{8}{|l|}{ Costos: } \\
\hline Operativos & & & $1,085,922$ & $1,085,922$ & $1,085,922$ & $1,085,922$ & $1,085,922$ \\
\hline Depreciación & & & 21,339 & 21,339 & 21,339 & 17,323 & 17,323 \\
\hline EBIT & & & 625,931 & 625,931 & 625,931 & 629,948 & 629,948 \\
\hline Intereses & & & 11,270 & 4,180 & $\cdot$ & - & $\cdot$ \\
\hline \multicolumn{8}{|l|}{ Ganancias extraordinarias } \\
\hline Utilidad antes de IR & & & 614,661 & 621,751 & 625,931 & 629,948 & 629,948 \\
\hline IR & $29.5 \%$ & & 181,325 & 183,417 & 184,650 & 185,835 & 185,835 \\
\hline Utilidad Neta & & & 433,336 & 438,335 & 441,281 & 444,113 & 444,113 \\
\hline \multicolumn{8}{|l|}{ FLUJO DE CAJA } \\
\hline & & $\begin{array}{c}0 \\
\text { Inversión } \\
\end{array}$ & 1 & 2 & 3 & 4 & 5 \\
\hline Ingresos & & & $1,733,192$ & $1,733,192$ & $1,733,192$ & $1,733,192$ & $1,733,192$ \\
\hline Costos operativos & & & $-1,107,261$ & $-1,107,261$ & $-1,107,261$ & $-1,103,244$ & $-1,103,244$ \\
\hline EBIT & & & 625,931 & 625,931 & 625,931 & 629,948 & 629,948 \\
\hline EBIT $(1-t)$ & & & $-184,650$ & $-184,650$ & $-184,650$ & $-185,835$ & $-185,835$ \\
\hline Cambio en KL & 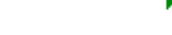 & 1 & & & & & \\
\hline Inversiòn & & $-231,021$ & - & - & - & - & - \\
\hline Flujo de caja económico & & $-231,021$ & 462,621 & 462,621 & 462,621 & 461,436 & 461,436 \\
\hline Flujo de financiamiento & & 115,510 & $-62,155$ & $-64,247$ & - & - & - \\
\hline \multirow[t]{5}{*}{ Flujo de caja financiero } & & $-115,510$ & 400,465 & 398,374 & 462,621 & 461,436 & 461,436 \\
\hline & VANE & $1,222,881$ & & COK & $26.3 \%$ & & \\
\hline & TIRE & $199 \%$ & & WACC & $17.7 \%$ & & \\
\hline & VAN & $1,239,263$ & & & & & \\
\hline & $\begin{array}{r}\text { TIR } \\
\text { PAY BACK }\end{array}$ & $\begin{array}{r}349 \% \\
1 \mathrm{mes}\end{array}$ & & & & & \\
\hline
\end{tabular}




\section{ANEXO 13: PUNTO DE EQUILIBRIO}

PUNTO DE EQUILIBRIO

ESCENARIO BASE

\begin{tabular}{|c|c|c|}
\hline COSTO VARIABIE & & \$\%. \\
\hline COSTO TE FILTRANTE & & 0.59 \\
\hline & & \\
\hline TOTAL COSTO VARIABLE & & \\
\hline
\end{tabular}

\begin{tabular}{|c|c|}
\hline COSTO FUO & s. \\
\hline GIF & 2,040 \\
\hline \begin{tabular}{|l|} 
GTOS ADMINISTRATIVOS \\
\end{tabular} & 155,590 \\
\hline GASTOS VENTA & 253,626 \\
\hline \begin{tabular}{|l|l} 
GASTOS DE INVEST.Y DESARROLLO \\
\end{tabular} & 13,866 \\
\hline TOTAL COSTO FIO & 425,122 \\
\hline
\end{tabular}

\begin{tabular}{|c|c|}
\hline UNIDADES VENDIDAS & 964,744 \\
\hline INGRESOS UN & S/. \\
\hline PRECIO UNITARIO & 1.44 \\
\hline
\end{tabular}

INGRESO TOTAL

INGRESO TOTAL

$1,386,554$

\begin{tabular}{|c|c|}
\hline COSTO TOTAL VARIABLE & 564,503 \\
\hline COSTO TOTAL FIJO & 425,122 \\
\hline COSTO TOTAL & 989,625 \\
\hline
\end{tabular}

\begin{tabular}{|r|r|r|r|r|}
\hline \multicolumn{1}{|c|}{ ANOS } & \multicolumn{1}{|c|}{ UNIDADES } & \multicolumn{1}{c|}{ VENTAS } & \multicolumn{1}{c|}{ COSTOS } & UTILIDADES \\
\hline 2018 & 964,744 & $1,386,554$ & $989,624.63$ & 396,929 \\
\hline 2019 & 982,833 & $1,412,552$ & $996,586.94$ & 415,965 \\
\hline 2020 & $1,000,922$ & $1,438,549$ & $1,003,549.25$ & 435,000 \\
\hline 2021 & $1,019,011$ & $1,464,547$ & $1,010,511.55$ & 454,036 \\
\hline 2022 & $1,037,100$ & $1,490,545$ & $1,017,473.86$ & 473,071 \\
\hline
\end{tabular}

PUNTO DE EQUILIBRIO

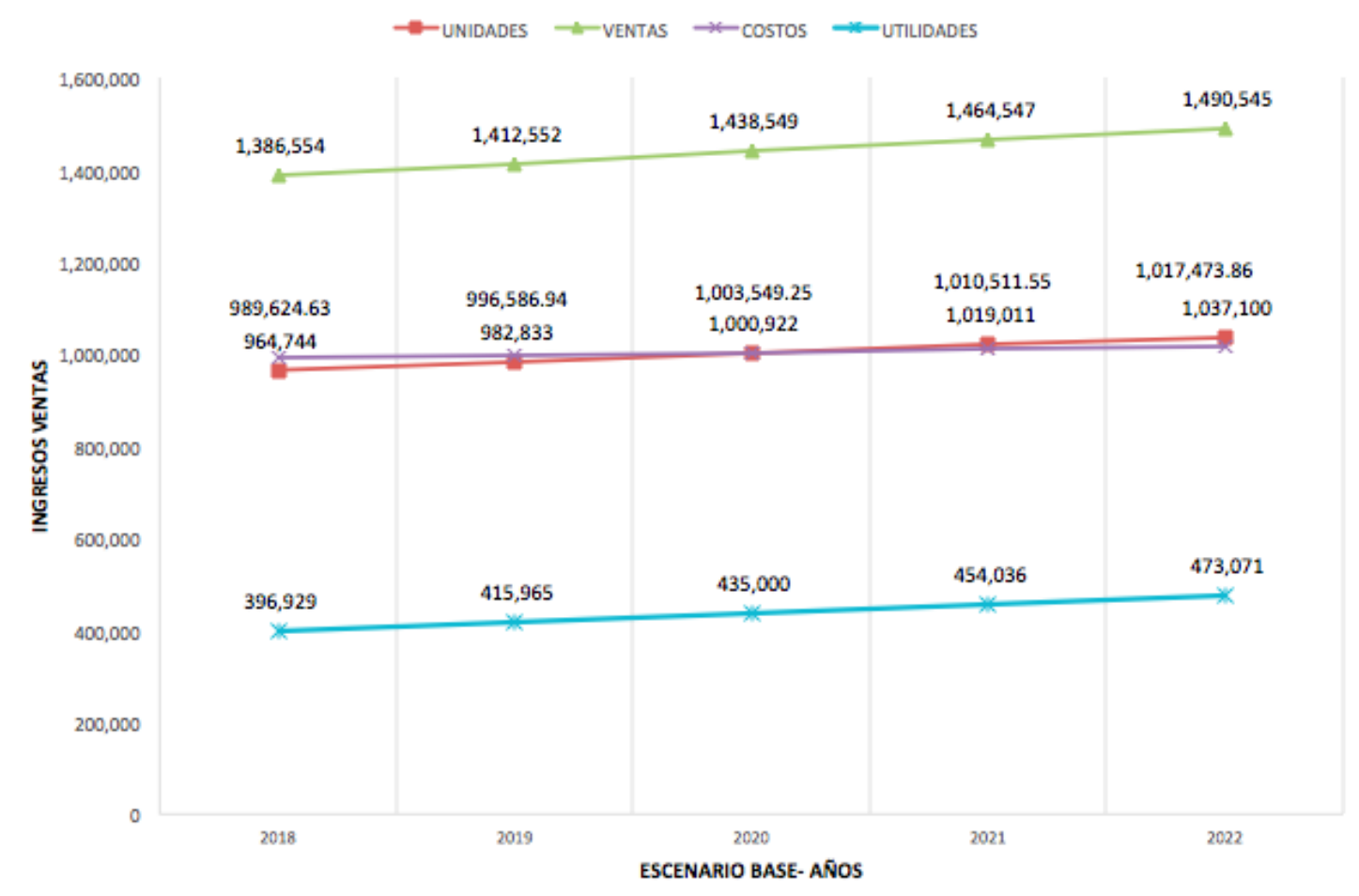




\section{ANEXO 14: MARKETING Y AUSPICIO EN FERIA}

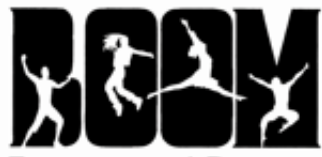

Fitness and Dance

Lima 10 de noviembre de 2017

Cotización Auspiciador EXPOBOOM

Señores A quien corresponda

El auspiciador de abonar el monto de 500 nuevos soles para separar un espacio de aproximadamente de $2 \times 2 \mathrm{~m}$. en el recinto separado por el EXPOBOOM.

El auspiciador debe entregar regalos relacionados a su rubro valorizado en 500 nuevos soles para que sean sorteados durante el evento del EXРОВOOM.

El auspiciador puede publicitar su producto a través del volanteo, degustación y demostración. También puede vender sus productos pero a precios promocionales.

El evento se realizará el día domingo 19 de Noviembre de 8 am a 1:00pm en el centro de Exposiciones del Jockey Plaza.

Atentamente.

Claudia Calle

Coordinadora General

BOOM fitness and dance 


\section{ANEXO 15: BEBIDAS SALUDABLES}

\section{= GESTIÓN \\ Empresas - Portada - Economía - Tendencias - Tu Dinero • Gestión TV • Blogs}

\section{CBC y AJE revelan su interés por ampliar su portafolio en bebidas más saludables}

G de Gestión. En el Perú ya se observa una migración en el consumo de gaseosa hacia las aguas embotelladas desde hace un par de años. CBC, operadora de bebidas de Pepsico, y AJE revelan su interés por ampliar su portafolio en esta categoría
in Compartir
f Compartir
G+ Compartir

Recuadro

La hora del té Después del agua, los tés embotellados son probablemente la alternativa percibida como la más saludable. Y, dada su baja penetración, su crecimiento en ventas alcanza hasta los tres dígitos en provincias. Según Kantar Worldpanel, en los dos primeros meses del año, los hogares peruanos gastaron $53,8 \%$ más en esta categoría. Y Euromonitor prevé que este mercado crecerá alrededor de $87 \%$ hasta el 2020 .

Aje participa en este rubro con "Cool Tea", "Free Tea" y "Free Tea Light", con lo que concentra el $52 \%$ del mercado. Tras un crecimiento anual de $23 \%$ en el 2015 , la compañía espera duplicar el tamaño de esta categoría para el 2017.

En tanto, CBC participa con "Lipton" y se encuentra trabajando en una revisión de su oferta "empaque-precio" (Price Pack) para impulsar su marca, además de evaluar traer nuevas marcas de té embotellado al Perú. 
